\title{
NEW SPORT TEAMS AND THE DEVELOPMENT OF BRAND COMMUNITY
}

\author{
Nigel Grant
}

2006

This thesis is presented in partial fulfilment of the requirements for the Master of Business degree at Auckland University of Technology, New Zealand 


\section{TABLE OF CONTENTS}

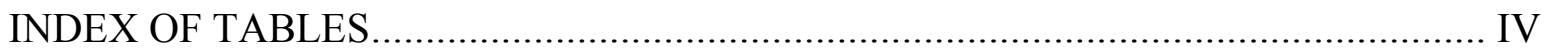

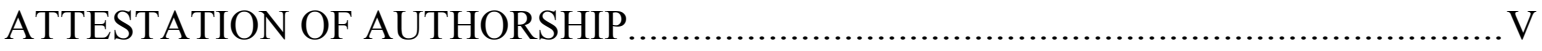

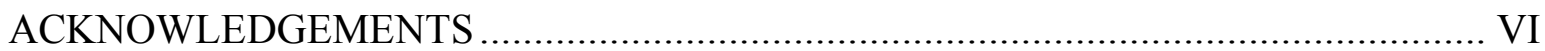

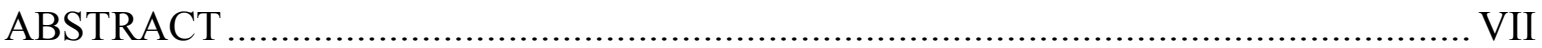

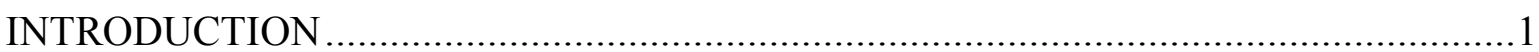

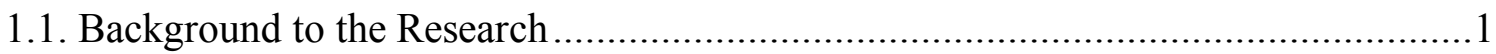

1.1.1. New Sports Teams.................................................................................

1.1.1.1. A Worldwide Perspective ……...............................................................

1.1.1.2. New Sports Teams in New Zealand ......................................................

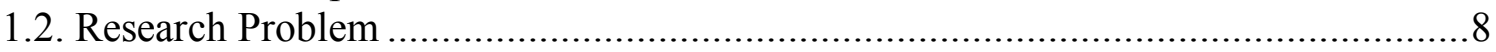

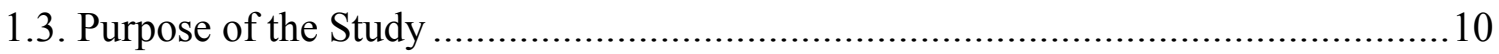

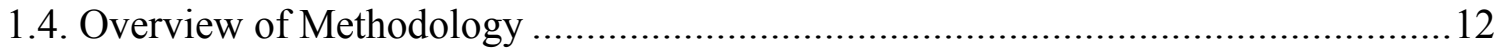

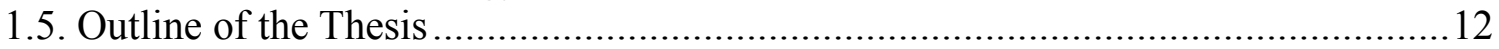

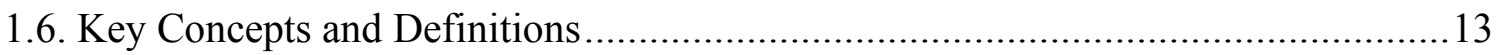

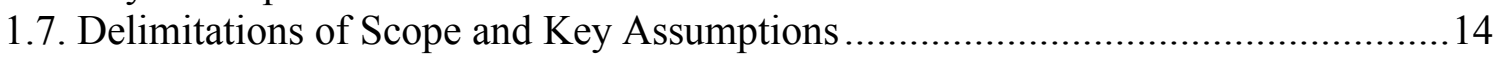

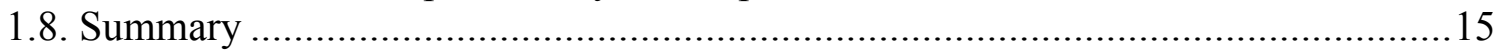

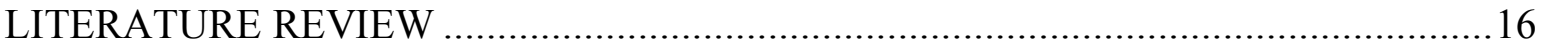

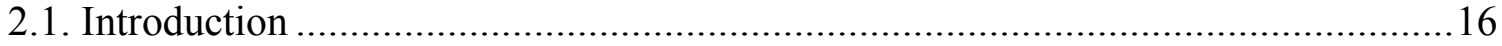

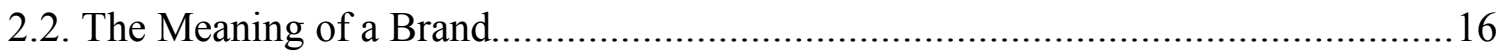

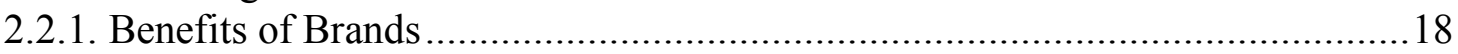

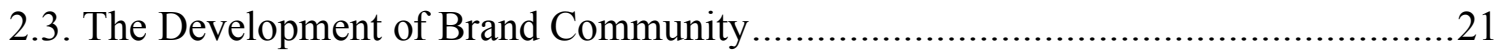

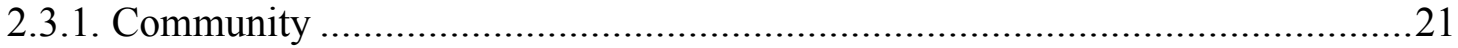

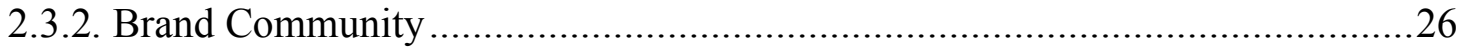

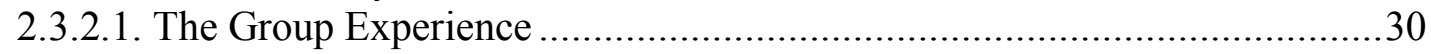

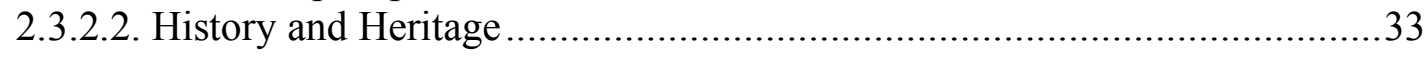

2.3.2.3. Rituals and Traditions ..........................................................................

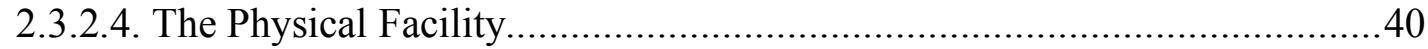

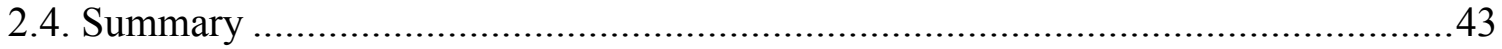

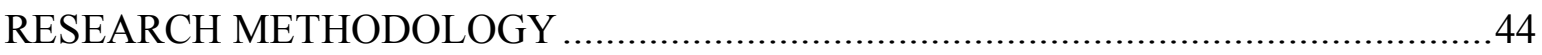

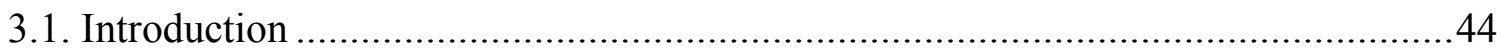

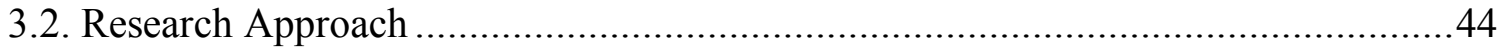

3.3. Data Sources and Selection .............................................................................

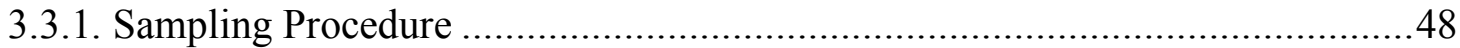

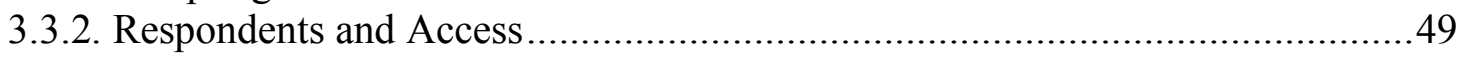

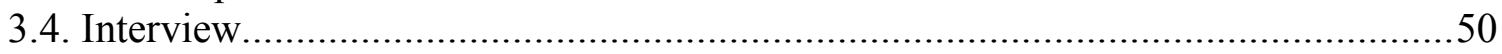

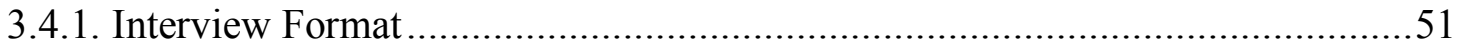

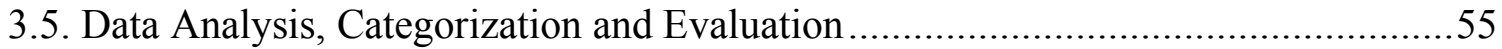

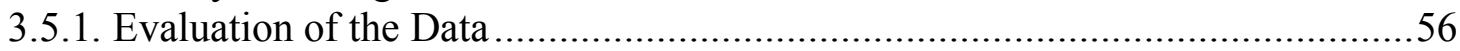

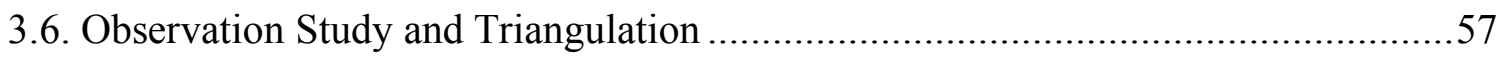

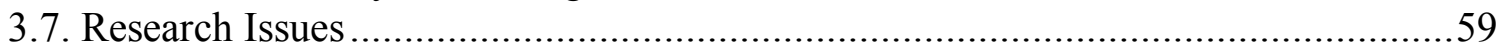

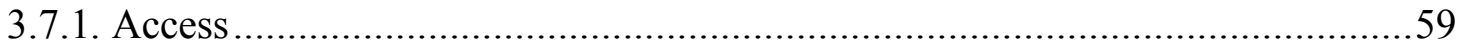

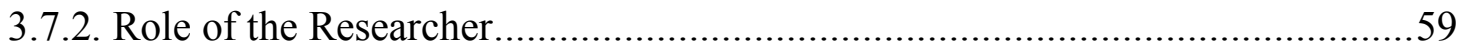

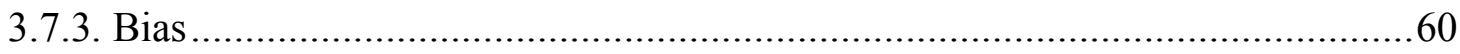




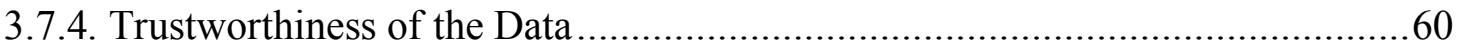

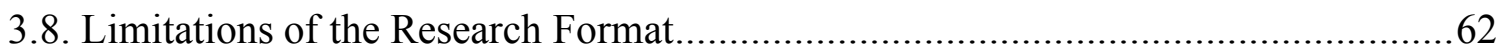

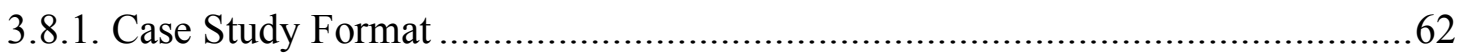

3.8.2. Respondent Knowledge and Employment Tenure ......................................6 62

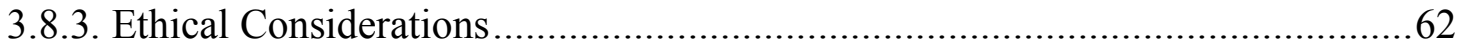

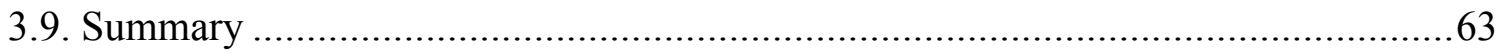

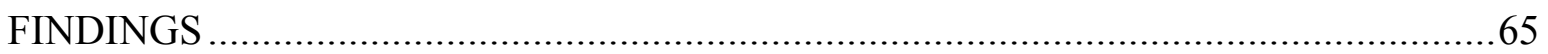

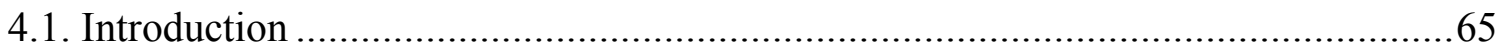

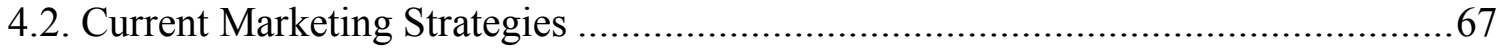

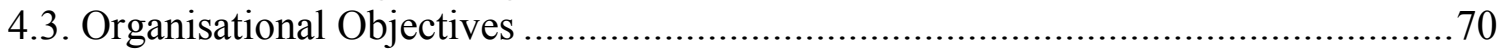

4.4. New Team Brand Development - Issues and Problems ................................... 73

4.4.1. Image and Lack of Awareness ............................................................ 74

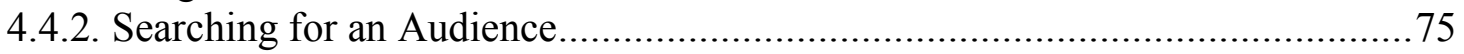

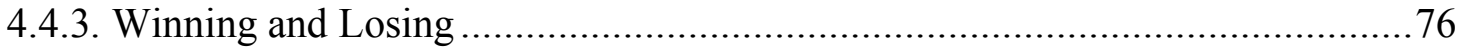

4.4.4. Team and Competition Quality......................................................... 76

4.4.5. Differences Between Established and New Teams.........................................77

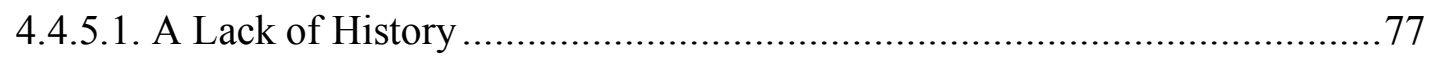

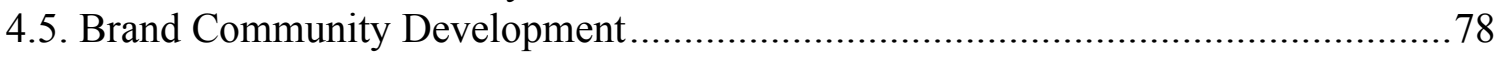

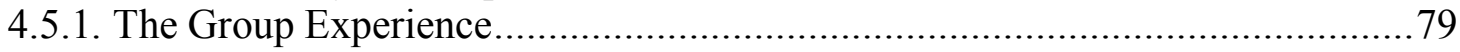

4.5.2. History of the Organisation............................................................... 88

4.5.3. Rituals and Traditions........................................................................ 92

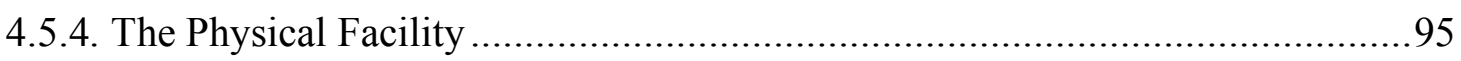

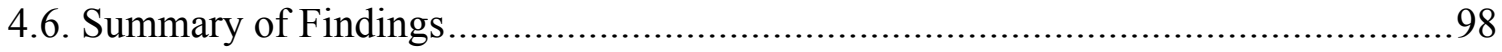

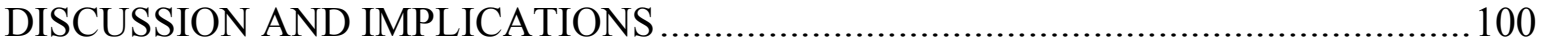

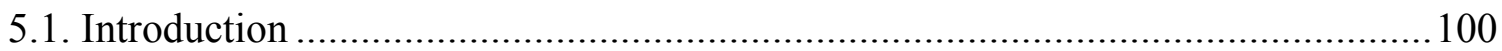

5.2. The Challenges for New Sports Team ............................................................... 100

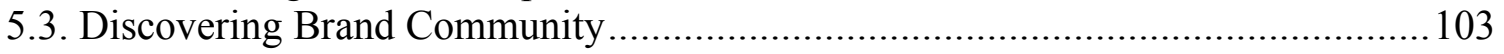

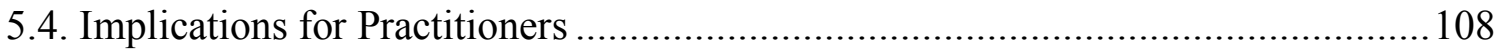

5.4.1. Developing the Group Experience ........................................................ 109

5.4.2. Promotion of History and Heritage ........................................................ 110

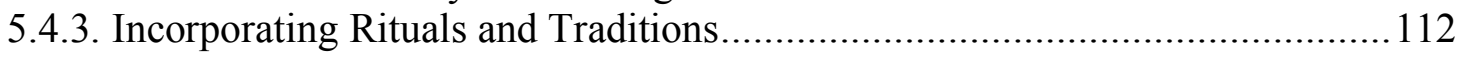

5.4.4. The Facility - More Than Just a Building.............................................. 113

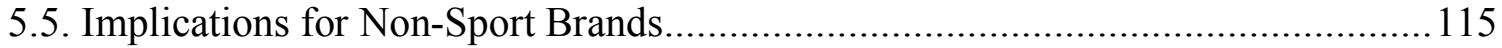

5.6. Implications for Future Research................................................................. 116

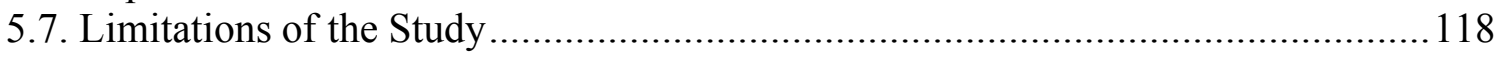

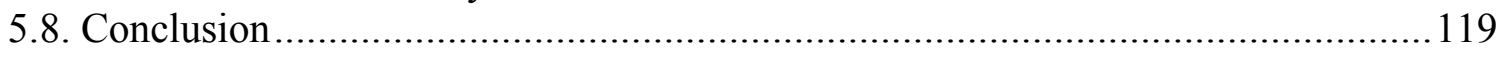

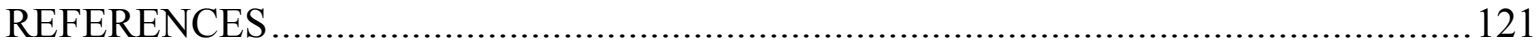

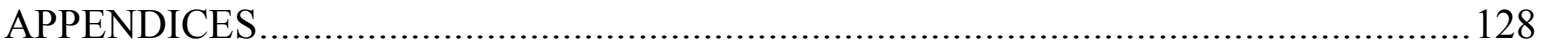

Appendix 1: Respondent Experience and Demographics........................................ 128

Appendix 2: Participant Information Sheet......................................................... 129

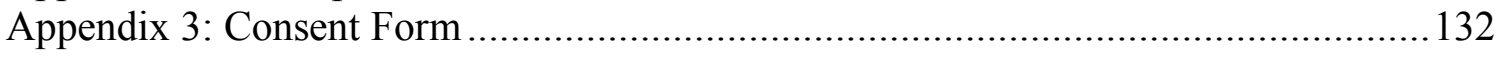




\section{INDEX OF TABLES}

Table 1: Interview Areas and Questions...................................................................52

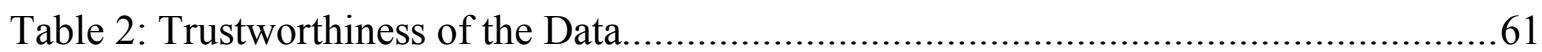

Table 3: Respondent Position and Abbreviations .......................................................66 


\section{ATTESTATION OF AUTHORSHIP}

I hereby declare that this submission is my own work and that, to the best of my knowledge and belief, it contains no material previously published or written by another person (except where specifically defined in the acknowledgements), nor material which to a substantial extent has been submitted for the award of any other degree or diploma of a university or other institution of higher learning.

Signed

Date 


\section{ACKNOWLEDGEMENTS}

Firstly I would like to thank Dr. Bob Heere for the enthusiasm and trust he showed toward both myself and this project. This project would not be where it is today without his knowledge and guidance. Along with influencing me to always aim to be the best, he has showcased that being a good person and having fun is as much a contributor to this as is all the brains in the world.

Second, I would like to thank Dr. Geoff Dickson for everything he has done for me. His promotion and enthusiasm for the sport management program at AUT led me to postgraduate study and consequently developed my passion for business. He has provided me with numerous opportunities, placed confidence in an untested student, and been my guide for the last two years. I look forward to working with you in the future.

Thirdly, I would like to thank Dr. Mark Glynn for his advice and guidance throughout the undertaking of this thesis. His knowledge of thesis development and the research process kept my feet on the ground, and reined me in when things got a little bit out of control.

To my fellow post grads during our time in the windowless office - Chief, Brett, Claire, Paddy, Nick, Grace, Purvi, Joe, Marcus, Katrina, Ian, Michelle, Jerry, Jamie, Darryl, Pete, Sue - thanks for making the last two years so enjoyable.

The Classic and all who inhabit it - thanks for giving me the best outlet from uni.

To my brother Steve - cheers for putting up with me the last two years.

Finally and foremost, I would like to thank and dedicate this thesis to my parents. Over the years they have invested so much of their time, effort and love into my brother and I, and asked for so little in return, often to the detriment of their own goals. I love you and will be forever grateful. 


\begin{abstract}
The professional sport market and its established teams offer consumers a service and experience that is typically high in social identification, emotional involvement (Underwood, Bond \& Baer, 2001) and a sense of community or social belonging (Heere \& James, in press). The strong social attachment to a sports organisation and its brand is proposed here to closely resemble the concept of a brand community (Muñiz Jr \& O’Guinn, 2001). For newly-established teams without a considerable history, along with having to compete with their established competitors, there is generally a lack of consumer identification or emotional investment in the team.

This study aimed to investigate newly-established teams within the New Zealand sports market with two specific research questions: 1) What issues affect the development of a new sports team brand, and 2) Do managers of new sports teams use antecedents of brand community or social identification in their branding strategies, and if so, how?

A qualitative, case study approach was used; featuring both interviews with managers of three newly-established New Zealand sports teams and direct observations of their stadiums. Findings suggested that the managers believed that existing image and awareness, audience nature, win-loss record, quality of the team or competition, and a lack of history were the main issues affecting the development of their brands. Respondents largely considered the antecedents of a brand community as important, with the exception of history. Promotion of these antecedents was largely absent from each of the team's branding strategies. Along with providing a detailed review of brand community literature, this thesis provides recommendations for managers of new teams on how to develop and position branding strategy toward the long-term goal of creating a community around their team brand.
\end{abstract}




\section{CHAPTER 1}

\section{INTRODUCTION}

\subsection{Background to the Research}

The teams that participate in professional sports leagues are a dominant feature of the modern sporting landscape. Many of these organisations have been in existence for well over a hundred years, with many more teams and sports leagues originating in the early stages of the $20^{\text {th }}$ century. Over time, leagues have included new teams to form highly popular and exciting competitions. The popularity of sports as an entertainment option has ensured that this growth has continued through the $20^{\text {th }}$ century into the present, with the frequent creation of new teams and franchises designed to capitalize on consumer demand for professional sport (James, Kolbe \& Trail, 2002).

\subsubsection{New Sports Teams}

Prior to detailing the development and creation of new sports teams in the industry, it is important to briefly examine generic marketing literature concerned with the introduction of new brands. The global market proliferates with the consistent introduction of new brands. Thousands of new products are introduced into the market every year, fuelled by millions invested in research and development (Calantone \& Cooper, 1981). Along with serving individual companies in their search for differentiation, new brands and the products they represent are required to fuel growth within the economy and country we live (Robertson, 1998). Although the introduction of new products is a necessary corporate step, as Calantone and Cooper (1981) warn, it also carries with it an extremely high level of risk.

The desire for growth has transferred to the sports industry, where the development of new sports teams or franchises is widespread. It is fairly common to have witnessed at 
some point in time the development or integration of new teams into existing leagues, or in some extreme cases, the introduction of a completely new sports league and teams. Mahony and Howard (2001) estimated that with the United States, as many as 170 new professional sports teams came into existence during the 1990s. The creation of as many as 13 new leagues since 1990 in the United States has created a pool of professional sports teams numbering over 600 (Mahony \& Howard, 2001).

The last ten years within the professional sport market has seen the continual development of new teams (James et al., 2002). James et al. observed that in the ten years leading up to 2002, three new teams were added to the National Football League (NFL), four teams to Major League Baseball (MLB), and six new teams in both the National Basketball Association (NBA) and National Hockey League (NHL). Primarily through the use of league expansion, sport-governing bodies (for example, the NFL, or MLB) have aimed at increasing their consumer bases and entering into new geographical markets. These new teams, and their respective brands, begin life with minimal devoted fans, no history or heritage to recall, no rituals that have graced the playing field in previous games, and potentially not inhabiting a hallowed sporting stadium. These elements, as will be outlined through the discussion of brand community and social identification branding theory, are suggested to be antecedents toward the development of a strong sports brand. It is the task of this study to investigate whether teams in their initial stages of growth are attempting to develop these attributes, and whether or not they consider them to indeed influence the creation of a successful sports team brand.

\subsubsection{A Worldwide Perspective}

As mentioned above, it is fairly common in the modern sports industry to have witnessed at some point in time the development or integration of new teams into existing 
leagues. Examples of teams introduced into established major leagues in North America within the last ten years include: 1) the Arizona Diamondbacks and Tampa Bay Devil Rays in Major League Baseball, 2) the Houston Texans in the National Football League, 3) the Charlotte Bobcats in the National Basketball Association, and 4) the Minnesota Wild, Nashville Predators, Atlanta Thrashers, and the Columbus Blue Jackets in the National Hockey League. This period also witnessed the creation of several sports leagues: The Extreme Football League (XFL), a creation from the owners of World Wrestling Entertainment (WWE) which subsequently lasted a single 2001 season; the Women's United Soccer Association (WUSA); and the launch of Major League Soccer (MLS) in 1996. The difficulties that new sports leagues face is evident from the fact that both the XFL and the WUSA are now non-operational.

Within an Australasian context, there has also been consistent development and expansion of leagues. The introduction of the Port Adelaide Power in 1997 to the Australian Football League partnered the merger of the Brisbane Bears and the Fitzroy Lions, creating a composite team, the Brisbane Lions. Over the past ten years, the Australian National Basketball League has had four new teams enter the league: the Cairns Taipans, Hunter Pirates, West Sydney Razorbacks and the New Zealand Breakers. This transformation of the league is further compounded by the recent confirmation that two new teams will enter the league for the 2006-2007 season: the South Melbourne Dragons, and the Singapore Slingers. Further expansion is evident in the re-branded Super 14 rugby union competition, with the inclusion of a Perth-based team, the Western Force, along with a new South African team, the Vodacom Cheetahs. 2007 will see the Australian National Rugby League become a 16-team competition, widening to include the Gold Coast Titans franchise. 
With the exception of the Port Adelaide Power and Brisbane Lions, those Australasian teams mentioned above have been plagued by mediocre performance. The Cairns Taipans, Hunter Pirates, West Sydney Razorbacks and the New Zealand Breakers are without championship titles; and the Vodacom Cheetahs and Western Force finished $10^{\text {th }}$ and $14^{\text {th }}$ respectively in their first year. Along with new teams in existing leagues, there has also been the launch of new sports leagues within the Australasian market. To coincide with the complete redevelopment of soccer in Australia, a new national league was created in 2005 to act as a showcase of the sport. The Australian Hyundai A-League consists of eight teams, of which several are completely new entities. The A-League was developed to supersede the former National Soccer League (NSL), with the aim of revitalizing soccer in Australia.

\subsubsection{New Sports Teams in New Zealand}

Within the last 12 years, the New Zealand sports industry has witnessed the development of several new sports franchises. This expansion and creation has corresponded with increased consumer interest in spectator sports and the perceived need for national sporting organisations to have professional teams or leagues to showcase their sport to the public. Subsequently, the Auckland region is now home to four recently established sports teams introduced since 1995: 1) the Vodafone New Zealand Warriors, 2) the Trusts Diamonds, 3) the Harvey Norman New Zealand Breakers, 4) and the New Zealand Knights. Of these four teams, only the Knights did not participate in this study.

The Vodafone New Zealand Warriors were created in 1995, as an expansion franchise to the then Australian Rugby League (ARL) Winfield Cup rugby league competition, the premier rugby league competition in Australia. Originally the Auckland Warriors, the franchise now participates in the re-branded National Rugby League (NRL) 
competition, featuring another 14 teams from around Australia. The Warriors are the sole representative team from New Zealand in the competition (National Rugby League, 2006).

The franchise has passed through a multitude of on and off-field problems, and is an organisation that is seemingly always plagued with troubles (Mirams, 2001). The team has been affected by several serious events in its short history: it has passed through the Super League versus ARL battle for control of rugby league, in which it switched to the rival Super League for a brief period; it lost two competition points in the inaugural season which resulted in an absence from the playoffs; it has been influenced by changes of ownership and conflict between prospective owners; and recently it has broken NRL rules with regard to breaching the player payment salary cap, resulting in a minus four competition points total prior to the 2006 season. On-field performance has been highly volatile, with lower league placings far outnumbering playoff appearances. Of the four teams discussed here, the Warriors are the only team to make a respective competition grand final; however, two years later they were placed $14^{\text {th }}$ in the 15 team competition (New Zealand Warriors, 2006). Ultimately, the Warriors have been erratic and unpredictable on the field (Mirams, 2001). These examples, along with many other problems that the club has faced in its short history have all contributed to the current image that the consumer has of the organisation, and the Warriors brand.

The Trusts Diamonds, representing the Auckland, Waitakere and CountiesManukau regions of New Zealand, is a semi-professional sports franchise that participates in the National Bank Netball Cup. This competition is the premier national netball league, and consists of eight teams representing regions around New Zealand. The team has been in operation since 1998, which is also the year in which the current competition was launched. Originally named the Auckland Waitakere Diamonds, the team has recently re- 
branded itself as the Trusts Diamonds. This brand, similar to the Vodafone Warriors, incorporates the major sponsor of the franchise, the Portage and Waitakere Trusts, a prominent association of liquor and gambling trusts throughout the region of West Auckland. The team has also recently been aligned to incorporate a team previously included in the competition, the Counties-Manukau Comets. In reducing the competition to eight teams, the Trusts Diamonds have added the player-pool of Counties-Manukau to their franchise.

The Diamonds have experienced much less public and media attention than the Warriors: Netball has struggled for television coverage when compared to rugby or rugby league, and is not broadcast on Sky, New Zealand's lone supplier of subscription digital television. The National Bank Cup is the least high-profile of the four leagues included in this commentary, as it does not feature Australian teams because of its domestic focus, and also it competes against the fanatically supported sport of rugby, the national team known as the All Blacks, and the regional Super 14 competition. Although fortunately there have been minimal problems or issues regarding the Diamonds that have warranted media coverage, there has also been a lack of positive events to capture the media and public interest. In 1998 and 1999, the Diamonds successfully made the competition playoffs, being eliminated in the semi-finals. In the following years, the team has failed to reach the finals of the competition, finishing no higher than fifth in 2003 and 2004.

An additional issue that the Diamonds are now faced with is the consistent evaluation and auditing of the National Bank Cup competition, with the aim of streamlining or eliminating teams that are believed to not be competitive. Along with the potential to reduce this national competition to six teams, Netball New Zealand is currently considering 
the opportunity of creating a trans-Tasman competition with Australian semi-professional teams. This would mirror the competitions of the other three teams discussed here.

The Harvey Norman New Zealand Breakers were conceived in 2003, playing their first season over the 2003-2004 period. The fully professional Breakers participate in the National Basketball League along with 11 other teams, and are no longer the newest team in the league, with the recent creation of the South Melbourne Dragons and the Singapore Slingers. The National Basketball League has constantly changed the complexion of its league, with four teams including the Breakers being introduced within the last 12 years; Both the Dragons and the Slingers will replace two of the existing NBL teams. As is common with the Warriors and Diamonds, the team commonly promotes its brand in conjunction with Harvey Norman, an Australasian homeware and electronics company.

The Breakers have had minimal on-court success, finishing $10^{\text {th }}$ out of 12 in their inaugural 2003-2004 season, $11^{\text {th }}$ of 11 in 2004-2005, and $9^{\text {th }}$ of 11 in the 2005-2006 season (National Basketball League, 2006). Subsequently, this performance has resulted in no post-season or play-off activity for the franchise. Management issues that have generated media attention have also affected the team: there have been three different head coaches involved with the team in its first three seasons, player-management conflict, the departure of several well-known New Zealand representatives from the team, and the failure to maintain a consistent home venue, switching between three venues around the greater Auckland region.

The fourth and final franchise is the New Zealand Knights soccer team. This fulltime professional team participates in the previously mentioned Hyundai A-league, and again is the sole representative from New Zealand in the eight-team Australian competition. The Knights originate from the previous New Zealand professional soccer team the Kingz. 
The Kingz were participants in the previous premier soccer competition in Australia - the National Soccer League (NSL). The Football Kingz, as they were known towards the end of their existence, began life in the $1999-2000$ season, finishing $8^{\text {th }}$ of 16 teams. In the following five seasons, performance steadily declined, culminating in bottom of the table finishes and a failure to advance to post-season play. With the franchise in financial and managerial crisis toward the end of the 2004 season, a UK businessman who aimed to restructure the team bought the Kingz. The Knights were created following a re-branding process and successfully applied to become part of the new Hyundai A-League.

Following the re-launch of the Knights, the team participated in their first season over the summer months of 2005 and 2006. In line with previous performances of the Kingz, the team finished eighth out of eight. Along with this poor on-field performance, the Knights have experienced player-management problems, resulting in players leaving the club, including the original club captain, and the sacking of two managers within one and a half seasons. Dwindling crowd numbers have also plagued the franchise, and comparisons to the original Kingz brand have been frequent. This has culminated in speculation surrounding the future of the team and its expulsion from the A-League (Brown, 2006).

\subsection{Research Problem}

Teams developed in the early stages of a sports league's existence have had the opportunity to build a relationship with the consumer through a lengthy past. As sports teams and their respective histories have developed, they have had the opportunity to become entrenched in the life of consumers. These teams have existed through periods full of past achievements, memorable moments, spectator interaction, heroic athletes and possibly on-field success. 
For teams that have not been in existence for a long time, such as the four mentioned above, these elements are in short supply. While a new team may be able to compete at a similar level on the field with its established competitors, new teams remain at a considerable strategic disadvantage. A newly-developed team possesses minimal history; it does not possess historic moments and unbelievable athletic feats; there is no past regarding how successful it has been on the field, nor how many previous championships it has captured. A new team does not possess any past upon which fans can recall their previous involvement or their personal or community's interest in the team; the established team will already possess consumers or fans that are loyal to the team. A newly-developed team cannot instantly create fan loyalty, and may have difficulty retaining fans. Only time can create a relationship between both parties. Research has also shown that new teams are considered far less valuable than their established competitors. Financial comparisons between established giants of the game such as the New York Yankees, Boston Celtics or Montreal Canadians as opposed to new entrants such as the Nashville Predators, Washington Nationals, or the Toronto Raptors suggest that new teams are regarded as considerably less valuable than well-established rivals (Forbes, 2006; O'Reilly \& Nadeau, 2006).

Factors such as history, previous success, heroic players, or the forming of bonds between fans have contributed to the development of strong and large fan groups that surround, consume and support established teams. This parallels recent research into the concept of brand community, or "a specialized, non-geographically bound community, based on a structured set of social relationships among admirers of a brand" (Muñiz \& O'Guinn, 2001, p. 412). While it seems that sports teams and their fans have always been excellent examples of communities, only recently have academics come to acknowledge 
them as such (Heere \& James, in press). This research proposes that established teams, through years of spectator interaction, historical moments, and the creation of traditions or rituals, are an excellent example of communities drawn together by a brand. The corollary of this is that newly-established teams are an excellent context within which efforts to establish a brand community can be explored.

\subsection{Purpose of the Study}

Unlike established teams that have passed through this difficult initial period and have developed a well-known brand in the sports market place, a new team must cultivate and develop a brand that is able to compete with its established competitors from the point of initiation. Where the established team has forged and developed a relatively stable brand over time, new teams possess brands with little stability, which can be easily influenced by poor on-field performance, a relatively common problem in the early life of a new team.

The first purpose of this study is to investigate the issues that affect newlyestablished sports teams in New Zealand and the development of their brands. The primary interest in this area is reserved for the issues that managers believe have plagued the development of their team brands in the past, or those that may still have an influence. Therefore, the first research question of this study is:

\section{Q1: What issues affect the development of a new sports team's brand?}

Following this, the subsequent second stage of the research is to investigate if and how managers of new sports teams are developing brand communities. Previous research has predominantly striven to investigate communities devoted to tangible products such as Harley Davidson motorcycles (Bagozzi \& Dholakia, 2006; McAlexander et al., 2002; Schouten \& McAlexander, 1995), European and American motor vehicles (Algesheimer et al., 2005; Muñiz \& O'Guinn, 2001), Apple computers (Muñiz \& O'Guinn, 2001; Muñiz \& 
Schau, 2005), and even the highly successful science fiction series, Star Trek (Kozinets, 2001). Minimal attention has been given to brand communities surrounding service brands, along with a gap in the literature pairing brand community and the team sport industry. This research will attempt to provide an insight into both these areas.

Existing brand community research has also focused primarily on well-established brands and their consumer followings, but has yet to discuss how managers create such a community. This focus could either take the perspective of an existing brand aiming to create a strong brand community, or a new brand wishing to develop community from its conception. The sporting context not only provides an excellent environment in which to investigate the brand community concept, but also is an extremely effective setting in which to develop conceptual frameworks or theories that can be translated to generic marketing models. This study will ideally contribute to a foundation from which applications of the brand community concept to new brands can be made, or to further investigation into brand community in service or mainstream marketing contexts. The study also aims to introduce the brand community concept to the sporting environment as a both a guide to all branding efforts, and an eventual target that all practitioners should endeavour to create.

Therefore, the second specific question that this research will aim to answer will be how managers of newly-established New Zealand sports teams are developing brand communities. This will be done through an examination into how managers are promoting or employing the antecedents that literature suggests contribute to the creation of brand community (Muñiz \& O’Guinn, 2001) and social identification (Underwood et al., 2001).

Q2: Do managers of new sports teams use antecedents of brand community or Underwood et al. (2001) in their branding strategies, and, if so, how? 
In summary, the purpose of this study was to answer two questions: 1) what issues managers believe have affected the development of their brands, and 2) if and how managers are developing strategies inline with brand community or social identification development.

\subsection{Overview of Methodology}

Three newly-established sports teams from Auckland, New Zealand, form the sample featured in the study: the Vodafone Warriors, the Trusts Diamonds, and the Harvey Norman New Zealand Breakers. The methodology consisted of a qualitative, exploratory, multiple case study, in which data was collected through semi-structured interviews. Respondents were those employees responsible for developing the team brand, and were questioned regarding their involvement with sports branding and their employer's branding strategies. A direct observation analysis of the physical environment in which each team played was undertaken to triangulate interview data, and determine whether interview statements truly reflected the delivery of the team sport service and brand.

Both the interviews and direct observation analysis were primarily used to investigate the presence of two key concepts within the new sports team environment: brand community (Muñiz \& O'Guinn, 2001) and social identification branding (Underwood et al., 2001). Featured throughout these two concepts are several elements that contribute to the development of a strong brand: the group experience, history and heritage, rituals or traditions, and the physical facility. Inquiry into if and how these elements are being used within each of the case organisations was the primary goal of this research study.

\subsection{Outline of the Thesis}

The following provides an outline of the sections featured within this thesis. Chapter 2 provides a literature review featuring discussion on brands and the importance of 
brands to the modern economic environment. This progresses into a review of the community concept followed by an in-depth commentary on brand communities, and the antecedents that lead to their development. Chapter 3 outlines the research methodology used in the implementation of the thesis, focusing on the qualitative case studies, interviews and direct observations methods.

Chapter 4 presents the findings of the thesis with respect to four major areas: 1) issues affecting new team brand development, 2) current team branding strategies, 3) objectives of the organisations, and 4) the use and implementation of the four studied antecedents - the group experience, history and heritage, rituals and traditions, and the physical facility. Along with providing an interpretation of the findings, Chapter 5 offers a comprehensive discussion of the implications to sports marketing practitioners, managers of generic brands, and also future research. Limitations of the thesis are also provided.

\subsection{Key Concepts and Definitions}

A key concept of this research is the 'new sports team' term, and its exact meaning throughout the study. For the purposes of this study, a new sports team is regarded as one that has been recently established in relation to it competitors in a specific competition or part of a newly created competition. As there were no sports teams in the first year of competition within the New Zealand industry, three teams were chosen that represented three stages of a newly established team's life, four, eight, and twelve years. This represents a continuum, where each of the three teams are at a different stage in their early development. Additionally, the focus of the study lies in understanding the development of a sports team brand during the early years. Therefore in summary, the new sports team concept is used with regard to recently created sports teams, rather than just those in their first season of competition. 
This study uses two key concepts as underlying foundations, namely brand, community and the work of Underwood et al. (2001), along with the antecedents that contribute to their creation. Definitions are primarily offered throughout the following literature review chapter, as the conceptualisation behind concepts such as history or rituals is given more detailed attention. However, an introduction to the two key terms used within the study may prove beneficial to the reader at this stage, namely 'brand community' and 'social identity'. A brand community is defined as "a specialised, non-geographically bound community, based on a structured set of social relationships among admirers of a brand" (Muñiz \& O'Guinn, 2001, p. 412). Further definitions and their conceptual underpinning are provided in Chapter 2.

\subsection{Delimitations of Scope and Key Assumptions}

The scope of this research study extends to newly-established sports teams in New Zealand, compiled from three located in the greater Auckland region. Newly-established rugby teams playing in the Super 14 competition were excluded because of accessibility issues, as was the previously-mentioned New Zealand Knights Football Club. While findings may be taken from this research toward alternative markets, the author makes no claims of all-encompassing generalisability. Each new team, as the unit of analysis, was represented by two managers responsible for the marketing and potential branding strategy

of each club; therefore the findings of this study are dependent on data collected from these sources. It is assumed that data collected from these sources is authentic and a true representation of respondent opinion.

The study did not aim to investigate directly if the teams are aware of and are developing brand communities, but more specifically focused on whether managers are 
using the antecedents to develop their brands, and if they regard them as important in the development of their team brands.

\subsection{Summary}

This chapter has provided the foundation upon which this thesis will be presented. It has introduced the background to the research, the problems and questions that it seeks to answer, and a brief introduction of the underlying literature that supports its initiation. The following literature review will provide a detailed path that will guide the reader toward understanding the use of brand community and the work of Underwood et al. (2001), and its application to the new sports team brand context. 


\section{CHAPTER 2}

\section{LITERATURE REVIEW}

\subsection{Introduction}

This review describes a current stream of research on the development of brands based upon the identification and creation of brand communities. Following a discussion regarding new sports teams and the issues that have affected them, the review will aim to propose that a worthwhile addition to brand development research and practice is the brand community, or the development of consumer identification with a brand. Based on the success of brand communities in the commercial sector, and the potential to regard established sports teams and their fans in a similar light, it will be suggested that the development of aspects of brand community and consumer identification are essential to creating a strong brand and consumer following.

\subsection{The Meaning of a Brand}

The concept of a brand is undoubtedly one of the most important business concepts in the modern world. Companies spend large amounts of money and time launching new brands, leveraging existing ones, and acquiring rivals (Kumar, 2003). Due to the integral use of the brand within marketing strategy (Grace \& O'Cass, 2002), extensive research has been done both on the definition and process of branding.

Since the earliest times producers of goods have used their brands or marks to distinguish their products (Murphy, 1998), ranging from Egyptian brickmakers through to whisky distillers (Farquhar, 1989). Modern branding and the development of individual brand names has its origins in the nineteenth century; If the nineteenth century was to give birth to the brand, the twentieth century produced the notion that branding was going to be central to both commerce and competition (Aaker, 1991). 
A widely-held definition of a 'brand' comes from the American Marketing Association, who defined the term as a name, term, sign, symbol, or design, or combination which is used to identify the goods and services of one seller or group of sellers and to differentiate them from competitors (Kotler, 1991). Aaker (1991), in his seminal work regarding brand equity, referred to a brand as a "distinguishing name and/or symbol (such as a logo, trademark, or package design) intended to identify the goods or services of either one seller or a group of sellers, and to differentiate those goods or services from those of competitors" (p. 7). These definitions have been widely used throughout marketing literature, and continue to provide a foundation for today's research.

Many definitions of a 'brand' have been proposed by authors based upon varying components believed to be central to the concept. In an extensive review of branding literature, de Chernatony and Dall'Olmo Riley (1998) found 12 distinct foundations of brand definitions. These ranged from the above 'logo' concept to constructs such as 'legal instrument, risk reducer, a value system, and relationship builder,' for example. The authors conceptualised a brand as a "complex multidimensional construct whereby managers augment products and services with values and this facilitates the process by which consumers confidently recognize and appreciate these values" (de Chernatony \& Dall'Olmo Riley, 1998, p. 436).

It is also important to distinguish the difference between a brand and a product. Kotler and Levy (1969) suggested that a product can take many forms, and that each type of organisation produces a product of at least one of the following types: physical products, services, persons, organisations, and ideas. Doyle (1989) proposed that a product is "something produced in the factory or the office. It is about materials, components, labour costs, quality and output specifications" (p. 78). 
In an effort to define what a brand was, Styles and Ambler (1995) identified two approaches to distinguish a product from a brand. The first followed the traditional 'product plus' definition, which viewed branding as an addition to the product. The second was the 'holistic view,' which considered the brand as the sum of all elements in the marketing mix. Hence, as the product is but one feature of the mix, it plays a part in contributing to a 'brand' (Styles \& Ambler, 1995). This notion of the brand being much more than just the product serves as a foundation behind this study. Murphy (1998), in line with this theme, suggested that modern branding is concerned with a brand's gestalt, assembled with a mix of both tangible and intangible values that are relevant to consumers. If a consumer perceives a brand to embrace values that are common to them, they may reject others purely on the basis of whether or not alternatives possess these important values.

For the purposes of this study, a brand will be defined based on this line of research, centred on the brand being more than just an identifying mark or product. Based on the work of Ambler (1992), Styles and Ambler (1995), and Ambler and Styles (1997), the holistic definition of the brand will be used as the background to this study: "The holistic approach defines a brand as the promise of the bundles of attributes that someone buys and that provides satisfaction. The attributes that make up a brand may be real or illusionary, rational or emotional, tangible or invisible" (Ambler \& Styles, 1997, p. 14).

\subsubsection{Benefits of Brands}

A brand can assist an organisation in its desire to achieve certain goals or objectives. For a typical business, the task of gaining new customers is usually far more expensive than retaining existing ones (Aaker, 1991). Aaker suggested that by fostering and developing a strong brand, loyalty could be created to assist in nurturing consumer 
attachment to a brand. Aaker conceptualises brand loyalty as a measure of attachment that a customer has to a brand, reflecting how likely that a customer will switch to another brand when faced with changes either in price or product features.

As well as retaining consumer interest in the organisation's own brand, customer satisfaction and relationships with a brand provide it protection from competitive offerings (Aaker, 1996; Shocker, Srivastava \& Ruekert, 1994). A number of studies have been completed regarding brand and consumer loyalty within the sports marketplace (Bristow \& Sebastian, 2001; Gladden \& Funk, 2001; Levin et al., 2004; Richardson \& O'Dwyer, 2003), suggesting that the ability of brands to generate consumer loyalty is common to the team sport service offering.

Along a similar line is the ability of brands to create the 'halo effect.' Applied to a marketing and brand context, the halo effect suggests that a consumer's perception of an individual product attribute can be affected or distorted by their attitude towards the overall brand (Leuthesser, Kohli \& Harich, 1995). The halo effect causes individual product attribute ratings to display greater variance than they would had the brand been unable to influence the consumer (Leuthesser et al., 1995). An example of the halo effect can be proposed within the team sport context: the influence of a strong overall team brand may be able to influence consumer perception of individual features present at a live sporting event, such as the performance of the team, the food or catering, or the condition of the stadium. The halo effect may override consumer perception that would normally be negatively influenced by aspects such as a team's poor win/loss record, or a decrepit stadium.

A brand can also assist a producer in enabling extension into alternative product categories. Many firms over the last decade have used the brand extension strategy to leverage existing brand equity (Glynn \& Brodie, 1998). Brand extension, or the process by 
which a current brand name is used to enter a completely different product class (Aaker \& Keller, 1990), is particularly attractive to firms that face the reality of possible new product failure. Aaker and Keller (1990) suggested that extensions allow a company to take advantage of existing brand name recognition and image to enter new markets. This reduces the risks of new product introduction (Dawar, 2004). Extending an existing brand to a new product or service can assist in entering a market more cheaply, establish a new product more quickly than an unknown brand, and increase overall exposure to the brand (Murphy, 1998).

A strong brand can also allow a company to inhibit the movement and market penetration of rival companies. Established brands and competition often make implementation of a new brand into an established market less effective or financially viable to competing organisations (Aaker, 1996).

Jary and Wileman (1998) reported that a strong retail brand with an established brand premium, is more likely to generate greater volume of consumer interest and market share. Along with influencing competitors in similar categories, a strong brand can provide a company with enhanced power to deal in distribution channels (Dawar, 2004). The need to develop a strong brand is further compounded by the developing influence and power possessed by distributors and retailers. Shocker, Srivastava and Ruekert (1994) theorised that, as retailers become ever-more influential and powerful within distribution channels, the need for a recognized brand has become ever more important.

In summary, the development of the brand concept within modern research and practice is unquestioned. As previously mentioned this study will adopt the brand concept as being more than just a point of identification, but as the promise of the attributes that someone buys and that provides satisfaction, it can be illusory, rational, emotional, tangible 
or invisible (Amber \& Styles, 1997). Along with the strategic benefits of brands discussed above, the ability for brands to act as a catalyst toward social interaction amongst consumers is a slowly growing literature.

\subsection{The Development of Brand Community}

The following section aims to provide an introduction to the community concept from a sociological perspective, followed by a detailed review of the literature concerned with brand communities and the justification behind its use within this thesis. Also investigated are the specific components that a brand community possesses such as the group experience, history and heritage, and rituals or traditions. The work of Underwood and colleagues (2001) into sports branding will be reviewed, along with the similarities it shares with brand community research.

\subsubsection{Community}

The community is one of the most important basic social structures in the formulation of global society. It has been of paramount importance in the development of human society through to present times, as it represents a critical stage of human development (Konig, 1968). As a core construct of social thought (Muñiz \& O'Guinn, 2001), the concept of community has been studied in immense detail. Muñiz and O'Guinn suggested that community was of prominent concern to scientists, theorists and philosophers during both the nineteenth and early twentieth centuries. Due to the historical presence of community, and the extensive research attention it has been allocated, it has undoubtedly been a significant contributor to human development throughout history (Chavis \& Newbrough, 1986).

Academic attention to the community concept continues in modern research, with contemporary literature investigating the transformation of the community environment 
(Cova, 1997; Heller, 1989; Putnam, 2000). Contemporary sociologists have attempted to analyse community from two perspectives: 1) that community is the ecological juxtaposition of people in the same location, and 2) community features interpersonal relations, no matter where they are located (Wellman, 2001). Further work has provided academic definitions of the community concept with reference to three varying perspectives: 1) the community as a place, 2) community as relationships, and 3) and community as a collective political power (Chavis \& Wandersman, 1990; Gusfield, 1975; Heller, 1989; Suttles, 1972). For the purposes of this review, the community as a place will be initially discussed, followed by the community as a relationship. The community as a political power will not be examined as it is deemed not to be appropriate to the context of this study. The community as either a place or a set of relationships is deemed to be more applicable to both marketing and brand community.

In his extensive review of the community concept and definition of the term, Konig (1968) proposed that the word community in general should be used in reference to localised community. Konig went on to offer to define community based on local groups of human beings that share their social, economic and cultural lives together, with common and accepted values and obligations. Delanty (2003) believed that the location perception of community has come from a sociologist perspective, with the community representing a particular form of social organisation based on small groups, such as neighbourhoods, small towns, or spatially bound locations. While the community as a locale appears to be a mainstream and well-serviced line of inquiry, the most applicable context to this study is that of examining the community as a set of relationships. Anthropologists have aimed to apply the community concept to culturally-defined groups, along with the idea of a 
collective identity. The community can be seen as the search for belonging, where importance is placed on cultural issues of identity (Delanty, 2003).

With regard to the community as a social relationship, Wellman (2001) defined a community as a network of interpersonal ties that provide sociability, support, information, belonging and social identity that is not necessarily limited to physical locations. In examining the term, Delanty (2003) proposed that community is an idea about belonging, the search for meaning and solidarity, and collective identities. Delanty went on to state that instead of seeing communities as location-dependent or socially-arranged, they should be seen as a way of imagining and experiencing social belonging.

McMillan and Chavis (1986) developed the 'sense of community' concept, which included four elements that would be crucial to the fostering of a sense of community. The first was membership, or the feeling of belonging and sharing a sense of personal relatedness. This was followed by influence, which was based around a sense of mattering to the group and, in return, the group mattering to its members. The third element was integration and fulfilment of needs, which concerned how member's needs could be met by those resources possessed collectively by the group. The fourth element was deemed to be a shared emotional connection. This connection between members featured the belief that as a community, members would share history, common places, time together and similar experiences (McMillan \& Chavis, 1986).

Based on this work, Chavis and Newbrough (1986) proposed that the development of community focuses on human empowerment. Community development is a process that provides opportunities for membership, for social influence, for the fulfilment of human need, and to share emotional support (Chavis \& Newbrough, 1986). Influenced by this statement, the development of a healthy community can aid in resisting social, 
psychological, and physiological problems whilst at the same time enable members to grow individually and collectively to their maximum potential (Chavis \& Newbrough, 1986). Delanty (2003) proposed that the popularity of community today can be seen as a response to the sense of insecurity that people feel in the modern world, that neither the state or society as a whole can ease. Putnam (2000) suggested that each of us derives a certain degree of belonging from the various communities which we may belong to, which, along with friends and family, can be found in work, church, or civic life.

As a result, the modern community has been forced to take on non-traditional forms. Putnam (2000) suggested that today people experience their community through friends and informal organisations, as opposed to traditional sources such as churches, family and voluntary organisations. Delanty (2003) suggested that 'in-between' spaces are beginning to have a growing importance in people's lives; places such as the airport lounge, the commuting train, the leisure centre, the Starbucks café, or the shopping centre. Delanty suggested that traditional communities where the family was central have been relegated to a more nostalgic perspective. Since people are more likely to not be living close to their own parents or traditional family communities, reliance falls upon other kinds of support to deal with the practical aspects relating to child care, illness and everyday life (Delanty, 2003). The overriding theme that emerged from Delanty's work was that modern communities are less bound compared to those of the past, as communicative ties and contemporary societies open up new possibilities for belonging and community

As outlined above, traditional geographical kinds of community are different from the new expressions of post-modern communities: virtual communities, gay communities, ethnic communities, and religious communities. Moving away from the traditional view to these new kinds of community, allows us to see that they have the ability to construct new 
social realities in which people can find a sense of belonging or social identification (Delanty, 2003)

Sports teams and their fans are an excellent example of a post-modern or contemporary community. Individuals may belong to a community that includes others who also follow and support the same team (Heere \& James, in press), or they may meet and interact with others in attending and supporting a specific team. Either way, it appears that a sports team can act as the centre point and reason for which people come together. Additionally, Heere and James offered that fans perceive themselves to be members of an organisation, rather than consumers of a service. This proposed relationship shift focuses on fans as consumers becoming fans as community members (Heere \& James, in press).

A similar perspective was forwarded by Melnick (1993), who proposed that sports spectating has emerged as a major event where spectators come together not only to be entertained, but to invest in the development of their social and psychological lives through the relationships available. Sports events display a communal structure in the way spectators revel at and cheer their favourite team while at the same time celebrate themselves (Melnick, 1993). While previous works have sought to examine community and sport have concentrated on the relationship between an individual fan and a specific team (Wann et al., 2001), there remains a paucity of literature concerned with the community appearance of sports spectators and consumption. Minimal attention has also been given to the integration of a sports team with its surrounding community (Heere \& James, in press).

Another particular perspective of community literature is that concerned with the affect that modernism and consumerism has had on traditional community. Muñiz and O'Guinn (2001) believed that consumption has been a major reason behind the morphing 
and transformation of community over time. As consumer culture has emerged and gathered momentum, branded goods have replaced unmarked commodities; mass marketing has superseded personal selling; and the communal citizen has transformed into the individual consumer. The heightened desire and need of the individual consumer are said to be a major influence on the decline of traditional community (Muñiz \& O'Guinn, 2001). McAlexander, Schouten and Koenig (2002) indicated that in examining contemporary communities, many can be identified based on their identification with either brands or consumption activities. Cova (1997) suggested that along with aspects such as shared emotions, styles of life, and moral beliefs, communities today can even be held together by consumptions practices. This provides the foundation to the notion of a community being based around an aspect of consumption, such as a brand.

\subsubsection{Brand Community}

The first conceptualisation of a community centred on a brand was presented by Schouten and McAlexander (1995), who introduced the term 'subculture of consumption.' It was proposed that a subculture of consumption was a "distinctive subgroup of society that self-selects on the basis of a shared commitment to a particular product class, brand or consumption activity" (Schouten \& McAlexander, 1995, p. 43). Along with this, the subculture of consumption was deemed to possess a hierarchical social structure, the use of unique jargons, rituals and symbolic expression, a shared ethos, and shared beliefs and values. Although the study investigated Harley-Davidson biker groups, communities that identify with one of the world's strongest brands, Schouten and McAlexander suggested that subcultures of consumption are ubiquitous throughout society, with everyday activities such as gardening, woodworking, or fly fishing guiding consumption and potentially forming the bases of subcultures of consumption (Schouten \& McAlexander, 1995. 
Although these subcultures of consumption appear to be centred on a common interest, they are not united over a specific brand or organisation.

A refinement to this concept was developed in the form of a brand community. Grounded in the previously mentioned community concept, Muñiz and O'Guinn (2001) proposed that a "brand community is a specialized, non-geographically bound community, based on a structured set of social relationships among admirers of a brand" (p. 412). Of particular application to this study and the sporting landscape are the common features of a brand community. Similar to other communities and the aforementioned subculture of consumption, it features a shared consciousness, rituals, history and traditions, and a sense of moral responsibility (Muñiz \& O'Guinn, 2001).

Of particular interest is the way in which an aspect of Muñiz and O'Guinn's work corresponds with the previously mentioned article by McMillan and Chavis (1986). Muñiz and O'Guinn included 'shared consciousness' as a component of a brand community; this parallels McMillan and Chavis' inclusion of the shared emotional connection element within their definition of a sense of community. This comparison provides some background to Muñiz and O'Guinn's inclusion of the shared consciousness component within their concept of a brand community.

Muñiz and O’Guinn proposed that brand communities are social entities that reflect the influence that respective brands have on the everyday lives of consumers. The study investigated how the inhabitants of a small American town were involved in brand communities, and the subsequent social links consumers had based purely on their involvement with a brand. Muñiz and O'Guinn (2001) proposed that brand communities may form around brands that possess a strong image, a rich and lengthy history, or are threatened by opposing brands. 
Building on this work was the case study by McAlexander et al. (2002). This study proposed that a brand community centres around the consumer rather than a specific brand, and the community was defined by the various relationships in which the consumer is situated. Along with providing an insight into the regularly examined Harley-Davidson consumer culture, the study provided an extensive ethnographic case study of the 'Jeep' brand community. Over a longitudinal period the authors found that by sharing meaningful experiences with one another at 'Camp Jeep' events, consumer appreciation for the product, brand and company marketers was enhanced. Consumers who were highly integrated in the brand community were also emotionally invested in the welfare of the company and genuinely interested in its success (McAlexander et al., 2002).

Muñiz and Schau (2005) later explored the way in which brand communities could remain even after a company had ceased production of the worshipped brand. Despite Apple's decision to abandon production and investment in their Apple Newton computer, a strong community remained devoted to the product. Along with elaborating on the devout interest in the product consumers portrayed, Muñiz and Schau highlighted the religious appearance of brand communities, suggesting that it may be an extremely important factor in why consumers form communities around brands.

An additional perspective on the brand community concept was provided by Algesheimer, Dholakia and Hermann (2005). In replication of the previous case study formats, the study investigated European car clubs with the aim of developing a conceptual model to explain the effect of brand communities on customer behaviour. The primary focus of the article was to explore the ways in which consumers identified with brands and subsequent identification with the respective brand community. Brand community identification was conceptualised as a process in which a person considers himself or 
herself to be a member, or belong to the brand community. This identification revolves around either a cognitive or an affective component: the cognitive involves a categorization process where the consumer creates and maintains self-awareness of membership to the group, whereas the affective denotes a sense of emotional involvement with the group. These components display similar properties to sports spectators, and the nature of the communities they create in support of various organisational brands.

Further investigation into brand community was completed by Bagozzi and Dholakia (2006), who stated that brand communities are venues where intense brand loyalty is expressed and fostered, and where consumers develop emotional connections with a brand. Their study aimed at investigating the difference between small communities of both brand and non-brand devotion, focusing again on the power of the Harley-Davidson brand versus motorcycle communities featuring multiple brands.

Of particular applicability to the context of this study is the perspective Bagozzi and Dholakia gave to brand communities, stating that they coincide with the popular movement of empowering the consumer. This process encourages firms to treat their customers as partners, providing control over information gathering and decision-making to them to a reasonable level, and co-operating with consumer competence in ways that are mutually beneficial and profitable. This is familiar to the sports industry, where consumers of live sport through their favourite team are commonly referred to as 'members,' purchase season tickets to confirm their membership, and actually contribute to the end service through their attendance at games. Heere and James (in press) advise that there is a necessity now to regard sports fans as community members rather than as purely consumers.

The development of this literature has resulted in a growing knowledge of the communities that have begun to congregate and base themselves around some of the 
world's most prominent product brands. One serious omission from this research at present is the lack of attention provided to service brands, such as recreation, arts, social events, and sports teams. Although not of the same literature concerning brand community, the theoretical framework provided by Underwood et al. (2001) featured similar antecedents to developing service brands through the use of social identity. Underwood and colleagues suggested that lessons could be taken from the sports industry on how to develop generic service brand equity. Their model proposed that characteristics of the sports service marketplace could assist in strengthening consumer identification. In line with the previously outlined attributes of brand communities, four antecedents were conceptualised as being important to this process: 1) the group experience, 2) history and tradition, 3) the physical facility, and 4) rituals. With the exception of the physical facility, group experience (similar to consciousness of kind), history and tradition, and rituals are all present throughout brand community literature.

\subsubsection{The Group Experience}

As the above section has briefly illustrated, the group experience and social interaction are critical components of the brand community concept. Although not referring to the group experience by that same heading, Muñiz and O'Guinn (2001) suggested that the most important element of community was consciousness of kind. Along with feeling an important connection to the brand, brand community members feel a strong connection to each other. As a result of their involvement with a brand, members feel that they know each other, even if they have never physically met. Even when members of the group are not necessarily physically together, online-based communities may flourish. While members may feel part of a largely unmet community, the strong ties stem from how easily the size of the community can be imagined. 
Muñiz and O'Guinn proposed two important characteristics featured within a consciousness of kind: 1) legitimacy, or the process by which certain members of a community differentiate between true or authentic members and those that they believe are not; and 2) oppositional brand loyalty, where community members derive community experience through their opposition to competing brands. Another important attribute was the acknowledgement that members have that they are indeed supporting a commercial relationship. Consumers are fully aware that their focus is generally on mass-produced and mass advertised branded products (Muñiz \& O’Guinn, 2001). Vincent (2002) added to this work, by explaining the relationship legendary brands have with social communities. These legendary brands gain strength through the formation of brand tribes that share an affiliation with the sacred beliefs of a brand. Vincent suggested that consumers who participate in these group tribes do so as proof of their beliefs about the brand.

Several examples have been provided in the literature with regard to group experiences surrounding consumption. McAlexander et al. (2002) looked at ways in which Jeep owners interacted and shared during Camp Jeep events. Algesheimer et al. (2005) explored brand community and the group experience through the interaction of German car club members. In an examination of the subculture of consumption that surrounds Star Trek, Kozinets (2001) investigated the interaction and differences between individual consumers of the Star Trek product. Kozinets findings implied that Star Trek consumption contributed to consumer's sense of self and belonging.

This commercial relationship is similar to the consumer-sports team relationship. The sports team sells services and experiences, yet the often fanatical involvement consumers have with various team brands suggests that some may consider the organisations more than just a producer of their favourite entertainment. Underwood et al. 
(2001) suggested that there may be very few other consumer experiences in which consumer bonding, interaction and affiliation is as intense as it is within the sports market place. Subsequently, Underwood et al. advocated that the group experience is crucial to the development of a strong sports brand, and were of the opinion that the sports marketplace is the most potent example of bonding and affiliation between consumers.

The article suggested that as consumers experience a sense of association with each other, this can contribute to the development of customer-based brand equity. As these social activities give meaning to a consumer or participant's life, the greater the related brand will benefit (Underwood et al., 2001). Underwood et al. offered a hypothesis proposing that the greater the degree to which the brand contributes to social interaction and social cohesion, the greater the social identity created. In their case study of the brand community surrounding the Jeep brand, McAlexander et al. (2002) found consciousness of kind to be present during their observations and interactions with Jeep camps and jamborees. The experience that consumers shared with one another was believed to strengthen interpersonal ties and develop mutual appreciation for the product, the brand, and the company marketers.

It is important to note that for the purposes of this study, two key attributes from the work of Muñiz and O'Guinn (2001) have been either omitted or included within other antecedents. Along with 'consciousness of kind', 'moral responsibility' was included in their concept of brand community. Consciousness of kind relates to the way members of a group feel as if they know each other: Members feel an important connection to the brand, but more importantly, they feel a stronger connection toward one another, almost as if they sort of know each other at some level, even if they have never met (Muñiz \& O'Guinn, 2001). It was determined that using the term 'the group experience' from the work of 
Underwood et al. was more appropriate for this study as it is a managerial concept, or one that is under the control of managers. Additionally, the researcher believes that consciousness of kind belongs to the group members, and is a derivative of managerial efforts to create group experiences.

'Moral responsibility' was not included in the study because of its perceived interpretation as a direct result of brand community creation. Muñiz and O'Guinn advocate that moral responsibility is a sense of duty to the community as a whole, its individual members, and the manufacturer behind collective action and group cohesion. While it is undoubtedly a strong factor in the internal creation and maintenance of a brand community, the researcher is again of the opinion that this factor is owned and operated primarily by the members of the community. While management may be able to develop a sense of responsibility to the brand or team, and amongst fellow consumers, the uptake and collective maintenance of this attribute is predicted to reside primarily amongst the community members. Therefore, the researcher provides the justification that the antecedents of the group experience, history and heritage, rituals and traditions, and the physical facility, are more applicable to this study as they can be directly used and manipulated within brand development strategies.

\subsubsection{History and Heritage}

Heritage is a particular version of the past (history) that belongs to a certain group (Baram \& Rowan, 2004). Costa (2004) proposed that heritage continues into the contemporary, whereas history becomes over and done with. Misiura (2006) suggested that marketing plays a role in bringing aspects of history and the past to the people through appropriate targeting of consumers. Therefore, with this in mind, heritage appears to be selected aspects of a certain history. From a marketing perspective, heritage has been 
defined as the ways in which selective material artifacts, mythologies, memories and traditions can become resources for the present (Graham, 2002). Graham also elaborated on the way in which we shape and use heritage for our own purposes, suggesting that heritage is an aspect of the past which we select for contemporary purposes, whether they are economic, cultural, political or social.

Where history marketing aims to retell a story in its entirety, heritage marketing is used with the specific intention of celebrating aspects of the past (Misiura, 2006). While heritage can be used and manipulated within marketing strategy, in general it is open to interpretation by society (Waitt, 2000). Marketing heritage can in some cases only provide a single perspective on a past event where many different viewpoints exist (Waitt, 2000). With this in mind, perhaps the most appropriate comparison of the two terms in the context of this study was made by Misiura (2006):

History is the main academic discipline that recalls and explains aspects of the past and aims to give a factual (based on what is known at the time) account, whereas heritage marketing is usually about celebrating one or more aspects of the past, which sometimes means leaving out issues that are not appropriate for the nature of a particular type of representation or the needs of a target market (p. 14).

It seems fairly straightforward to assume that a brand or organisation with a lengthy history and heritage behind it would be well known and trusted by the consumer. The relationship between branding and heritage is that as a brand can adopt certain values, organisations are looking to integrate aspects of heritage into their profiles, marketing, or products and services (Misiura, 2006). Underwood et al. (2001) suggested that history contributes to the identity of many of the world's most valuable brands. This may seem comparable to the relationships we have with close friends as opposed to complete strangers: we have knowledge of what friends are like and how they behave, but with strangers there may be uncertainty, doubt, and a lack of trust. Established teams such as the 
Chicago Cubs or the New York Jets may take on the role of a long time friend, known for their values and certain qualities.

Underwood et al. (2001) observed that the sports market incorporates the concept of history as aspects of services on offer to consumers. However, this seems to be in reference to well-established sports organisations, as opposed to the focus of this study - newlyestablished teams. Underwood et al. advocated that historical associations with sport increase the emotion and sense of identification consumers have towards a given team or event, and subsequently assist in the forging of links to the team brand. It is also suggested that recognition of historical assets can improve brand associations, awareness and image. Underwood et al. did reserve a space for newly-developed teams, proposing that teams without a strong sense of tradition could benefit from linking their own team to the tradition of the sport. Kelley and Hoffman (1999), who investigated the relocation and rebranding of the Hartford Whalers to the Carolina Hurricanes, observed that the Hurricanes used the history and tradition of ice hockey in general to create an appreciation for history in a state not known for its interest in the sport. In a study observing the creation of a new Australian Football team, Haimes (2005) observed that the Fremantle Dockers linked themselves with the strong history of football in Western Australia and historical aspects of the Fremantle region.

Preliminary research has also suggested that history and heritage may be a key influence on the ultimate goal of revenue generation. O'Reilly and Nadeau (2006) examined the four American major league sports, in the search of identifying variables that significantly related to team revenue; heritage was identified as one of eight that had significant effect, and of these was one of the three most significant. The author's heritage variable included five components - the stage at which the team was inducted into the 
league; the number of hall of fame players that had represented it; the number of former player's jerseys that had been retired; the number of league championships won; and the number of finals visits made by the team. O'Reilly and Nadeau suggested that even though history appears to be important to the major league sports, existing literature appears to largely ignore this important attribute.

\subsubsection{Rituals and Traditions}

Prior to introducing rituals and traditions, it important to examine the concept of tradition, and what meaning it holds for the remainder of this thesis. Wells (1994) believed that although the use of tradition-based genres and motifs in a commercial sense is by no means a recent strategy, many traditional activities have always possessed economic properties. Wells proposed that the marketing of tradition comprises two specific phenomena. The transformation of tradition features the modification of traditions to appeal to a perceived market, including changes in performance, repertoire or style, and the conscious creation of objects whose sole function is to be sold to tourists. The cultural appropriation of tradition involves the use of traditional concepts, forms and symbols to create an association with traditional ideas and values (Wells, 1994).

While it may seem that the concept of heritage may be interchangeable with tradition based on the above research, this author believes that the term tradition has begun to represent two things: 1) 'tradition' as either heritage, history, or the past in general, and 2) 'a tradition' as either a ritual behaviour or attitude. The article by Underwood et al. (2001) featured tradition in the same section as history, and appeared to use the two terms interchangeably. Although the article provides a foundation to this study, the term 'tradition' will not be used with regard to history or heritage in this research, but rather tradition will correspond more appropriately with rituals, and hereafter be referred to as 
'traditions'. In support of this, Graham (2002) stated that traditions among others act as a resource in the creation and management of heritage.

Rituals surround us and offer opportunities to make meaning from the familiar and the mysterious at the same time (Imber-Black \& Roberts, 1992). Rituals connect us with our past, and show us a future path as we pass on ceremonies, traditions, objects, symbols, and ways of being with each other to new generations (Imber-Black \& Roberts, 1992). Rituals may appear in a variety of forms - ceremonies, performances, symbols, objects and sounds (Imber-Black \& Roberts, 1992; Westerbeek \& Smith, 2003). Along with being highly repetitive, they typically offer a no-alternative mode of participation (Kelly \& Kaplan, 1990). Vincent (2002) identified rituals as the dramatic re-enactment of a myth that could be classified into either of two categories: mundane or sacred. Where mundane rituals are similar to everyday habits, sacred rituals often have deeper meanings and cultural significance, which often feature a set of actions that serve to activate a narrative or myth.

The application of the ritual concept to a consumption environment was forged with the article by Rook (1985), which sought to introduce the idea that the ritual construct could be a vehicle for interpreting consumer behaviour. Rook suggested that ritual behaviour contributes positively and meaningfully to the human experience, and offered the following definition of ritual, which will be the foundation behind the terms' use in the remainder of this thesis:

The term ritual refers to a type of expressive, symbolic activity constructed of multiple behaviours that occur in a fixed, episodic sequence, and that tend to be repeated over time. Ritual behaviour is dramatically scripted and acted out and is performed with formality, seriousness, and inner intensity (p. 252).

Rook commented on the ability of rituals to effect the creation of community and kinship, and their power to include or exclude individuals from religious, fraternal, and civic settings. Modern civic rituals such as Super Bowl Sunday can invoke themes of 
community and social inclusion, which may feature national songs, pledges of allegiance, parades, and commemoration ceremonies (Rook, 1985). Rook suggested that despite social research's extensive focus on ritual behaviour, research had at the time neglected the nature of post-industrial ritual phenomena and the integration of goods and services in ritual practices. Wallendorf and Arnould (1991) expanded on this work, by examining the consumption rituals surrounding the Thanksgiving Day holiday in America. Through a similar methodology that will be used in this research, interviews and observation, it was observed that Thanksgiving Day celebrations demonstrate to participants their ability to meet their basic needs through consumption. Additionally, the study provided an initial insight into how Americans use ritual consumption to construct their culture.

With regard to the commercial context, a culture may form around a brand quickly when a brand is used within some form of consumer ritual (Vincent, 2002). Vincent suggested that brands are regularly involved with mundane forms of rituals; yet very rarely take advantage of sacred rituals. The work aimed to categorise three types of consumerbased ritual, based on the strength and requirement of a specific brand to the ritual. Noncategory specific rituals are those where any branded product can be used as a part of the ritual, e.g. at Christmas or birthdays, gifts of any type or brand can be given. Categoryspecific rituals are those where specific types of product are required, e.g. spraying of champagne being used to celebrate a victory or win. The third are brand specific rituals. This category requires the use of a single specific brand within an individual product or service category. For example, to be involved in Harley-Davidson based activities, you must be the owner of a Harley-Davidson. Vincent concluded with the argument that if rituals begin to form within a specific consumer group, the corresponding brand is developing successfully. 
Underwood et al. (2001) stated that rituals are concerned with the relationships of people that are involved in shared experiences. Translated to a sports environment for example, the performance of a pre-game ritual may not assist in the goal of on-field success, or increased profitability, but will contribute to the social environment of the event (and ideally to the development of brand community and heightened social identification). Underwood et al. (2001) proposed three important characteristics of rituals: 1) ritual behaviour is marked by a degree of elaboration; 2) rituals display repetitive or habitual properties; and 3) rituals must be built on a strong sense of continuity.

Underwood et al. stated that rituals built upon these three properties can assist in the developing of the 'team fan' concept as part of an individual's identity, and can assist in linking ordinary games or under performing seasons to special or famous ones. Relatively simple ritualistic activities performed independently by fans or by the organisation can contribute to the development of the brand. By investing in the development of rituals, organisations can add a measure of value to the consumer service, while at the same time promoting team identification (Underwood et al., 2001). Richelieu (2003) added that rituals offer a sports team the chance to develop its brand, enhancing the ambience of the game and helping promote the game as an event.

Although rituals are recommended in the development of a strong brand, organisations may understandably disregard them or deem them not worthy of investment. Westerbeek and Smith (2003) suggested that even though rituals are activities that are unnecessary to achieve a certain goal, they are vital to the collective perception of what is socially right. Westerbeek and Smith progressed to conceptualise the term 'fractured traditions,' or those traditions that have been lost or changed during the commercialisation of sport. Westerbeek and Smith advise that those sports clubs that have the opportunity to 
capitalize upon their traditions while at the same time progressing through economic and technological advancement will succeed in the never-ending task of attracting fans. While the use of heritage aspects within marketing of sports teams is a crucial strategy, comments by Friedman and Silk (2005) and Westerbeek and Smith (2003) recommended that it must be done with respect and not in an over commercialised manner.

Haimes (2005) provided examples of rituals that the Fremantle Football Club used to develop consumer relationships with their brand. Haimes observed that despite all the difficulties that the club faced in its early years, the culture and identity was developed based on the implementation of major ceremonies, rites and symbols. Examples of these included the ceremonial coin toss, the 'Len Hall' games in memory of war-time heroes and events, the club song, and Purple Haze day (Haimes, 2005). Haimes suggested that a new club could, over time, develop varying ways to project the clubs brand to the consumer away from purely on-field performance. By embracing aspects and artifacts of the community and sport played, teams may be able to provide reasons for consumer interaction and attendance based not purely on winning percentage.

\subsubsection{The Physical Facility}

While literature does not yet consider it an antecedent to the concept of brand community, the physical facility is an important component of the work by Underwood et al. (2001). A possible reason that the physical facility has not been incorporated into the brand community research thus far is that the literature has focused entirely on products as opposed to services, and that the physical environment does not play as important part in the consumption and purchase of products.

For services and the delivery of a service brand, the physical facility plays a vital role in that it can act as a critically important tangible which the consumer can evaluate and 
remember. Previous research has investigated the way in which the 'servicescape,' as it has been described, affects perceptions of quality and consumers intention to repurchase (Baker et al., 1994; Bitner, 1990, 1992). While it is believed that in some cases the 'place' influences purchase decision of generic products (Kotler, 1972), within the leisure services environment, research has suggested that the servicescape is of heightened importance (Hightower Jr et al., 2002; Wakefield \& Blodgett, 1994, 1996). Wakefield and Blodgett (1996) believed that the perceived quality of a servicescape contributes to consumer satisfaction, which in turn can affect return business and desire to stay in the service environment. While this research elaborates on the importance of the facility to consumer repurchase and satisfaction, it was the work of Underwood et al. (2001) that suggested that the physical facility could affect the development of brand equity or the identification consumers had with a sports brand. Underwood et al. compared the stadium to that of company owned stores, which, along with showcasing the brand, can reflect core attributes central to the brand.

There are many examples of stadiums that act as a catalyst to consumer identification with a team or brand, or indeed have strong brand equity themselves. Underwood et al. described places such as Wrigley Field, Yankee Stadium, and Madison Square Garden as sharing intimate relationships with fans. Howard (1997) elaborated on the importance that historic Lambeau Field has to not just the Green Bay Packers NFL franchise, but also to the people and community of Green Bay, Wisconsin. Friedman and Silk (2005), in their review of the Boston Red Sox and their renowned Fenway Park stadium, uncovered that, while it is the smallest and most user-unfriendly facility in the league, it is continually sold out and staunchly protected from modification by fans. The overriding message that can be taken from Friedman and Silk's commentary is that Fenway 
Park is a critically important component of the Red Sox brand, is a core association that consumers have with the Red Sox organisation, and it provides a theatre in which fans become a contributor in the creation of baseball history.

While in less abundance than other countries, several examples do exist of famous stadiums in New Zealand: Auckland's Eden Park or Wellington's Basin Reserve. However, New Zealand's focus on new facilities has resulted in the vacating of famous grounds such as Carlaw Park, rugby league's spiritual home, and Athletic Park, the inhospitable home of Wellington rugby. Albeit that the typical New Zealand stadium is typically used by multiple teams of varying sports codes, these examples are places that resonate with fans, and conjure up dramatic images of the past or act as a place of worship or respect (Underwood et al., 2001). Underwood et al. also believed that, for many sports teams, these facilities serve as the most tangible and visual representation of the sports brand, and can act as a distinctive brand attribute that differentiates from other offerings in the market.

Underwood et al. developed two main propositions behind the importance of the physical facility to a team brand and the development of consumer identification. The first was concerned with the degree to which a team's stadium reflects its brand: "The greater the degree to which the facility represents core brand associations, the greater the degree of social identification." The second hypothesis was reserved for how a facility can act as a catalyst to shared consumer experiences: "The greater the degree to which attributes of the facility foster shared experiences among consumers, the greater the degree of identification." While these hypotheses were not tested, they act as an extremely relevant departure point for future research into the area. 


\subsection{Summary}

This literature review has aimed to provide an insight into the literature and theories that this study will be founded upon. The concept of brand community, initiated by Muñiz and O'Guinn (2001), is partnered with the work completed by Underwood et al. (2001). Together, these concepts feature four similar antecedents that can contribute to the development of a brand, and a subsequent community around it: 1) the group experience, 2) history and heritage, 3) rituals and traditions, and 4) the physical facility. Therefore, the aim of this study was to examine whether managers of new sports teams established in New Zealand are using the above antecedents in their branding strategies. 


\section{CHAPTER 3}

\section{RESEARCH METHODOLOGY}

\subsection{Introduction}

The following chapter explains the methodology used in the present study, the aim of which was to investigate the ways in which newly-established New Zealand sport teams develop their brands. This chapter begins by describing the exploratory, qualitative research approach used to investigate how new team brands are being developed within the industry. The multiple, embedded case study format is also explained. Information regarding the selection of participants, techniques used to collect data, and the overall design of the research will be provided. Key research issues and limitations of the study will complement the final stage of data analysis and interpretation.

\subsection{Research Approach}

The approach for this study featured three key components - 1) a qualitative study, with 2) an exploratory perspective, and 3), investigated through the use of case studies. The study operated under a subjective research assumption. The subjective approach proposes that the very notion of truth is problematic (Rossman \& Rallis, 2003). Except for certain principles about the physical world, few absolute truths exist, but rather there are multiple perspectives about the world (Rossman \& Rallis, 2003). The study aimed to investigate the presence of both the brand community and Underwood et al. (2001) concepts and their antecedents within the participant organisation marketing strategy. Therefore, the study attempted to uncover facts specifically about the environment under investigation rather than making universal or all-encompassing statements about the sports industry as a whole. Rossman and Rallis proposed that a subjective approach features, for example, the use of case studies, data in the form of words, and aims to compare varying 
perspectives. These attributes are all facets that were employed in the present study. The focus of the study resided in developing understanding of the environment, rather than the testing of theories or creation of universal laws.

Further discussion into the research paradigm featured in the study surrounds the use of the interpretivist perspective. Interpretive research typically attempts to understand the social world as it is (or the status quo) from the perspective of the individual experience (Rossman \& Rallis, 2003) or the actor's own perspective (Taylor \& Bogdan, 1998). The individual experience in this research was held by each of the interviewed participants featured in the study. Their interpretations and involvement with brand development of new sports teams was the area under investigation, and any prior or present development of brand community or social identification antecedents was examined. The interpretivist approach of this research also advises that the research is prepared to accommodate any new dimensions that may arise in relation to both brand community and social identification. If a new dimension materialized from the data collected, this study would rightfully include it for consideration among those four already used, and it would be honoured with due consideration and commentary.

As a result of the above paradigm shaping the approach of this study, a qualitative method was predictably applied. Auerbach and Silverstein (2003) defined qualitative research as that which involves analysing and interpreting text and interviews in order to discover meaningful patterns that describe a particular phenomenon. Qualitative researchers, in their search for answers, aim to learn about aspects of the social world in order to generate new understandings that can then be used (Rossman \& Rallis, 2003). Strauss and Corbin (1998) suggested that qualitative research can refer to research about lived experiences, behaviours, emotions, and feelings as well as social movement, cultural 
phenomena and organisational functioning. Organisational practices and management opinion regarding brand community and development issues affecting new sports teams was the focus of the study, therefore a qualitative approach in which a large amount of data could be gathered directly from the environment under investigation was used.

An exploratory perspective was also used because the area of investigation was relatively unexplored. An exploratory study is employed when not much is known about the current situation, or minimal to no information is available on how similar research issues have been solved previously (Sekaran, 2003). While some research has been conducted on the use of branding within the sports industry, there has been very little attention devoted to branding of new sports organisations. While the study was exploratory in nature, and was set in a largely undeveloped literature, this study was influenced by underlying theory, namely that of brand community (Muñiz \& O'Guinn, 2001) and branding through social identification (Underwood et al., 2001). Rather than investigating an area with no guiding or pre-conceived theories in a grounded theory approach (Glaser \& Strauss, 1967), the study examined aspects of brand community and social identification.

The exploratory perspective was partnered by the use of multiple, in-depth case studies. The case study is a research strategy focusing on understanding the dynamics present within individual settings (Eisenhardt, 1989). The underlying objective of undertaking case study research is to obtain rich data and depth of understanding (O'Leary, 2005), with analysis focusing on organizing data by specific individual cases with the target of in-depth study and comparison (Patton, 2002). Yin (1994) advised that case studies could contribute to the investigation of events such as life cycles, neighbourhood activities, and in the context of this study, organisational and managerial processes. Case studies were also deemed appropriate due to their common and suitable application to qualitative 
marketing research (Bonoma, 1985). The advised method to investigate this process within the context of this study is to treat each organization as a single, in-depth case study. Rather than use a questionnaire to investigate the organisational practices, case studies were used to gather as much information as possible to assist in future theoretical framework development and possible quantitative investigation of themes uncovered.

A multiple case study design (Yin, 1994) was used because of the number of organisations involved in the study. Rather than examine a single organisation and its branding practices, this study sought to provide a greater insight into multiple variations and current trends in new sports team branding. This also contributed improved validity to any conclusions made following the investigative process. Each case study also possessed two respondents in the form of varying staff members, making it an embedded, multiple case study (Yin, 1994).

Rather than featuring the empirical testing of the brand community or social identification branding concepts within a sports industry context, it was important to provide a qualitative perspective on the environment for future research. Previous work in the brand community field has also predominantly featured qualitative methods, including interviewing, ethnography, and case study formats (Algesheimer et al., 2005; McAlexander et al., 2002; Muñiz \& O'Guinn, 2001; Schouten \& McAlexander, 1995).

\subsection{Data Sources and Selection}

The unit of analysis selected for this study was three newly established sports teams within the New Zealand sports industry. These were 1) the Vodafone New Zealand Warriors, 2) the Trusts Diamonds, 3) and the Harvey Norman New Zealand Breakers. Although each team featured individual respondents, the unit of analysis rested with each team as a whole due to the nature and focus of the research on varying organisations 
(Sekaran, 2003). The teams included in the study were chosen based on the premise that they have been recently created and launched into the New Zealand market. Each of the three teams is in various stages of development, and has also been in existence from between 4 to 12 years. New Zealand Super 14 rugby franchises, which have been in existence for the same period as the Warriors, were not included in the study as the researcher was not able to obtain access to them. Super 14 brands have also already received some academic attention with regard to brand development (Gilhooly, 1999).

New teams were chosen over established sports organisations primarily due to the problems that seem to plague their initial years. The three teams included in this study have experienced problems and issues in their development, some on a much larger scale than others. These issues have ranged from failure to perform on the field or court, right through to breaking of league rules or players walking out on the team. The selection of new teams as the unit of analysis was also influenced by the paucity of branding literature concerned with new brand strategy. While extensive work has been compiled on how to improve or maintain existing sports brands, minimal attention has been allocated to brands in their initial stages. Additionally, the context that brand community research has investigated thus far has been entirely based on products, and is yet to investigate either new brands, or those based upon services.

\subsubsection{Sampling Procedure}

The above selection of participant organisations corresponds with that of judgment sampling (Sekaran, 2003). Sekaran stated that judgment sampling involves the choice of subjects who are in the best position to provide the information required. As the present study aimed to examine several prominent new sports organisations, and the strategies used by those responsible for their brands, information could only be gathered directly from 
these sources. Therefore, a judgment sample was used to select the organisations that could provide these viewpoints.

Teams were also selected based on their location, and subsequent convenience to the researcher. A convenience sample is that where information is collected from members of a population who are conveniently available to provide it, and typically used in the exploratory phase of research (Sekaran, 2003). All three teams are located in the greater Auckland region, which allowed the researcher to be within close proximity to the location of each organisation, and also enabled the study to incorporate return visits and easy rescheduling of interviews at little inconvenience to the researcher.

\subsubsection{Respondents and Access}

A key task of the study was to gain access to the selected organisations. Those people who are in charge of an organizational setting are typically referred to as 'gatekeepers' (Taylor \& Bogdan, 1998), and often act as the first step in entering the research field (Patton, 2002). Each organisation was approached with an initial phone call, introducing the project to the chief executive or marketing manager. This was followed by email, written documentation and consent forms being sent to each organisation. These gatekeepers were approached prior to the inclusion and interaction with research participants.

Representatives or participants from the three organisations included in the study were managers or staff involved in the marketing of the team brand. Positions such as marketing manager, communications manager, managing director, or chief executive, for example, made up the participants in the study. While all staff members employed at a sports organisation contribute to the development of a brand, it was deemed that staff 
directly involved in the marketing of the new brand were in the best position to provide necessary information. Two representatives from each team were interviewed.

\subsection{Interview}

An interview is a method of data collection that involves researchers seeking openended answers in relation to questions, topics, or themes (O'Leary, 2005). These questions aim to obtain in-depth responses about people's experiences, perceptions, opinions, and feelings (Patton, 2002). Interviews are a widely-used feature of qualitative research, to a point where their use has become so prominent that they are now regarded as the gold standard in qualitative research (Silverman, 2000). Interviewing is also one of the most important and widely-used sources of information that a case study can draw upon (Berg, 1998; Yin, 1994).

The present study used a specific type of interview technique: semi-structured. The semi-structured interview format is a hybrid of both the structured and unstructured methods. It incorporates the use of a flexible format in which the interviewer can digress from pre-determined questions in order to follow important themes and the natural flow of the conversation (May, 2001; O'Leary, 2005). Gillham (2000) recommended that semistructured is the most important form of interviewing to the case study method, as it can provide the richest single source of data. The advantage of this method is that data collected conforms with the original requirements of the study, but also enables the researcher to view unexpected and interesting data that emerges from individual respondents (O'Leary, 2005). The semi-structured format also assists with the comparative analysis of data between each interview (May, 2001).

Patton (2002) referred to semi-structured interviews as those governed by an 'interview guide'; a plan to ensure that consistent lines of inquiry are pursued with each 
interviewed respondent. This was a necessity of the present research, as it was important to allow for participants to speak freely about their organisation's branding, but also allowed for consistent comparison between each of the four teams. The semi-structured interview assisted with the selected format of questions included in the interview. As the previouslymentioned elements of the group experience, heritage, rituals, and the physical facility arise during the interview, the semi-structured approach allowed the researcher to probe further into these areas without directly asking structured questions about them.

\subsubsection{Interview Format}

The interview was framed around the themes uncovered from the brand community work of Muñiz and O'Guinn (2001), and the development of brands through social identification by Underwood et al. (2001). However, questions were not directly asked on whether or not respective organisations were using these concepts, but focused on the previously mentioned antecedents. The ability to digress from set questions to explore themes as they arise was enabled by the semi-structured nature of the interview. The interview questions were based around the following areas. Each section featured one or two priority questions (bullet-points), complemented by several sub-questions that acted as prompts toward further discussion: 
Table 1: Interview Areas and Questions

\begin{tabular}{|c|c|}
\hline Area & Question examples \\
\hline Introduction questions & $\begin{array}{l}\text { - What is your position of employment within your organization? } \\
\text { - How many years experience do you have within marketing roles? } \\
\text { - How many years experience do you have within sport marketing roles? } \\
\text { - How many years experience do you have working within the sports } \\
\text { industry? }\end{array}$ \\
\hline $\begin{array}{l}\text { Organization } \\
\text { characteristics }\end{array}$ & $\begin{array}{l}\text { - What are the overall goals or objectives of your organization? } \\
\text { - How does your marketing fit in with those objectives? } \\
\text { previously? } \\
\text { - Are your current objectives being achieved? } \\
\text { - What activities or programs are you using to achieve these objectives? }\end{array}$ \\
\hline $\begin{array}{l}\text { New team brand } \\
\text { development }\end{array}$ & $\begin{array}{l}\text { - As new sports teams are introduced into the industry, they tend to face } \\
\text { various issues that affect the development of their brand. What issues } \\
\text { have you experienced in the development of your organisation's brand? } \\
\text { - What issues do you believe alternate new teams face in the } \\
\text { development of a team brand? } \\
\text { - What differences do you perceive there to be in the branding of a new } \\
\text { team compared to an established team? }\end{array}$ \\
\hline $\begin{array}{l}\text { Current branding } \\
\text { strategies }\end{array}$ & $\begin{array}{l}\text { - Could you please elaborate on your knowledge of current campaigns in } \\
\text { use by your organisation? } \\
\text { - What are the key objectives of these campaigns? } \\
\text { - What are the key themes that these marketing approaches aim to } \\
\text { promote? }\end{array}$ \\
\hline Group experience & $\begin{array}{l}\text { Managers often talk about the importance of the community to } \\
\text { organisations. Do you believe that fan interaction is important to your } \\
\text { team and organisation? } \\
\text { - If so, how do you promote it? } \\
\text { - Do you believe that there is a strong community or group aspect to } \\
\text { your spectator or fan base? } \\
\text { - What kind of role does the community aspect play in your marketing } \\
\text { approach? } \\
\text { the team? }\end{array}$ \\
\hline $\begin{array}{l}\text { The history of the } \\
\text { organization }\end{array}$ & $\begin{array}{l}\text { Established teams can fall back on years of success or star players that } \\
\text { have been part of the team. As a new team, your organisation does not } \\
\text { possess this. How important do you believe history to be to your } \\
\text { organisation? } \\
\text { - How would you describe your organisations history? } \\
\text { - Which aspects of your organisations history do you currently use in } \\
\text { your marketing approach? } \\
\text { In which ways are you incorporating the use of history in your current } \\
\text { marketing approach? }\end{array}$ \\
\hline Rituals/traditions & $\begin{array}{l}\text { - Are you aware of traditions that surround, are shared between the team } \\
\text { and fans, or are used by your fans? If so, please elaborate. } \\
\text { - Do you believe these to be important? } \\
\text { - Within your current marketing approaches, do you incorporate or } \\
\text { promote these traditions? } \\
\text { - Are you attempting to develop and promote new traditions? }\end{array}$ \\
\hline
\end{tabular}


- For some sports teams, particularly those that have been around for a long period, the physical facility or stadium in which they play can act as an extremely important symbol in creation of the brand. Do you believe your facility is important to the development of your brand?

- Within your current marketing approaches, do you incorporate or promote the physical facility? If yes or no, why?

- Which aspects of the physical facility do you currently use or promote within your marketing strategies?

The introductory section of questions aimed to provide the study with background information of the respondent. This was to gauge previous involvement in areas such as marketing, sports marketing and branding. This section was also used to develop a degree of rapport with the interviewee. The questions were sequenced to avoid asking the more complex questions at the beginning of the study.

Enquiry into characteristics of each sports team was used to detail the environment and organisational settings in which each case operates. Along with a focus on the overall goals and objectives of the organisation, this section specifically asked the respondent about their knowledge of current organisational marketing objectives, as these were predicted to provide a picture of how each organisation brands itself. Areas of interest were how marketing corresponded with organisational goals, how marketing strategy changed over time, and what specific marketing programmes or activities were being used to meet organisational objectives.

The third section of the interview sought to gather respondent opinion on the topic of branding new sports teams. Questions focused on exploring the issues that respondent's believe had previously or currently affected their organisations, issues plaguing other new sports teams, and the differences or challenges that they faced in comparison with established sports brands.

Current brand strategy questions focused on creating a discussion regarding strategies currently in use by the organisation to develop its brand. Key objectives, themes, 
and eventual objectives of these strategies were discussed. The aim of this section was to provide a preliminary insight into whether traces of brand community or those featured in the work of Underwood et al. (2001) could be located within each case's branding strategy.

The section titled group experience sought to inspect the characteristics of each organisation's fan or membership group, and the relationship it shares with the organisation from a management perspective. At the outset, this section aimed to discreetly initiate discussion regarding the group experience, and stimulate respondent thought on the team's fan base. Questions were then used to link this concept to how the fans of the team were incorporated in marketing strategy.

Questions reserved for the history of the organisation were designed to construct a picture of the organisation's history from the perspective of each interviewed employee. The sections purpose was to enable the respondent to provide their perspective on history and heritage as a component of the team, followed by a similar probe into how heritage is being used in each organisations marketing or brand initiatives.

The penultimate section of the interview featured questions regarding the ways in which rituals or traditions were present at each team's games or included in marketing strategy, from the perspective of management. Initial discussion centred on whether management were aware of any rituals that either fans or the team perform, and also those that are shared between the two. Along with investigating whether or not management was attempting to develop new rituals, the use of rituals in marketing strategy was questioned.

The final section of the interview followed the previous three in terms of format, featuring an inspection into the use of the physical facility within marketing and branding strategy. Each of the above four sections on the group experience, heritage and history, 
rituals and traditions, and the physical facility featured a line of questioning investigating whether or not management deemed these concepts to be important to brand development.

Interviews were conducted in a location at the discretion of the respondent, which was usually the location of the organisation and its employees. This was to ensure that the respondent was comfortable in the interview environment, and accommodated staff availability. Interviews were tape-recorded to allow for complete transcription to occur, and also featured the researcher noting key points or interesting themes throughout each interview. This ensured that as important issues were uncovered, they were noted and the interviewer was able to investigate them further through the semi-structured format. Along with allowing the interviewer to concentrate on the conversation and non-verbal gestures of the interviewee, audio recording also prevented the interviewer from substituting their own words for those of the participant (May, 2001).

\subsection{Data Analysis, Categorization and Evaluation}

Transcription of the interviews was the initial stage of analysis following data collection. In line with the advice of Riessman (2002), the transcription process began with a complete, first draft of each interview in its entirety. This was followed by reexamination of each transcription, and analysis of selected sections. Data analysis and grouping was the natural progression following transcription, investigating the approaches of brand community and Underwood et al. (2001).

The process of coding and organizing qualitative data generally occurs as it is collected (O'Leary, 2005). The process employed to analyse this data followed that proposed by O'Leary. This involved: 1) reading and re-reading of the data, 2) growing the understanding of the data through notes and memos, 3) organizing and coding data, and 4) searching for patterns to develop and build theories. Each individual interview was 
transcribed immediately following its completion, assisting in the coding and interpretation of the data. The technique used throughout the study in conjunction with the process of coding was constant comparison. Initially proposed by Glaser and Strauss (1967), constant comparison is where the researcher simultaneously codes and analyses data in order to develop concepts (Taylor \& Bogdan, 1998). In undertaking constant comparison, the researcher generally engages in line by line or paragraph by paragraph reading of interview transcripts (O'Leary, 2005). Using this method allows the researcher to continually compare incidents or themes in the data from each text, and subsequently create a theory through refinement and relationship exploration (O'Leary, 2005; Taylor \& Bogdan, 1998).

Rather than using a numerical coding system, coding took the form of ordering data under headings and theme areas common to the context of the study, and that which represented those areas of questioning from the interview. For example, data relating to the group experience was grouped under an umbrella heading of the group experience. From these initial groupings, data was further divided into more specific categories corresponding to each of the questions used throughout the interview process. Data located that corresponded more appropriately with alternate areas or themes of the interview was coded and grouped accordingly. This was to ensure that data was analysed within appropriate contexts.

\subsubsection{Evaluation of the Data}

Evaluation of the data collected in this research project was consistent with the interpretivist research perspective stated at the beginning of the chapter. In evaluating each case, initial analysis was given to each on a neutral, non-comparison basis. Each organisation was treated as an individual entity, and had unique properties that were evaluated individually. As opposed to evaluation of brand community or Underwood et al. 
(2001) variables through hypothesis testing, evaluation occurred through data collection, observation and description of each organisation within the context and environment in which it exists (Schein, 1992).

Results were presented through a comparative analysis, evaluating the three cases with respect to relevant themes of the study. Of particular interest will be the comparison of the key antecedents of brand community and the work of Underwood et al. (2001): 1) the group experience, 2) history and heritage, 3) rituals and traditions, and 4) the physical facility. As has been completed in previous studies concerned with these theories (Muñiz \& O'Guinn, 2001; Muñiz \& Schau, 2005; Schouten \& McAlexander, 1995; Underwood et al., 2001), presentation of the results was on a theme by theme basis. Focus was reserved for two main research question areas - organisational issues and use of the above antecedents, along with an examination of organisational objectives and current marketing strategies.

\subsection{Observation Study and Triangulation}

In order to triangulate the data collected from the empirical portion of the research, a secondary analysis was completed. Triangulation is the process of researching multiple sources of data, or using a variety of methods to build a picture of the area you are investigating (Rossman \& Rallis, 2003). Through varying sources of data and methods, tests for consistency can be made prior to the development or conceptualisation of theories (Patton, 2002). Along with primary research through the use of interviews, this study featured a direct observational perspective.

Within the case study method, direct observation is one of the six key sources from which data can originate (Yin, 2003). Yin suggested that this approach generally involves field visits to a site that features within the case environment. Assuming that the data 
required is not based on historical occurrences at the site, relevant behaviour or environmental conditions will be observable to the researcher. Yin also advocated that direct observations can support alternate sources of data such as interviews, and are useful in providing additional information about a studied topic. Wells and Lo Sciuto (1966) suggested that the main advantage in undertaking direct observation is that it can produce a highly detailed and accurate record of what people actually do compared to what they say.

Brand community research has occasionally taken on an observational perspective, examining the environment in which either consumers have created or companies have manufactured for their brands (for example McAlexander et al. 2002). However, this line of research seems to have taken more of a perspective focusing on the human interactions within an environment, rather than specifically observing the physical environment. This may be because, as previously mentioned, brand community research is yet to delve into service brands, or those that use the environment in their delivery.

For the purposes of this study, direct observation of the case study site occurred as follows. The focus of the observation was not on consumer behaviour, but on the environment and what marketing strategies or initiatives were present from each case organisation. Five games were attended in total, the exception being that only one Trusts Diamonds game could be observed as opposed to two for both the Warriors and Breakers. By the time that an observation component was confirmed as part of the study's methodology, only one game remained in the Diamonds 2006 home schedule. Attendance ideally began 45 to 60 minutes prior to the commencement of each game, and the researcher remained behind for 15 minutes following each match. Written documentation of the observed environment was completed by the researcher, examining activities, promotions, and organisational practices employed by each team. Photographs of the sites 
were also taken. Specific reference was devoted to examining whether the elements of group experience, heritage, rituals, and any active use of the physical facility were present in the facility in which each team plays.

\subsection{Research Issues}

\subsubsection{Access}

The eventual results and presentation of the research study depended on the access that could be obtained to the selected organisations. The partnership between the researcher and each team was achieved by communicating that the research project posed no threat or harm to the organisations, and inclusion in the study would assist in the development of branding knowledge within the sports industry. Communication involving phone, email and written documents aided in the creation of a working relationship between the researcher and each organisation.

\subsubsection{Role of the Researcher}

The role of the researcher within the context of this study was to act as a neutral presence and record all information provided by the respondents. While it was the task to record information that was not influenced by the researcher, the fact that the researcher was present may have had an influence over any data collected. Staff could have potentially adapted their answers to accommodate the presence of the researcher. For this reason, it was important for the researcher to act in a professional and neutral manner, transferring confidence to the respondent that all information collected would be kept confidential. The role of the researcher was that of pure investigative enquiry into the practices used by each of the teams; the researcher's personal involvement with the organisations went no further. As the research project sought to investigate organisational practices, respondents were not required to talk about themselves on a personal level, with 
the exception of their marketing experience. This assisted in maintaining a perspective strictly concerned with the organisation, and not an investigation into each respondent personally.

\subsubsection{Bias}

Bias could have affected areas of this research project, namely the data collection and interview stage. As the interview method featured in this study was semi-structured, the situation may have arisen where the researcher could have led or offered suggestions to the respondent to comment on. This approach depended on the conversational skills of the interviewer more than the standardized formats, and subsequently may have been vulnerable to the interviewer leading or questions producing biased results (Patton, 2002).

In order to combat this, the researcher used suitable prompts during interviews. These were predetermined phrases to assist any respondents that may have had difficulty in answering a question, but were not worded in a way that influenced the prospective answer. The interviewer also ensured that comments following respondent answers were neutral and not judgmental. A professional, non-threatening nature also assisted in the development of integrity, as suggested by Flint, Woodruff and Gardial (2002).

\subsubsection{Trustworthiness of the Data}

Rather than incorporate traditional criteria such as validity and reliability to evaluate this data, this study assessed data from an alternative perspective. Flint, Woodruff and Gardial (2002), in a grounded theory based study, used nine criteria upon which the trustworthiness of interpretivist research could be analysed: 1) credibility, 2) transferability, 3) dependability, 4) confirmability, 5) integrity, 6) fit, 7) understanding, 8) generality, and 9) control. These criteria were drawn from the work of Hirschman (1986) and Strauss and Corbin (1998). 
The following table discusses each of the above criteria used in this study to assist in maintaining and collecting trustworthy data. The corresponding strategy and techniques used to achieve these criteria are also provided.

\section{Table 2: Trustworthiness of the Data}

\section{Trustworthiness Criteria \\ Credibility \\ Extent to which the results appear to be acceptable representations of the data \\ Transferability \\ Extent to which findings from one study in one context will apply to other contexts}

\section{Dependability}

Extent to which the findings are unique to time and place; the stability or consistency of explanations.

\section{Confirmability}

Extent to which interpretations are the result of the participants and the phenomenon as opposed to researcher biases.

\section{Integrity}

Extent to which interpretations are influenced by misinformation or evasions by participants.

\section{Fit}

Extent to which findings fit with the substantive area under investigation.

\section{Understanding}

Extent to which participants buy into results as possible representations of their worlds.

\section{Generality}

Extent to which findings discover multiple aspects of the phenomenon.

\section{Control}

Extent to which organisations can influence aspects of the theory.

\section{Strategy}

One month conducting interviews

Consultation of findings with other sports marketing researchers

Comparison of case studies

Questions focus on topics and themes relevant to each organisation

Interview data analysed and audited by co-researchers Researchers will observe a perspective that supports the data provided to them

Interviews will be professional, of a non-threatening nature, and no respondent names will be used

Addressed through the methods used to achieve credibility, dependability, and confirmability.

Summary of results will be provided to respondent organisations

Semi-structured interviews will allow for open individual respondent perspectives

Variables within the brand community or social identification branding theories are aspects over which participants have some degree of control. 
Note: Adapted from "Exploring the phenomenon of customers' desired value change in a business-to-business context.” By D. J. Flint, R. B. Woodruff, \& S. F. Gardial, 2002, Journal of Marketing 66(4), 102-117.

\subsection{Limitations of the Research Format}

\subsubsection{Case Study Format}

This research was limited to a multiple case study analysis of newly-established sports teams in Auckland. The result of this is that results drawn from this study are largely specific to the three featured teams and the environments in which they operate. The results uncovered may be generalised to other organisations; however, the marketing and branding techniques used here may be far different to those employed by other sports teams.

\subsubsection{Respondent Knowledge and Employment Tenure}

Interviews were restricted to the information that respondents possess. An issue that may arise around this is with regard to questions investigating previous organisational brand strategies; if a respondent was new to an organisation, their knowledge of previous or possibly current strategies may have been limited.

\subsubsection{Ethical Considerations}

During the undertaking of this research project, there was a requirement to consider any important ethical issues that may have occurred. Individual participant confidentiality was protected through the use of position aliases throughout the study and transcription of interviews. Additionally, confidential comments that could possibly have identified the participants were omitted from the study. Data will be stored as is required for five years within the facility housing the conducting of the study. Audiotapes will be stored along with full transcriptions, which will be destroyed following this period. 
Although the project involved the collection of information regarding organisational marketing practices, the investigation of these will not disadvantage the organisations or individuals. Along with revealing information that is freely available to consumers of the sports product, the information that was collected does not expose respondents or their respective sports team to any discrimination or criticism. In a situation where it may have been important to observe and consider principles of the Treaty of Waitangi, participants in the study who were of Maori origin were treated with the same care, respect and consideration as all participants. The results of the study may also be of benefit to Maori sports leaders and organisations wishing to establish themselves and their respective brands in the industry.

\subsection{Summary}

This chapter introduced the research methodology that was used in conducting this study. Three newly-established sports teams formed the sample featured in the study: the Vodafone Warriors, the Trusts Diamonds, and the Harvey Norman New Zealand Breakers.

The methodology consisted of a qualitative, exploratory, multiple case study, in which data was collected through semi-structured interviews. Respondents were those employees responsible for developing the team brand, and were questioned regarding their involvement with sports branding and their employer's branding strategies. A direct observation analysis of the physical environment in which each team plays was undertaken to triangulate interview data, and determine whether interview statements truly reflected the delivery of the team's sport service and brand.

Both the interviews and direct observation analysis were primarily used to investigate the presence of two key concepts within the new sports team environment: brand community (Muñiz \& O'Guinn, 2001) and social identification branding (Underwood 
et al., 2001). Featured throughout these two concepts are several elements that contribute to the development of a strong brand: the group experience, history and heritage, rituals or traditions, and the physical facility. Inquiry into if and how these elements are being used within each of the case organisations was the primary goal of this research study. 


\section{CHAPTER 4}

\section{FINDINGS}

\subsection{Introduction}

Six qualitative interviews were conducted with three of Auckland's newlyestablished sports teams - the Vodafone Warriors, The Trusts Diamonds, and the Harvey Norman New Zealand Breakers. Follow-up interviews were conducted with four of the six respondents, so that the physical facility antecedent to the study could be incorporated. Interviews and the 20 featured questions produced over 7 hours and 100 pages of data, which were analysed using the process suggested by O'Leary (2005). The process involved 1) reading and re-reading of the data, 2) growing the understanding of the data through notes and memos, 3) organising and coding data, and 4) searching for patterns to develop and build theories. Analysis was also completed through the use of a constant comparison technique (Glaser \& Strauss, 1967).

Data obtained from the case study interviews was coded and grouped according to the interview question it corresponded with. If data was located in one question that was more appropriate to an alternate area of the interview, it was positioned accordingly. A simple coding process was used: statements were assigned to the question deemed to fit them most appropriately. Frequently recurring themes that occurred in sections of the interview or specific questions were also identified. In order to identify interview data, respondent organisations and their positions were abbreviated when attached to each comment, as outlined in the following table. These abbreviations, along with interview dates, will identify respective respondent quotes. 
Table 3: Respondent Position and Abbreviations

\begin{tabular}{ll}
\hline Organisation and Position & Abbreviated \\
\hline Vodafone Warriors Football Manager & WFM \\
Vodafone Warriors Sales and Marketing Manager & WSMM \\
Trusts Diamonds General Manager & DGM \\
Trusts Diamonds Chairman & DC \\
Harvey Norman New Zealand Breakers Marketing & NZBMSM \\
Services Manager & \\
Harvey Norman New Zealand Breakers General & NZBGM \\
Manager & \\
\hline
\end{tabular}

Triangulation was achieved through the use of a direct observation study of each team's stadium or playing facility. Data was collected and analysed in a similar capacity to the interview, with the aim of validating any statements proposed by the participants. Presentation of the findings will integrate the results from the direct observation stage of the study with interview data, rather than presenting them in a separate section. Each case study was analysed individually, followed by a comparative analysis, which is presented here. The following comparative analysis focuses on the two foundation research questions of the study:

Q1: What issues affect the development of a new sports team brand?

Q2: Do managers of new sports teams use antecedents of brand community or Underwood et al. (2001) in their branding strategies, and if so, how?

Following an introduction of current marketing strategies and organisational objectives, issues that have affected the development of the new team brands will be discussed through the identification of prevalent themes. Components of brand community and the work of Underwood et al., and their use within each of the case organisations will be discussed, focusing on each of the four antecedents, along with direct observation research. Previous research such as that of Muñiz and O'Guinn (2001) and Underwood et al. (2001) has presented results with regard to themes critical to their underlying theories. 
This study took a similar approach, producing an overall summary of results examining the antecedents, and their placement within the studied context. Respondent demographic and experience data is provided in Appendix 1, featured on page 128.

\subsection{Current Marketing Strategies}

Marketing strategies employed at the time of the study were individually tailored, and did not display a general pattern or consistency. As each of the three teams is in different stages of evolution, and has different budget allocations for marketing, this is understandable. In such a case, the following section will aim to elaborate on each case individually.

The Vodafone Warriors current marketing strategy was elaborated on by the Sales and Marketing Manager, and clearly resembled a strategy of brand building compared with the other two teams. Two themes that emerged were the attempt to open the club's brand to incorporate the community, and the promotion of the players' images and personalities. The theme of promoting the player's non-playing personality, or showing that they are much more than players, incorporated promoting the players for more than just what they do on the field. "So it's not necessarily all about how many hit ups, how many tackles, it's not the sporting statistics. It's more about the lifestyle or personal side of being a professional sport athlete" (WSMM, June 2, 2006). Additionally, the Sales and Marketing Manager aimed for the players not to be seen "as miserable and moody, aggressive, that they don't talk, and that they are just gladiators that go on the field and beat people up" (WSMM, June 2, 2006).

In order to achieve this, methods such as appearances on music television shows, articles about players lives in the Vodafone One Tribe magazine, interviews and players meeting the general public were being used. 
By getting them to do more interviews, by getting them to be out there and meet people, by getting them on a music show and talking about something they are enthusiastic and passionate about, people see that human side and hopefully make a connection with them... and then if we do lose a couple of games, hopefully they won't turn around round and walk away. They will say, oh well he seemed like a decent chap, I'll support him again (WSMM, June 2, 2006).

From the researcher's interaction with the Warrior's stadium, it was hard to observe whether these themes were being actively promoted. With the exception of the Vodafone One Tribe initiative, and the players entering the field through a 'guard of honour' of youth players, the researcher was did not observe any opening of the brand to include the community. A similar conclusion can be drawn toward the promotion of player personality and image, as the researcher did not witness this from their visits to the stadium. Perhaps a conclusion that can be made is that the physical facility is not a place in which the promotion of these two themes is easily visible. Further discussion on opening the Warriors brand to include the community will be provided in the group experience section.

The Trusts Diamonds and their current marketing campaigns appear at a far different stage than that of the Warriors. Their focus relies primarily on generating crowd attendance and ticket giveaways. The game that was attended by the researcher was a sellout, which may be largely down to the Diamonds opponents being the top of the table, and featuring one of New Zealand's premier players. As outlined by the Chairman, "there has been no big brand campaign, simply because we can't afford it" (DC, September 8, 2006). The organisation has however sought to develop a slogan to be attached to the team: "Diamonds - a cut above."

So it is a cut above, which is a play on the cut of the cards, cut of a diamond, on the you know, a cut above the rest and stuff...The Diamonds, like all Auckland teams have an image of sort of silver tail image...flashy, vacuous, that sort of stuff in the rest of the country. So yeah, we are just doing a bit of a play on that...we don't really push that. It is more of a, not subliminal, but a bit of a background thing, so it is pretty low key (DGM, September 8, 2006). 
The administration has also been careful not to brand themselves with a specific region of Auckland, thus not to alienate any group of supporters. Instead they "have been pretty careful in using "the Diamonds" (DC, September 8, 2006).

Apart from this, there has been minimal focus on branding initiatives by the Diamonds. When asked if the organisation had looked at pushing a certain image or brand, the Diamonds Chairman (September 8, 2006) said, “no, not really. I mean, I don’t think that we are at that place in terms of what's our brand positioning and what's our brand essence and what's our, all the technical marketing stuff" (DC, September 8, 2006). In line with these comments, the researcher did not observe any specific or tailored brand initiatives for the Diamonds within the playing venue. The Chairman (September 8, 2006) also stated that if he were "to run a brand positioning workshop and develop a brand essence for it, you know everyone would just look at me sideways and go you are nuts." However, as the Diamonds had secured sponsorship for a considerable period, there was the potential to look at branding more seriously:

We are probably at a point where it is something that we need do need to be a little bit more strategic about, but particularly now that we have secured our sponsorship for another four years, it means that we can say right, we have got some time to build on something (DC, September 8, 2006).

In similar fashion to the Warriors, The New Zealand Breakers appear to be pursuing a course of marketing to build their brand and create a relationship with the consumer and sports fan. The recent appointment of the Marketing Services Manager has seen the introduction of new branding initiatives. Along with a similar focus to the Warriors on developing player and team profiles, primary attention seems to be reserved for creating a consistent Breakers brand.

The problem is that, when I say consistency before, the problem was that a lot of times when you saw the Breakers logo, it was different colours, or it was on a 
different background...so I think in my mind, that is hard for the public to recognise that brand (NZBMSM, June 8, 2006).

Promotion of both messages appeared evident in the facility: banners and posters of the players were prominent around the stadium, and while not promoting personality of the players, was a step toward putting names to faces of the team. There was consistent use of the light blue from the team's uniform on and around the court side area, and on the lower stands. Along with creating consistency in the delivery of the brand and the organisation logo, the organisation has developed a slogan and set of core words. The General Manager suggested that the 'every 24 seconds' campaign was being used to educate people on why basketball was better than anything else, and that it is strongly tied in with the core words:

We have five core words. In communicating our tag line every 24 seconds, our core words are 'relentless, passionate, hungry, intimate, and dynamic...so all those words and the tagline, and everything we do is hopefully to build some consistency and educate people about basketball. Hopefully that in turn will build the brand image, and increase sponsorship, and increase fans (NZBMSM, June 8, 2006).

The rationale behind this was that, in order to run more specialised branding campaigns in the future, a foundation must be created. "For right now it is really creating a foundation, because if you don't, or just spring something up out of the blue, then people won't respond to that" (NZBMSM, June 8, 2006).

\subsection{Organisational Objectives}

The employment of current marketing and branding strategies corresponds with the selection and importance placed on various organisational objectives. Understandably, the overriding objective was to win and achieve a level of high performance. This was a view that was shared by all six respondents. Although each of the respondents individually mentioned several different objectives each, there were several that were shared by at least two interviewees: 1) generation of high attendances, 2) talent identification and youth 
opportunities, 3) providing and developing sponsorship relationships, and 4) community contribution.

The role that marketing played in fulfilling these objectives was the next stage of inquiry. As each of the respondents discussed how their marketing corresponded with their individual and fragmented objectives, there was little correlation between each respondent's answers. A discussion on this area could at best be undertaken based on the few objectives shared by two or more respondents. As it is unreasonable to expect marketers to have any control over the performance of the sports team, marketing was not mentioned as having an influence over the achievement of this objective.

Four of the respondents spoke about the priority to increase attendance, and the use of marketing to achieve it, through aspects such as TV, radio, press coverage (Warriors), communication with existing season ticket holders (Breakers), and free ticket offerings to schools (Diamonds). The General Manager of the Diamonds (June 6, 2006) outlined that by giving away tickets, the organisation may be able to increase the overall attendance and revenue over time: "We just want to get a crowd along and we are confident that once they have been, that they will come back or a percentage of them will come back."

The Vodafone Warriors have been using partnerships with sponsors of the team to achieve community-orientated objectives. For example:

Our schools programme, we don't do that in isolation. Konica Minolta, which are one of our sponsors...have a presence through schools and universities, so when we visit schools we go into partnership with them...They use our guys as their heroes. I think that it is called through the eyes of a Warrior, where they send our players out to... a dozen schools over the year. Just by fulfilling those sponsorship commitments we are actually fulfilling our own community objectives (WSMM, June 2, 2006).

The Diamonds respondents primarily focused on initiatives dedicated to ticket sales and attendance generation. Along with school coaching clinics, the main focus was on group discounts and encouraging large groups to attend. The reliance and focus upon 
increasing or maintaining attendance in the initial stages of a team's existence may contribute to a lack of brand development or investment in long-term brand initiatives. Both Diamonds respondents and the General Manager of the Breakers mentioned how focus is reserved for getting people along. "I suppose for a new team, to start-up, you immediately just want people at your game” (DGM, June 6, 2006). The Breakers General Manager went on to state:

It is a matter of simply focusing on bums on seats, and in those early years you can sort of focus on techniques, like what the entertainment industry would use for an event... When you are a new team, you have got to look at those kind of ways of generating your crowd early on so you can survive, and then the longer term buy in you get from people is much longer term thing which you can't, I guess you have to wait for to a degree (June 6, 2006).

Perhaps this is a limiting factor in that brand development initiatives are forfeited in the favour of simply attracting people to attend each game. Managerial focus on short-term revenue and even survival may put undue pressure on marketers to forgo long-term brand equity in favour of price or attendance incentives.

Along with attendance generation, respondents of the New Zealand Breakers mentioned a variety of activities including the development of a youth basketball institute, and a more personal marketing approach to corporate partners. The Breakers Marketing Services Manager also focused on branding initiatives revolving around brand consistency, and the creation of a Breakers tagline to educate the market on basketball and the excitement of the Breakers product. The general consensus when asked whether the organisation's objectives were being achieved was positive. This corresponded to objectives such as youth development, community interaction, and professionalism of the organisation. While being hard to definitively measure, the Sales and Marketing Manager of the Warriors suggested that objective effectiveness could be estimated based on the attendance or season ticket renewal the following season: 
The trend has been that we probably lose 20-25\% of our season memberships if we have an unsuccessful season...If we retain that number or we were able to increase that, that's because one or two initiatives we are offering are better. A better membership package, or it's because the profile or the image of the club that we have created has kicked in (WSMM, June 2, 2006).

With regard to the historical nature of marketing and organisational objectives, three of the respondents commented that they had changed considerably since the inception of each team. The Warriors Sales and Marketing Manager (June 2, 2006) suggested that objectives had changed from the previous year, “because we didn't do anything community wise, or school wise." The Diamonds Chairman suggested that as the organisation moved out of a survival focus, there was an adoption of marketing. When asked when the integration of marketing occurred, the answer was "probably three seasons ago" (DC, September 8, 2006). The Breakers General Manager suggested that the last year had heralded a change for the business, in terms of looking at community programmes a lot more. The preceding section has aimed to provide an overview of the organisational objectives and marketing strategies that have been and are in use by each of the three case organisations. The following section progresses to the first of the two foundation questions underpinning this research: although these organisations have specific objectives and marketing strategies, what issues have affected the development of their brand?

\subsection{New Team Brand Development - Issues and Problems}

Q1: What issues affect the development of a new sports team brand?

As outlined above, the issues that have affected the development of each team's brand were the focus of research question 1. Questioning sought to investigate the respondent's opinion on issues that had affected the development of their respective brands, issues they believed others faced, and also the perceived differences between new and existing brands. 


\subsubsection{Image and Lack of Awareness}

For their own brands, the most frequent theme to emerge was that of existing brand image or awareness issues. Undesirable brand image or low brand awareness was deemed to be an area of concern by four of the six respondents. With reference to brand image, respondents, particularly the Warriors Sales and Marketing Manager, proposed issues such as the need to be authentic in developing a brand, and the image of the team and stereotypical fan:

I guess the comments previously were that when you said the Warriors to people...people saw that as quite an aggressive, broody, moody, non-inclusive brand. I guess my own stereotypical image was that our fans are, or were male 1839, blue collar, and lived in South Auckland...Just talking to the car companies, two of the three companies said oh, the Warriors fan doesn't fit our demographic (WSMM, June 2, 2006).

Both the Diamonds and Breakers respondents mentioned the lack of awareness about both their sport and the team brand as an issue that has affected each club. This is understandable, as both domestic netball and basketball do not have the same profile or coverage as the Warriors and rugby league. The chairman of the Diamonds and the Breakers Marketing Services Manager believed that people are not in a position where they are aware of what each brand is, for example:

Sometimes I say to people, you know, I work at the New Zealand Breakers, and they say oh, what are they? Well, that's your challenge right there; trying to create a relationship between basketball and the Breakers that people know that, and then to recognise the brand itself (NZBMSM, June 8, 2006).

Additional areas of concern were devoted to awareness of the competition participated in, or the gender of the sport. For the competition, statements such as "the competition is so small, when you are in it everyone knows about it...but the issue is getting everyone's awareness of it pre-season" (DC, September 8, 2006) and "the competition that we play in is ... relatively unknown in New Zealand" (NZBGM, August 
$31,2006)$ suggest that teams that participate in competitions without high brand awareness are at a considerable disadvantage. The Diamonds Chairman also thought that the awareness of women's sport in general was also a hindrance to the development of their brand:

Awareness is one. Not only of the Diamonds, but also just awareness of women's elite sport in terms of netball... when the competition is on, people kind of tend to know about it but it is still not in their face enough (DC, September 8, 2006).

Respondent comments suggest that both image and awareness of their brand, competition or sport have affected brand development. Previous brand image may affect management initiatives to change or implement new branding strategy, whereas awareness levels may affect attendance and the ability of the team to generate revenue. Additionally, a general lack of history may contribute to this lack of awareness, as consumers may not be able to recall past experiences with each brand.

\subsubsection{Searching for an Audience}

The nature of fans in Auckland and the region's geographical size was discussed as an issue that has potentially influenced the development of each brand. Respondents commented on the fickle traits of supporters in Auckland, and fluctuating attendance:

There is a swinging audience of ten to twenty thousand people, who will go to either game depending on who is winning. If the Blues are winning they will follow the Blues. If the Warriors are winning they will follow the Warriors. There is that sort of crowd in terms of attendance. We are both sort of vying for that sort of audience (WFM, June 2, 2006).

Additionally, the General Manager of the Diamonds (September 8, 2006) believed:

We face the problem that a lot of Auckland Teams have of anonymity, that it is hard to establish an identity in a large city of a big geographical area...There is a culture in Auckland that is not really around going to sporting events. It is more around going outdoors and doing all the rest of it.

Along with the strong following that the sport of rugby has within New Zealand and the Auckland region, Auckland supporters are known for their fickle nature. Attendance at 
Auckland sports events, in line with respondent comments above, typically fluctuates with winning and losing records, and there remains a general lack of loyalty among Auckland supporters. Perhaps this may be grounded in a generally low level of identification that Aucklanders have with their sports teams.

\subsubsection{Winning and Losing}

Along with their own brands, respondents provided a range of issues they believed fellow new teams faced. In line with their comments regarding their own teams, three respondents regarded the issue of performance as an issue for new teams: "If you are unsuccessful on the field, it makes it doubly difficult" (WSMM, June 2, 2006) and "if you win they will come; if you trot out average performances, they won't." (DC, September 8, 2006). Two of the respondents related the performance issue to the development of a fourth new team brand in the Auckland market - the New Zealand Knights. The Chairman of the Diamonds and the Sales and Marketing Manager of the Warriors believed that the Knights issue is primarily about their performance, which has been extremely poor in their opening season and the initial stages of their sophomore year. The Vodafone Warriors Football Manager also linked the effect that performance has on a brand based on the number of people playing a sport, citing basketball as a prime example.

\subsubsection{Team and Competition Quality}

In a similar area to on-field results, three respondents regarded the quality of the competition and its players as an influence over brand development. One respondent from each team believed that the quality of players in a competition had a significant affect: "You have got to get it right on the field, you have got to have the right players and the rest of it" (DC, September 8, 2006). The Breakers General Manager thought that the public were not aware of how high the quality of players was in the Australian National Basketball 
League: "There is good quality players here; better quality than the majority of the sports running around in other areas of New Zealand, and people don't have that perception" (August 31, 2006). The Football Manager of the Warriors considered the Knights and even the Breakers to be prime examples of inferior playing quality:

Soccer do have the mass, I mean soccer have huge numbers that follow, but you can't honestly say that the players, with all due respect to them, the players that play for the Knights, or the players for the Breakers are not the best in the world in their sport, or their position... When our opposition turns up they are the best in the world. In the Warriors, even now, you've got Ruben Wiki, Steve Price and Clinton Toopi. You have players you can come and watch now and know that they are the best in the world. So I think that is what they struggle with, soccer and the Knights (June 2, 2006).

Based on these comments, it can be suggested that the quality of the competition a new team takes part in may contribute to the development of its brand. A new league or one of low quality relative to other offerings domestically or internationally may inhibit team brand growth. The same may be concluded for the athletes of a team or competition, as a general theme of mediocrity may harm brand-building efforts.

\subsubsection{Differences Between Established and New Teams}

\subsubsection{A Lack of History}

The final area of questioning sought to obtain any differences respondents believed there were between new and established team branding. Three general themes emerged from the respondents: the task for new teams of generating exposure and awareness of the team; the non-restrictive nature of building a new team brand; and the lack of history to draw upon for new teams.

The latter of the three, history and heritage, will be expanded on later in this thesis, but two of the respondents covered the aspect as a perceived difference in branding new versus established teams. The Warriors Sales and Marketing Manager (June 2, 2006) offered the following: "With a lot of sporting institutions, it is all around that history, 
what's happened in the past, what does this club mean, building on family interest. Whereas with a new brand you just haven't got that at all." Additionally, the Diamonds General Manager said:

I think if you have been around for 30 years that your organisation will have developed a history and a personality which you can't necessarily change; you have got to sort of link into that. I suppose if you are a team that has got a history of losing, you would have to think about how you could twig that (June 6, 2006).

Both the above respondents carried on the theme of historical family support, with the Diamonds General Manager (June 6, 2006) stating that "the longer you are around, the more of that sort of inter-generational support you have got."

The above section has provided a commentary on several issues that respondents believed had affected the development of their brands and fellow new teams. Issues such as past brand image or awareness, fluctuating attendance, past team performance, and the quality of both the players and competition appear to have hindered each of the teams, brands. A general lack of history was also regarded as a key difference between new and established teams.

\subsection{Brand Community Development}

Q2: Do managers of new sports teams use antecedents of brand community or Underwood et al. (2001) in their branding strategies, and if so, how?

Following on from a discussion of the issues that have affected the development of the three case teams, the degree to which managers are using the antecedents featured in brand community and social identification to overcome these issues was the second focus of this study's findings. In response to research question 2, respondents were asked whether they deemed each of the four antecedents important, and how they were developing each within their branding strategy. 


\subsubsection{The Group Experience}

As the first of four antecedents contributing to both brand community and social identification, the group experience is important to the creation of both. Investigation into the organisational objectives of each team revealed an underlying consideration of the community concept. Prior to discussing its use within the team's marketing or its perceived importance to brand development, Warriors and Breakers respondents shared their views on its inclusion as a goal of the organisation. For example, the Warriors Sales and Marketing Manager (June 2, 2006) revealed:

The pride side is what we have tried to achieve this year by doing more things in the community, and more direct communication with the fans. Try and build on that personal connection between the players as people and personalities, rather than just purely athletes on the field.

Both New Zealand Breakers respondents provided a statement on the community and marketing, suggesting that "the North Shore community will be our main focus" (NZBMSM, 8 June, 2006) and "we have our interaction with the community such as our community programmes, and our work in schools" (NZBGM, August 31, 2006).

As briefly mentioned previously, the Warriors had recently placed a large emphasis on showcasing a transparent brand to the public. The issue of transparency in the club translates back to the previous administration, which was responsible for a breach in the salary cap rules of the NRL competition. This resulted in the Warriors being docked four competition points prior to the commencement of the 2006 season. The current administration, as outlined by the Sales and Marketing Manager, appears to have changed this previous closed-doors approach, and wishes to be seen as an open, transparent organisation which the public are can trust:

Along the community lines, to make us a more open and transparent club. I guess this is the way, as we have been accused in the past of being quite insular, and if there is an issue within the club then we close the doors, we are not communicating 
with the fans... We want to open that up (the brand)...open to all areas of the community (WSMM, June 2, 2006).

All six of the respondents deemed the group experience to be important in the development of their respective brands. There were three reasons shared by two or more respondents validating why they deemed the aspect to be important: important to the organisation's athletes, important to the team's fans, and important to the organisation. Each of the respondents from the New Zealand Warriors believed that fan interaction was important to the team's players, as "without the fans there is no point in playing," and "having the fans present adds meaning to the athletes experience" (WFM, June 2, 2006). Although with regard to fan interaction with the team rather than with fans interacting with each other, the Sales and Marketing Manager suggested that as players meet fans, it can be a positive influence on them:

I think it is great for the players as well because they get to see how much of a role model or hero, or what they mean to the fans...If they actually see what they mean to the guy on the street...the real hardcore fan, then that will hopefully fill them full of confidence (WSMM, June 2, 2006).

Along with the effect on players, there was a belief that the group experience was important to the fans. Both Warriors respondents deemed the aspect to be important to fans, as did the General Manager of the Diamonds:

It is really just being part of a crowd, and it's just what any sporting event is really from that point of view... what people like about crowds I couldn't really tell you, but people, they do like being part of a group of people (DGM, June 6, 2006).

The final justification was in the importance of the group experience to the organisation as a whole. The Warriors Sales and Marketing Manager agreed with both Breakers respondents, believing that the group experience was critical to survival. "You don't exist without your fans" (NZBGM, August 31, 2006). The Warriors Sales and Marketing Manager believed that the group experience, among other aspects, was an 
important factor in encouraging people to attend live Warriors games rather than watching on television: "Anything we can do that promotes that community, shared experience, connection with the players that they can only get when they are here at the stadium, all the better. That is going to promote our ground" (WSMM, June 2, 2006).

The primary methods of development of the group experience that were the most frequent among respondents were the use or potential to use after-match or pre-match functions, or initiatives during the games. Two of the respondents, in this case one from the Warriors and Diamonds, had both used and given consideration to using after-match and pre-match initiatives to encourage fan interaction. The General Manager of the Diamonds (June 6, 2006) stated that "we tried to provide a social facility after the game, so that they don't just leave after the game as they tend to do...we had an area for them." However it was outlined that with certain configurations of their home stadium, the planned area is unable to be used. Additionally, a curtain raiser match was provided prior to each game to encourage fans to arrive early. The Warriors appear to be in a more advanced position, and, along with current corporate or season ticket holder pre-game functions (of which one was visible to the researcher), in future they aim to offer something to all supporters:

It might be that we put on; we have a specific lounge where we encourage all the supporters to gather in before the games. So, you know, discuss the game and meet each other...If people are having a drink before the game, they are all doing it independently around Auckland. It's in our benefit from a financial perspective and also an atmosphere perspective, to get them here early and gather in together at the stadium (WSMM, June 2, 2006).

Respondents mentioned activities or initiatives during matches that they believed promoted and would assist in creating interaction amongst fans, apart from organised preor after-match functions. The Warriors suggested creating a 'loud zone', where extremely vocal fans were encouraged to sit together; and also encouraging the majority of season 
ticket holders to sit in the East Stand. The Diamonds General Manager commented on the 'Diamonds Dance,' where fans are encouraged get up and dance during a period of each game, with a member of the crowd singled out for a prize. This was visible to the researcher, and was strongly supported by a predominantly young female population.

The newly appointed Marketing Services Manager of the Breakers was considering using activities such as the 'dot race,' which is where "during a time out, you have like three dots, and hey fans, pick the dot or whatever. There is dots racing around, and everyone is like blue, green, and red. It's just interaction like that that keeps the fans involved every time" (NZBMSM, June 8, 2006). However, the Breakers did not appear to be actively promoting or developing interaction amongst fans, except for pictures of several groups of fans in their complimentary Breakers New Zealand Herald newspaper. Their marketing appeared to focus on interaction with the team and the Breakers brand, such as product giveaways, seat upgrades for fans, and announcements of birthday parties in the crowd.

An initiative tailored to developing the group experience is the Vodafone One Tribe: a joint initiative between the Vodafone telecommunications company (official sponsor of the Warriors) and the Warriors, which is funded by Vodafone. Direct observation revealed that fans were encouraged to participate in activities and sport, create their own custom placards or posters, and place temporary tattoos and face paint on each other. The One Tribe is open to anybody: “it's non-exclusive, you don't have to be a Vodafone customer, you don't have to be a Warriors season ticket holder" (WSMM, June 2, 2006). Along with allowing for fan interaction with the team, the initiative seems to be designed also to encourage Warriors fans to meet each other and participate in activities together: 
The focus for us was...creating that interactivity and the way of connecting with the players. So, One Tribe members get to be in the tunnel when the players run out, or they get to be in the lounge after the game to meet the players, or they come along to a training session after work on a Wednesday. So it's all about getting the fans closer to the team (WSMM, June 2, 2006).

Group experience initiatives employed outside of the game environment were outlined by all three teams, ranging from extensive sponsor programmes to simple playerfan barbeques. The Warriors aimed to deliver both fan interaction with the team and interaction amongst fans through the use of their sponsored community programmes. Similar to the previously mentioned 'Konica Minolta schools programme,' these sponsor initiatives primarily serve to deliver fans meeting the team rather than focusing purely on fan interaction. The Diamonds schools programme, while only briefly covered by the Chairman of the organisation, appears to follow a similar theme of fan and player interaction. The Breakers revealed that they offer a Christmas function for fans where the players prepare and offer a barbeque to their supporters. "We have a Christmas function where...the boys are cooking on the barbeque, and they can come in and hang out with the team” (NZBGM, August 31, 2006).

Continuing the interview, respondents were asked whether they believed that there was a strong community or group aspect to their fan base. Following comparison of the six respondents, comments from the Warriors portrayed a much more 'community' appearance than those of either the Diamonds or Breakers. The Diamonds respondents discussed aspects such as the fans of the team were all participants themselves in netball, and also discussed where different groups sit in respective areas of the stadium. The Breakers respondents mentioned that their idea of a community around the team stemmed from the move back to the North Shore City area, and it's strong basketball playing community. The respondents believe that this community is a strong basketball community, but made no 
mention that there is a strong community of Breakers fans. The Warriors representatives provided a different picture of a community of fans around the Warriors, discussing heightened community or group behaviour than that proposed by either of the Diamonds or Breakers.

They are the group of people that come to watch the Warriors rain, hail or shine. Winning or losing, they'll keep turning up to watch the Warriors...That's a core group of fan. This club has been going now for eleven years and a lot of those people know each other too. They all sit in the same seat each week, and they all turn up and know each other (WSMM, June 2, 2006).

The respondents combined to provide several examples of the type of groups that regularly attend Warriors fixtures, such as regional club members, or work or groups that are employed together:

You have got 13,000 people that have been coming here from day one... and within the 13,000 there are more groups as well. There will be the Mount Albert fans, and the Otahuhu fans. So it is very much a family, community feel here coming to the Warriors...you will find for instance in bay 12 ...of the west stand is almost entirely the Mount Albert club (WFM, June 2, 2006).

Additionally, both respondents commented on the nature of the stadium and its South Stand - an area where particularly vocal and seasoned supporters congregate:

The southern stand is quite a hard case place to watch football. Again, most of the people in the southern stand have been there for a long time, and they are kind of proud of the fact that they are South stand supporters (WFM, June 2, 2006).

Both respondents were familiar with the creation of unofficial online communities

by Warriors fans, in the form of internet discussion forums. For example:

There is also a group of fans who have started an informal, unofficial Warriors website, nzwarriors.com...so now you have got a group of cyber fans who sort of talk and do all their things. It's got nothing to do with the club (WFM, June 2, 2006).

To coincide with this, the next question aimed to uncover what role the community played in each organisation's marketing approach. The general consensus that emerged from the data was that the community is at the least a large focus for each organisation's 
marketing, with three respondents stating, that it was a part of everything they did. Whether respondents deemed the community as their community of fans, or the geographic community in which they are located is unknown. In line with other questions, this question was primarily aimed to see if each of the organisations were undertaking initiatives more advanced than simply sending tickets to various sections of the community. Both the Warriors and Diamonds suggested that they did this, with specific targeting of both the rugby league and netball playing communities.

Each of the organisations produced a similar line of thought regarding why the community was a focus for their marketing - to build a relationship or partnership with the fan or consumer. "Communicating this profile, this brand that we are trying to...purvey, communicate that we want to be a club where everybody is invited, everybody's welcome" (WSMM, June 2, 2006). The Breakers Marketing Services Manager (June 8, 2006) suggested that along with generating a community around the team, the process was "also letting the community know that we support their community with our team." To the Diamonds Chairman (September 8, 2006) "it's all about the brand touching the community in a way that's meaningful."

Several of the respondents did discuss some initiatives that were being used by the teams to generate involvement with the community: schools and community programmes with the players; establishment of a partnership with the city council; featuring landmarks in player photos common to the local community; and the use of different colours in the team uniform to represent the fans. The later is an initiative from the Breakers, reserving the light blue and silver of the Breakers uniform for groups of fans. This was clearly visible upon observation of the physical facility:

That blue is for the fans and we encourage the fans to wear blue. The silvery grey colour will represent our season ticket holders, which we will call our MVP's, and 
also our corporate sponsors; anyone from what we like to call the family. The media, the corporate sponsors, the people who are our season ticket holders (NZBMSM, June 8, 2006).

The final question investigating the group experience sought to examine how the organisations were specifically encouraging fans to interact with the team. Three main strategies emerged, concerned with post-game autograph signing, managed after-match interactions with the players, and the offering of one-off events. Autograph signing was mentioned by five of the respondents, and corresponds closely with the offering of an aftermatch activity. The general consensus was that autographs were provided to fans at the culmination of each home game: "Always at the end of the game they are signing autographs, and they are always available, and there is always lots of interest in that" (DC, September 8, 2006). Observation validated this, particularly the extensive signing provided by the Breakers and Diamonds.

After-match facilities and activities appear to naturally act as a platform to deliver autograph signing, and four of the respondents directly mentioned after-match offerings. Albeit that the budget and facility of each organisation must be in a position to be able to cater for the after-match, each of the teams were at least considering activities of varying scale. The Diamonds Chairman stated that "we have usually had an after-match function, where both the captains have spoken, and that has been...pretty much open to anybody" (September 8, 2006). The Breakers offer the on-court area as an arena in which fans can interact with the players, and in addition this year are offering an after-match function at a sponsors' bar. The Warriors said that they have the facilities to offer a supporter's lounge, whereas the Diamonds and Breakers provide the playing court as an area for supporters to congregate.

Directly after the game we are encouraging as many fans as possible to walk into the club lounge, and then 45 minutes after the game the players come up there as 
well. So photo opportunities, autographs, the chance to ask questions (WSMM, June 2, 2006).

Fan interaction with the team was more prominent throughout each of the visited games, with each team allowing fans to meet and talk to the players. While the researcher was unable to attend Warriors after-match lounges, players did sign a limited amount of autographs and talk to fans from on-field positions. Both the Diamonds and Breakers provided after-match autograph signing. Both the Breakers and Warriors teams, when entering the stadium for the first time, ran out through the fans; the Breakers through the VIP or corporate courtside fans, and the Warriors through a predominantly young players guard of honour.

One-off or annual events in which team members can interact with supporters were offered as school or community environment programmes, end of year functions, or private sponsor parties. The Breakers also revealed that they aim to provide a personal interaction between each season ticket holder and a member of the playing squad: "Our season ticket holders will all get a call from one of the players in December to see if they are enjoying the season" (NZBGM, August 31, 2006). While the Diamonds Chairman disclosed that it had not been undertaken this year, the Diamonds had created the idea of a 'Diamonds Ball;' a gala dinner and dance featuring players to which fans of the team could attend. The previously mentioned Vodafone One Tribe also aimed to be a catalyst in joining players and Warriors fans:

In a couple of weeks there is going to be a tribal trial...there will be a series of activities that Vodafone One Tribe will put on...There will be exercise bikes, a tug of war, and rowing machines, that sort of thing. So, the day-to-day work that the players do in the gym, those will be replicated out there, and the idea is that the fans will get to see that...Steve Price can row 500 metres in a minute and a half or whatever it might be. Then they get to see how far they can row in a minute and a half, and compare themselves to the stars (WSMM, June 2, 2006). 
In summary of the group experience, it is evident from the above that even though respondent organisations may be considering the antecedent, and deem it to be important, a general lack of strategy to implement this concept is present. Implementation of strategies toward promoting fan interaction with fellow fans seem to be lacking, with the focus devoted primarily to fan interaction with players.

\subsubsection{History of the Organisation}

Unlike the group experience, respondents provided various responses regarding the importance of history to their organisations. Three believed that history was important, yet in contrast three did not believe it to be important to their team, or as important as other aspects controllable by the marketer. In line with this perspective, the use of history appeared sparse in each of the visited facilities. Amongst those respondents that believed it not to be important, there were varying degrees of sentiment. The Warriors Sales and Marketing Manager (June 2, 2006) believed it to be not as important as "the community aspects, or the player profile, or the results on the field," and the Diamonds Chairman believed it not important to the Diamonds, but important to those teams that were established. The Breakers Marketing Services Manager regarded history as not important, stating that she had been provided with a clean slate in terms of the marketing: "I don't because I am not relying on anything that we have done in the past for this year. I'm doing everything totally different" (NZBMSM, June 8, 2006). As will be elaborated on shortly, this directly conflicts with the promotion of an aspect of the Breakers history observed by the researcher upon attending the first of two games.

A general theme that emerged was that respondents believed there to be a general lack of history among their teams. This is predictable due to the newly-established nature of the teams included in the study. Various justifications were provided for this, ranging 
from a short period in which to develop history, to an overall lack of success. The Warriors Football Manager even suggested that as the Warriors were only eleven years old, history had to be taken from the national representative rugby league team, the Kiwis:

If you look at clubs like South Sydney and the Roosters and St. George, they have a long history of rugby league in the Sydney competition. So our history, you know, we are eleven years old, so when you try and tap into rugby league history you have really got to go talk about Kiwi rugby league teams as opposed to the Warriors rugby league team (WFM, June 2, 2006).

In describing organisation history, the general consensus was that each had a past featuring underperformance, unachieved potential, and organisational problems. Five respondents mentioned that their respective teams had underperformed or had been inconsistent in their performance on the field or court. From an administration or management perspective, history was also described as having gone through unfavourable periods. The Diamonds, along with moving their home stadium frequently, have emerged from the previously mentioned survival phase to a focus on marketing and growth. The Breakers suggested that in the initial years, the organisation was created with good intentions, yet was not nurtured through its introductory years:

I think that it was created with the best intentions in mind; it's just that no one was there to help it along. I mean you can't have a baby and then not do anything, leave it...I just do not think that they gave it enough energy and time that it was due (NZBMSM, June 8, 2006).

The Warriors passed through a period where the club passed into receivership through to its present ownership structure. When asked whether they believed that this had affected the development of the brand, the Warriors Football Manager (June 2, 2006) stated, "no doubt."

It is a professional sport; it's a business and so the club had to go through that period and into receivership underneath the Auckland Rugby League until its present time when it was privately owned...It was a necessary path of the transition from amateur sport when the Warriors first started through to professional sport (WFM, June 2, 2006). 
The incorporation of historical aspects within each of the organisation's marketing appeared to be largely non-existent, a statement validated both by observations of each facility and the importance placed on the attribute. The Warriors Sales and Marketing Manager reiterated the point that compared to other teams in the NRL, the Warriors had very little history to use:

Until we have been around, I guess in 10 or 11 years there are things that we can draw upon from history, but I mean we wouldn't have the history of someone like the Roosters or Dragons, or Norths or Souths or whoever it might be (WSMM, June 2, 2006).

The respondents were largely unanimous in their opinion that there was minimal history used in marketing. The Diamonds Chairman suggested that the only things that had been used from a historical point were the logo and the colours of the playing dress, while the Breakers Marketing Services Manager stated that the logo was the only aspect carried over from previous initiatives. When asked how history was currently being used within the marketing of each organisation, a strong theme emerged: it wasn't. Several reasons for this were provided, such as varying owners of the team attempting to establish themselves and disregarding the past; a lack of success; a lack of marketing material in which to incorporate history; or simply because the organisation was new.

Varying comments were given regarding whether respondents were using history such as "I think we largely ignore our history" (WFM, June 2, 2006), "I think we have gone away from the history" (WSMM, June 2, 2006), "not really" (DC, September 8, 2006), and "nothing or hardly anything that we have had in the past is what we are doing now" (NZBMSM, June 8, 2006). The Diamonds were the only team that suggested they were looking at marketing history in the future: "We are looking at incorporating it in for next year. Just making people more aware of our, of the history" (DGM, June 6, 2006). The 
Warriors did provide two examples of historical marketing, however whether they considered this to be aspects of marketing needs to be taken into account in comparison with their comments regarding their non-use of history above. The Football Manager revealed that montages of previous games are played prior to current games, and the Sales and Marketing Manager commented on the use of replica jerseys from previous seasons, albeit that it was conducted prior to his arrival at the club:

Last year they used the opportunity, because each year we are allowed to showcase a one-off jersey, and last year they did the replica of the original jersey for the Broncos game...that was a specific occasion rather than something we could keep going back to each year (WSMM, June 2, 2006).

Upon visiting the facilities, the Warriors did display highlights on a large television screen of a previous game against both opponents. On the night of the first game attended by the researcher, a curtain raiser match was played featuring famous former rugby league players. The 'legends of league' match featured two teams, one made up of former New Zealand rugby league stars, with the other comprising predominantly former Australian greats. A large crowd had attended this game, and had arrived early at the stadium for this event. Whether this game was initiated by the Warriors is beyond the reach of this study, but it directly conflicts with the lack of importance reserved for history by the Sales and Marketing Manager.

The Breakers, during the first game visited, provided fans with a complimentary copy of an imitation New Zealand Herald newspaper, detailing a four-page spread on the new team, fans, community programmes, and the Breakers reaching 100 games. The later aspect of the newspaper was located on the front page, and included a brief history of the path to the current team, pictures of the first game, and 'now and then' of two original players who also celebrated 100 games for the team. It was interesting to find this feature, as it was made clear to the researcher by the Breakers Marketing Services Manager as 
stated above that history was not important. The Diamonds game did not feature any promotion of the team/organisation's history, at least any that the researcher could see.

\subsubsection{Rituals and Traditions}

Respondents were unanimous in their opinion that rituals were important to their organisations. Along with suggesting that it creates history, respondents believed that rituals contributed to the creation of a sense of belonging, offer entertainment and encourage people to attend live games. The Chairman of the Diamonds (September 8, 2006) expanded on this, stating "I think those things are hugely important, in any sport whether it's soccer, or where you have got those heritage aspects that you can leverage in the right way." The Breakers Marketing Services Manager suggested:

It's audio, it's visual, it's feeling. There are a million traditions that you can create, but they have to be special to your team... whether the crowd knows what colour to wear to every game, or whether the crowd knows that at the end of the third quarter you sing this song, just basic things (NZBMSM, June 8, 2006).

The general opinion that rituals are an important part of the team contrasts with the respondents' view regarding the history of the organisations. As rituals are closely linked to behaviour of the past, this is an interesting finding. This will be given due consideration and commentary in the following discussion section of this study.

Respondents were subsequently asked whether they were familiar with rituals of either the team or the fans. For four of the respondents, the shared view was that they were not aware of any rituals. This answer may have been dependent on what each respondent deemed to be a ritual, yet some of the proposed rituals that respondents did suggest were behaviours such as award dinners, face painting, banner making, post-match functions, team entry to the field and post match walking around the ground, team arrival at games, defence chants, and the music that is played at games. While the majority of respondents were not generally aware of rituals that surrounded their teams, several suggested activities 
that resemble ritualistic behaviour. Along with both Warriors respondents discussing the way the team enters the field for games through a tunnel in the side of a hill, the Sales and Marketing Manager commented on the use of Polynesian drummers at home games. The Diamonds General Manager, following prompting by the interviewer, was asked to comment on the use of a male cheer squad observed by the researcher during the triangulation visit to the Diamonds home game:

That was spontaneous...they are former Otago students, and they were doing it down there with the Rebels, and they did that from the second game. I mean I do everything that I can to help them, but they just do it...I suppose the crowd's reaction to them is something that we haven't engineered. The fact that they love them is something that, that's a tradition already after two weeks (DGM, June 6, 2006).

In line with the above, most respondents outlined that there was minimal incorporation of rituals or traditions within each organisation's marketing. While a couple of the respondents provided examples such as the way the players run onto the field, or use of signature songs for players during a game, the Diamonds General Manager was the solitary respondent who commented on the promotion of rituals or traditions. While he outlined that it is a focus for the future, it was stated that the Diamonds would aim to promote and have photos of the Cheer Boys available.

Unlike the above where respondents had largely avoided promoting rituals within marketing initiatives, respondents were quite forthcoming describing rituals or traditions they were considering developing for the future. A general theme that emerged was that each team had the aim of developing or allowing rituals to develop, but at present this was largely underdeveloped. For example, although the Diamonds Chairman stated that the Diamonds were not attempting to develop or promote new traditions, he later said:

I guess the answer is it is not that I wouldn't like to, it's just that we are evolving as an organisation...So would we be developing rituals, and would we be putting more 
effort into our marketing and been a lot smarter about that, definitely. But it is going to evolve; it is going to take time to get there (DC, September 8, 2006).

The Breakers Marketing Services Manager also outlined how she was interested in developing rituals in the future, but this would be influenced by observing the behaviour of Breakers fans:

Of course I will try to, and I think part of that is also after being at a couple of games paying attention to what the crowd responds to. Paying attention to what your crowd gets excited about, and then creating a tradition around that (NZBMSM, June 8, 2006).

Along with several rituals such as Maori or cultural dancers, special embroidered jerseys for debut games (Warriors), community group performances (Breakers), and the above cheer boys (Diamonds), a common aim among the three teams was to develop songs and associate them with either individual players or special occasions.

One of the things that we are working on in conjunction with Flava (radio station) is to have a theme song tune, which is associated with each player. The idea behind that is that as that player's name is called out when they run on the field, a snippet of the track is played, or if they score a try or something significant happens, then that track is played. I guess that is pulling on what happens in soccer in the UK and Europe, or where fans sing a song that is attributed to one of the particular players, and it's really a way of manufacturing that (WSMM, June 2, 2006).

The Breakers Marketing Services Manager added:

If you were to create a sound that every time a three point shot is made, fans get to recognise that sound. Also, music is a hugely important thing. Associating perhaps maybe a player song, a particular song with a player or that you play music when something big happens or something like that. You know, your fans enjoy that and get used to that (NZBMSM, June 8, 2006).

Albeit that each of the teams have been in existence for various periods, from the researcher's perspective, there appeared to be few rituals in use by either the fans or employed by the organisations that mirror the teams featured in the work of Underwood et al. (2001). However, it may be that behaviour or activities observed that were not regarded as rituals or traditions by the researcher could be interpreted differently by other persons. 
In the opinion of the researcher, the following rituals or traditions were observed around the games visited:

The Warriors players enter the field from a tunnel, separate to any of the stands of the facility. A Warriors chant was used sporadically throughout both visits to the stadium, and did not appear to correspond with a regular moment of a Warriors game. The Diamonds game featured the repetitive use of 'thunder sticks' after the scoring of each Diamonds goal. Thunder sticks are inflatable plastic devices that are banged together by fans, which combined create a considerable noise. The game also featured the use of the previously mentioned 'cheer boys,' a group of male cheerleaders that inspire the crowd and entertain them during various intervals. The Breakers game did feature consistent behaviour at each of the two games visited. For example, the way the team entered the court was consistent, with lights dimmed, smoke, and announcement of the each player's name. Cheerleaders and 'Breaker Girls' danced at various points during the game, and at half time in both games, two fans were chosen to participate in an activity to decide a winner of a sponsor's prize.

In observing these activities or behaviour, most appeared to be initiated by the organisation's themselves. A preliminary assumption may be that as these teams are predominantly new, there will be little or no rituals or traditions that are developed or used by the fans themselves. The majority of rituals or traditions present at these team's games appear to be made up of those artificially developed and managed by the organisation.

\subsubsection{The Physical Facility}

Respondents were generally in agreement with the opinion that the physical facility is important to brand development. The sole exception to this was provided by the 
Marketing Services Manager of the Breakers, who believed that the promotion and marketing inside the stadium was much more important:

With North Shore Events Centre, the facility itself, no I don't think that that is big part of our brand in playing there. Now that being said, what we are doing to it, I think that is going to be a huge part of our brand (NZBMSM, June 8, 2006).

The importance of the facility to respondents varied from the affect it had on the players and opposition (Warriors Football Manager), to the affect it had on portrayal of the organisation's brand: “The stadium is a huge part of our brand and our personality, and what we are" (DGM, August 31, 2006). The Diamonds Chairman went on to comment on the difference between new stadiums such as the Trusts Stadium where the Diamonds play, to that of historic Eden Park: "Has it become an iconic feature of the Diamonds yet like an Eden Park? No, not quite. That's a long way to go yet" (DC, September 8, 2006). The Warriors Sales and Marketing Manager believed that Mt Smart Stadium, home to the Warriors, acted as a place where fans could remember aspects of the Warriors history:

When the fans come along, they will probably remember when someone scored a hundred-metre try, or scored in such and such a corner. That was the billboard where somebody smashed into, or in that game do you remember when someone hit the post. It's got all those tradition and history (WSMM, August 30, 2006).

The overriding theme amongst the representatives was that although promotion of the physical facility took place, it was focused on informing the consumer that the event took place at the stadium, and what facilities the stadium had to offer. For both the Diamonds and the Breakers, attention had been placed on making sure the public knew where the teams were playing: "it was all about that we are here, this is where we are playing, come along to the games, and this is how to get there" (DC, September 8, 2006), and "it really isn't the facility itself, it's more the location, and the team" (NZBMSM, August 31, 2006). Additionally, the Sales and Marketing Manager of the Warriors commented on the importance of showcasing the new facilities available: 
Rather than a branding, or an atmosphere, or a heritage or a tradition, it is more about the facilities, particularly in the East stand, because it is only a couple of years old...more from a facilities than a heritage and a tradition perspective I would have thought (WSMM, August 30, 2006).

Aspects of the stadiums that were mentioned to feature in the marketing of each team were the catering services, the member's lounges, that the stadium was brand new, and comfort. "Its more the sort of catering and the food and beverage facilities are the thing that you would push rather than...the stadium is one hundred years old and all these things" (WSMM, August 30, 2006). Respondents from the Warriors and Diamonds did outline that although their focus had been on aspects of stadium service, they would like future initiatives to promote less tangible symbolic or emotional aspects: Along with the Diamonds General Manager (August 31, 2006), who stated that "we would like to make this like the House of Diamonds or whatever," the Warriors Sales and Marketing Manager stated:

Maybe in 10 to 15 years time, or if we were to host a home semi here or a home quarter final, and we have a great victory, then you might play on that a little bit. But I don't think it has probably got the longevity yet, or the heritage to be able to do that (WSMM, August 30, 2006).

In summary, rather than promoting non-tangible, symbolic aspects, or aspects linked to social identification of their homes, the teams' main focuses were given to marketing stadium facilities: "We don't really promote anything about the facility...it's all about that we play there basically" (NZBGM, August 31, 2006). Although several respondents believed the stadium to be important to their brand, discussion did not eventuate on how this was being accomplished, or how the facilities were being incorporated as a core brand association.

During direct observation, promotion of the physical facility by each organisation appeared to have received minimal attention. Albeit that investigating whether promotion 
of the facility occurred within the stadium itself may have not been the most appropriate method, there was no marketing of non-tangible or symbolic properties. As will be discussed within the limitations section of this thesis, analysis of the incorporation of the stadium within brand strategy may be most appropriate in alternative mediums of delivery, such as those prior to attendance (television, radio or print).

\subsection{Summary of Findings}

The preceding chapter has aimed to provide the reader with a path upon which to follow findings expressed through conducting this study. Along with an introduction into current marketing strategies and the underlying objectives of the three teams, issues that have affected the three case organisations' brand development were uncovered. Issues such as a lack of awareness, unfavourable brand image, and perceived quality of competition and players, were identified as having played a part in the historical development of each brand, coupled with the unfortunate playing records of the teams. Current marketing strategies consisted of varying themes, primarily tailored to each organisation. The Trusts Diamonds campaign centred primarily on attendance generation, and the New Zealand Breakers primary focus resided in creating brand consistency. The Warriors perspective, along with promotion of the player personality, lay in opening the club to include the fans and community.

With regard to the four antecedents used within brand community and social identification, respondents believed the group experience, rituals and traditions, and the physical facility to be important to brand development; history and heritage were deemed important by only half of the respondents. Respondents were aware of the concepts, and were able to discuss current and potential use, and integration within future branding strategy. The group experience appears to be that which is most frequently considered, and 
traces of this antecedent are currently visible within the case organisations. Both history and rituals appear largely disregarded from marketing or branding; consequently the lack of interest in history promotion reflects the lack of importance placed on it. Physical facility promotion centres on conveying information around the facilities or services available rather than including non-tangible themes or linking the stadium to the identity of the team. Overall, while the organisations seem aware of the precursors to brand community or social identification, currently there is minimal practice or development. 


\section{CHAPTER 5}

\section{DISCUSSION AND IMPLICATIONS}

\subsection{Introduction}

This study began with the aim of partnering the brand community work of Muñiz and O'Guinn (2001) and the social identification work of Underwood et al. (2001), and then applying it to newly-established sports brands. The empirical component of the thesis was undertaken with respect to new team brands, and whether managers were using antecedents that are recommended as critical to the creation of brand community and social identification. This chapter provides a discussion of the findings of the study, primarily with regard to each of the guiding research questions. It also aims to provide a presentation regarding implications of this study for future research and practice.

\subsection{The Challenges for New Sports Team}

Q1: What issues affect the development of a new sports team brand?

In the past, the three cases observed have experienced a multitude of on and offfield issues. Along with the previously mentioned lack of team performance, the most influential issue that respondents believed that they were plagued by was existing brand image or awareness. Existing brand image will have been created from previous marketing of varying associations, such as in the Warriors case of players as gladiators or bruising athletes. This conflicts with the current images that the Warriors management wish to portray to the consumer. The ongoing issues that have affected the three teams in conjunction with a lack of consistent branding strategy will have produced varying or undesirable consumer brand associations, ultimately leading to an unfavourable brand image. 
While undesirable themes or images may be associated with these brands, the lack of winning seasons from these teams may have had the affect of fans placing their shortterm focus purely on how each team performs either game-by-game, or season-by-season. Subsequently, as results have been poor, the equity behind each brand has failed to build, or in some cases such as the Warriors following their sole Grand Final appearance, has eroded. If fans have no past success to recall, as is the case for these new teams, emphasis will be placed on how a team is currently performing.

Along with the performance factor, respondents did state issues such as awareness of their sport, particularly women's sport in the Diamonds case, lack of sponsorship revenue, the nature of Auckland fans, and the dominance of rugby in New Zealand.

Awareness and participation levels of the three sports involved appear as follows: Statistics New Zealand (2001) state that rugby league does not register in the top five sports played in New Zealand schools; basketball is fourth for boys and third for girls; and netball is the dominant girls' sport. Young New Zealanders, once they have left the school environment, on average choose to participate in eight other sports before they consider rugby league, basketball, or netball. Whether or not this has an affect on the attendance or investment in the live sport entertainment offering is unknown, yet it is offered here that it may have an affect on the identification

When compared to rugby, these sports are of far less importance and spectator interest to New Zealanders. As outlined by Hindson (1999) the domination of rugby over other sports was cemented early with the establishment of a national body in 1892 , along with inter-provincial competitions and the success of New Zealand teams touring overseas. New Zealand's 'obsession' with rugby as Hindson calls it, may overpower all new offerings into the sports market such as those teams included here. This focus on the 
masculine sport of rugby may also affect the development of feminine sport such as netball, and the possible development and identification with brands such as the Diamonds.

However, in outlining the issues and problems that have affected the development of these brands, the researcher is of the opinion that two particular issues have been the main catalysts: poor team performance and a lack of history. It is beyond the reach of this study to investigate the development or the equity of these three brands had their respective teams been consistently successful from the point of conception. Since there appears to be a paucity of literature concerned with new teams and their brands, and whether win-loss records or performance greatly affects initial brand development, this study proposes that as new teams suffer from a lack of history for consumers to recall, immediate brand evaluations will be based on short-term performance. Based upon the three cases observed here, this does not appear to be a path brand managers would want to tread or attempt to recover from.

The lack of history that these teams possess has undoubtedly affected consumer identification and investment. As illustrated above, rugby in New Zealand and its professional teams have been established since the late $18^{\text {th }}$ century, and while the sports of rugby league, basketball and netball have significant histories, they are not nearly as well promoted as that of rugby. Each of the codes has significant stories to tell, for example netball in New Zealand was derived from basketball, and traces back to the first game played in Auckland in 1906 (Netball New Zealand, 2006). While the teams featured here may not benefit from a long and fruitful story, the sports they represent do.

Based on these proposals, the argument behind this study is that as these teams are recently established and do not benefit from having a long history, coupled with the inferior performance of the teams, the result has been a lack of brand equity development and low 
consumer identification. The use of antecedents of both brand community and the work of Underwood et al. (2001) are thought to contribute toward alleviating these issues, and developing strong brands based not just on fluctuating on-field performance. If and how managers are using initiatives featuring and incorporating the group experience, history and heritage, rituals and traditions, and the physical facility, within brand strategy was the consequential aim of the study

\subsection{Discovering Brand Community}

Q2: Do managers of new sports teams use antecedents of brand community or Underwood et al. (2001) in their branding strategies, and if so, how?

While respondents were unanimous in their opinion that the group experience was important to brand development, it must be questioned what each respondent considered the term meant. This can be seen in several of the respondent's comments, suggesting that the group experience was important to players. Whether some respondents regarded the group experience as fan and player interaction as opposed to fan and fan interaction is undistinguishable at this stage, but it may have been an interpretation taken from the questions. Aside from this, a general theme that emerged from the analysis of the data collected was that respondents believed the experience to be important.

While respondents believed this, a general lack of incorporation of group experiences into marketing initiative was present throughout the cases. In some cases respondents outlined that they were considering promoting the concept, while others simply were not thinking of it at present. Several initiatives were being integrated slowly into team marketing, including the Warriors joint venture with the Vodafone One Tribe, the 'Net Ball' with the Auckland Diamonds, and after-match functions at a local bar for Breakers fans. With reference to after-match functions, determining whether managers responsible 
for these regard them as simply mandatory opportunities to meet players as opposed to vehicles to meet other fans was outside the reach of this study.

While fan interaction with the team or players is important, it is the interaction amongst fans that is at the heart of the group experience. Although a sports team and its athletes are a point of attachment and interest for fans, spectator sports are characterised by a sense of spectator belonging (Underwood et al., 2001). Underwood et al. believe that the professional sport environment provides the most intense example of shared bonding and affiliation between consumers. While new teams may not initially possess the ingredients to develop these communities and shared experiences, it should be considered as equal, and potentially more important than fan interaction with the team.

Of the four antecedents included, history appeared to be regarded as the least important to development of the three cases' brands. This requires considerable discussion as to whether respondents consider history less important purely because they do not possess it. If their teams had been around for another 20 years, it is unclear whether or not the respondents would have the same judgment toward history. The researcher is of the opinion that since the respondents appear to not have a large amount of history at their disposal, they deem it to be less important.

Even though half of the respondents were of the opinion that history is unnecessary for their brand development initiatives, fans and consumers of the team and its brand will have vivid memories of their experiences with it; they will remember. Along with Underwood et al. (2001) and Muñiz and O’Guinn (2001), research by Passikoff (1997) suggests that a team or league's history is a key driver of fan loyalty and growth. With this in mind, a manager who is willing to disregard their own team's history or heritage could potentially be disregarding their own fans memories and experiences. In the case of these 
new teams, even the Breakers with just three seasons to recall do have a history. To view a new team's history as unimportant to its brand does not concur with research that provides the foundation of this study.

In connection with the importance placed on history, it was stated that branding initiatives do not feature historical attributes. Visits to each team's live games validated this, with minimal promotion of history visible to the researcher. As mentioned previously, there was the Breakers newspaper of their $100^{\text {th }}$ game, and the playing of a previous game's highlights by the Vodafone Warriors. Apart from these instances, comments from respondents and observations of the game environment paint a picture where historical aspects are largely ignored.

The reason behind this lack of willingness to promote the history of each organisation is both subjective and beyond the range of this study. Although the organisations are relatively new, they do possess history; even though managers may wish to initiate or undertake their own branding strategies, the brand still possesses history. It is the opinion of the researcher that history is not only a powerful antecedent toward the development of a brand community, but also a direct link between the organisation and each individual consumer of the brand. By disregarding the history of the team, managers are potentially ignoring the time, money and emotional effort that their fans have invested. By celebrating and remembering the past, managers can send a message to fans that their efforts and participation with the organisation will not be forgotten.

It is of interest to compare the difference in opinion between the importance placed on history, and that placed on rituals and traditions. Respondents were unanimous in their view that rituals were important to brand development, yet half regarded history as unimportant when compared to other concepts. As outlined above, rituals incorporate 
aspects of and are derived from the past (Imber-Black \& Roberts, 1992); therefore if rituals are deemed to be important, history must be just as important. Perhaps respondents did not regard rituals as a part of their team's history, and viewed them through a more contemporary perspective of behaviour.

As new teams, it is understandable that respondents were largely not aware of many, and did not currently promote rituals or traditions of their teams. Discussion did extend to the development of rituals (such as the association of songs with specific players or moments), but managers suggested that this would be dependent on fan behaviour and the path each organisation took in the future. Observation of each team's environment provided minimal examples of rituals similar to those identified by Underwood et al. (2001). However, the identification of rituals at this stage in each team's life may be beyond the capacity of the researcher, this study, or the team's management; for example, individual or small groups of fans may have their own rituals that are not directly visible or known to the marketer. Perhaps it can be proposed that rituals or traditions may be the antecedent that is the least controllable in the immediate future of these teams. Over a period of time, ideally rituals will have naturally developed, and it will be the responsibility of each team to actively promote and nurture these.

Promotion of the physical facility does not appear to extend any further than the standard marketing of facilities and tangible properties. While this has been identified as an important part of service marketing (Bitner, 1992), and is also a necessity in delivering basic information to consumers, there remains minimal use of the facilities to develop community or social identity. Underwood et al. (2001) strongly suggest that there are two aspects of facility management that are directly related to consumer identification with a service: 1) How strongly the facility is integrated into the organisation's brand identity, and 
2) the degree to which attributes of the facility (e.g. design, customer amenities) foster formation of group identity.

Albeit that each team is new and they do not directly own their facilities, the stadiums appear to be currently used as empty shells, within which the brand is promoted and encountered. While managers do consider the facility important to brand development, and aspects such as brand personality or team heritage, it appears that at the present time the stadiums are being primarily marketed based on their amenities. Whether or not these facilities and their amenities in their current form contribute to the creation of brand community or development of social identity remains an area for future research.

In conclusion, the above findings and discussion suggest that teams are at least considering the concepts examined in this study. Respondents seem aware of the antecedents of both brand community and social identification and deem most to be important, however, visits to the physical facilities coupled with the majority of respondent interviews display minimal promotion or development of the four antecedents.

It does appear that each team can be placed on a continuum-like scale, looking at the implementation of brand community and social identification strategies. The Trusts Diamonds, although older than the New Zealand Breakers, appear to be the team least interested in developing a brand community. This may be due to a focus primarily on attendance generation, or financial constraints. The Breakers appear to be migrating toward social identification, with development of player personalities, after-match functions, and promotion of fan colours for example. However at present it appears that managerial focus is given to creating a consistent logo and brand amongst media and promotional sources. The Warriors appear to be pursuing an avenue clearly associated with brand community and social identification. Along with the use of the Vodafone One Tribe 'brand fest', and 
after-match functions, managerial strategy resides in opening the brand up to incorporate the community. Although the Warriors and Breakers strategies appear to be progressing toward fostering the group experience, history, rituals, and the physical facility are largely ignored.

Despite this current strategy, as the majority of respondents featured here believe the antecedents of both theories to be important; gradual implementation of these into branding policy is achievable. Perhaps the Achilles heel to this strategy is the perceived short-term focus on attendance generation, and a season-by-season survival perspective. A long-term focus is required if a new team is to join its established competitors; a prime example of which is the goal of developing a high degree of social identification in search of the utopia of branding - the development of a brand community

\subsection{Implications for Practitioners}

The overriding proposal behind this thesis was that established sports teams provide an excellent example of a community centred on a particular brand. It is proposed here that an essential process for managers resides in observing aspects crucial to successful brand communities, and incorporating them in branding initiatives of newly-established sports brands.

For these newly-established teams, the predominant focus for managers must centre on creating associations with their brand that are not purely dependent on the win-loss performance of the team. Team performance will always influence consumer sentiment to a certain degree; however investment in fostering consumer identification with the brand and providing an environment in which fans can develop a community around the team will assist in linking alternative consumer associations to the brand. As Underwood et al. (2001) suggest, by building awareness, image, and loyalty, sports franchises may be able to 
achieve attendance levels and financial goals that are not simply dictated by win-loss records alone.

Underwood et al. indicate that in order to develop customer-based brand equity (Keller, 1993), a sports organisation may be best enhanced by recognising the importance of fans' identification with the organisation and initiating strategies to foster a deeper sense of affiliation with the team and between fans (Underwood et al., 2001). Through the use of the work of Underwood et al. and the concept of brand community by Muñiz and O'Guinn (2001), it is advised that these strategies include promotion of: 1) the group experience, 2) history and heritage of the team, 3) rituals or traditions, and 4) the physical facility.

\subsubsection{Developing the Group Experience}

Promotion of group experiences should centre primarily on the interaction that consumers have with each other under the host brand. Underwood et al. (2001) advise that organisations that provide a service, such as professional sports teams, "should attempt to create opportunities for group experiences, and leverage these to build stronger identification" (p. 9).

Previous research identified in this study highlights opportunities that are provided by brands to their communities, or are independently created such as internet discussion forums and websites (Algesheimer et al., 2005; Muñiz \& O'Guinn, 2001; Williams \& Cothrel, 2000), and large festivals of brand users and the host brand, otherwise known as 'brand fests' (McAlexander et al., 2002). An excellent example of this is the 'Vodafone One Tribe' concept. Albeit that the strategy is not entirely based around the Warriors brand (if anything the initiative appears to be a campaign to create a brand community for both brands), it is a strong example of creating shared consumption experiences. 
The service that sports brands offer provides an enviable starting point in this regard, as every game has the potential to act as a 'brand-fest' similar to those identified from previous research such as 'Camp Jeep' events (McAlexander et al., 2002). Consumers or fans are all brought together to the stadium to consume the sports service and engage with the brand. Although managers may view this as the most important relationship, a potentially more potent link to consuming the brand may be the relationships consumers share with each other. Managers of sports organisations, whether new or established, should consider their brands or team as a form of catalyst to consumer interaction. Future branding initiatives could possibly consider the sports organisation as a place where fans consume the group experience rather than the sports product. Perhaps instead of portraying an emotional sense of responsibility to the team, a sense of responsibility to each other may be a more compelling theme to communicate to fans.

\subsubsection{Promotion of History and Heritage}

If a brand is fortunate enough to possess a long history, it has a strategic advantage over new competitors that enter the market. Underwood et al. (2001) suggest that communication of historical or traditional aspects of a company can act as a method to strengthen consumer identification and create positive brand associations. A particularly problematic area for new brands is that a brand with no history is in an undesirable position. Not only does it possess minimal brand equity, but also the consumer cannot recall past positive experiences that they have shared with the brand.

New sports brands however are at least in the position to be able to call upon the history of the league or the sport in which they participate. Consumers that are considering investing their time and money in a new team will ideally have had an interest in the host sport or competition, and be aware of aspects of its past. A recent example of this method 
comes from the introduction of the Carolina Hurricanes ice hockey team to the unfamiliar region of North Carolina. Marketers concentrated on linking the team with the history of the NHL and other famous NHL players (Kelley \& Hoffman, 1999). Along with the work of Fisher and Wakefield (1998), Underwood et al. (2001) strongly advise this tactic, suggesting that teams that do not possess a sense of history of their own may benefit by linking to the history of the sport.

Underwood et al. suggest that marketing strategies that involve a strong sense of history can not only differentiate a team brand, but also elevate and strengthen a fan's obligation to the team. Revenue generation may also be assisted through the use of implementing programmes to create or promote team heritage (O'Reilly \& Nadeau, 2006). Strategies such as the recognition of former teams or players, or the use of past uniforms are simple yet effective examples (Underwood et al., 2001). Even within the context observed in this study, new teams should always be able to locate a source of history, whether it is derived from the sport, league, or original years of their team. Managers may wish to forget this period, but fans will always remember these experiences and times.

An additional perspective that managers may find worthwhile investigating is communicating the history of the fans and supporters. To the knowledge of the researcher, there exists minimal application of this technique, with history and heritage marketing predominantly looking at the team. Managers and organisations may benefit from actively researching and promoting the history of fan groups, their lineages, and what famous team moments they have witnessed. In conclusion, the history of the organisation should not just incorporate the team, but the fans as well. 


\subsubsection{Incorporating Rituals and Traditions}

As stated by Muñiz and O'Guinn (2001), rituals and traditions typically centre on shared consumption experiences with the brand. Therefore, initial investment in ritual or tradition development should focus on providing areas or events where shared consumption or interaction with the brand can occur, or group experiences. From this interaction, managers are at least providing an area in which ritual behaviour can be initiated by fans.

Of the four antecedents, development of rituals or traditions may be the least controllable by the marketer. Once rituals or traditions exist and are an established behaviour, promotion can occur; however as managers of new teams may be predominantly without entrenched rituals to use, development of rituals must be integrated within the development of initial branding strategy. Apart from providing an environment in which consumers can generate their own rituals, the manager may wish to develop their own around the service offering. Underwood et al. (2001) suggest that within areas they control, managers should attempt to develop meaningful rituals around the consumption process:

If managers can identify even small elements of the service offering that can be formed into ritual observances that cue the customer's social identification with the firm, they have the tools at their disposal to make service encounters more unique and special to customers" (p. 10).

Along with those examples provided in the literature review of this study, Underwood et al. provide several examples of prominent sporting rituals, such as the flaming lance planted at midfield by Seminole Chief Osceola at Florida State University; the process of throwing opposition home run balls back onto the field by Chicago Cubs bleacher fans; or standing as "The $12^{\text {th }}$ Man" at Texas A\&M. Rituals common to New Zealand sport include examples such as, the entrance of the Crusaders Horsemen and the playing of the team's theme song, "Conquest of Paradise" (Canterbury Rugby Football Union, 2006); or the All Blacks and assorted New Zealand national teams' use of the 
Haka. Underwood et al. (2001) suggest that simple activities such as remaining standing till the first point is scored, or introducing players in an energetic manner are examples of ritualistic behaviour that can foster fan identification. The employment of such initiatives will ultimately provide a measure of added value to the brand, differentiating it from competitors (Underwood et al., 2001).

\subsubsection{The Facility - More Than Just a Building}

As the physical facility aspect has not been included within brand community research thus far, the work of Underwood et al. (2001) remains the sole foundation upon which to link its importance to the development of sports brands. When considering the physical facility as an antecedent toward brand community or social identification development, it is important to remember the two propositions of Underwood et al.

The first states that "the greater the degree to which the facility represents core brand associations, the greater the degree of social identification" (p. 7). This procedure may be more manageable by those teams that own their stadiums such as in America or Europe; unfortunately for the teams included here and the majority of New Zealand sports teams, this is seldom the case. However, in selecting and managing a stadium, sports teams should very carefully consider the brand identity of themselves and the stadium they use. For example, if a sports team wishes to convey the identity of a working class, blue-collar team, it would be undesirable from a branding perspective to play in a stadium that did not share those brand associations. In conjunction with the hypothesis from Underwood et al., it is suggested here that the greater the stadium represents the sports team brand and the fan of the team, the greater the social identification possible.

Specifically for new teams and the initial period that has been identified in this study, the above may prove well beyond the financial and managerial capabilities of the 
start-up organisation. A new team may only be in the position to take what stadiums are on offer to them, not dictate which ones suit their desired brand identity. In this case, and particularly if the team does not privately own the stadium, alignment with the brand associations of the stadium's geographical location will be just as important.

The second hypothesis conceived by Underwood et al. was that "the greater the degree to which attributes of the facility foster shared experiences among customers, the greater the degree of identification" (p. 8). Initial development is evident amongst examined teams, with member's lounges and after match congregations in early stages of implementation. Along with this, Managers could potentially reserve areas of their stadium for specific demographics, such as students or families. If spaces in the stadium are reserved for specific groups to congregate and regularly attend, shared experiences are more likely to develop.

Even though Underwood et al. suggest that there has been little attention devoted to investigating the facility and its relationship to consumer identification or brand equity, in their regard it is an extremely important contributor to the creation of consumer social identification. Managers, where applicable to their resources and situation, must change their view of the stadium from just a building where their sport service is played and viewed; as well as being a direct association to their brand, it is now a place of social gathering where potentially the sports product is secondary to the interactions and experiences shared by consumers. People hold social gatherings and parties frequently at private houses, bars or clubs to interact, meet new people, and share experiences with friends. Perhaps managers should regard their facilities from this perspective in the future. 


\subsection{Implications for Non-Sport Brands}

While it is has been proposed here that brand community and social identification development is crucial to sport brands and potentially service brands, various product-based brands have just as much consumer identification associated with them, as evident in previous research (Algesheimer et al., 2005; McAlexander et al., 2002; Muñiz \& O'Guinn, 2001; Muñiz \& Schau, 2005). Underwood et al. (2001) propose that in particular, the group experience is becoming an increasingly important part of retail strategy, where progressive retailers such as Barnes and Noble, are recognising the importance of providing consumers with a social experience. Therefore, the development of brand community around consumer products can and should be a strategic long-term goal of brand managers.

For a company or organisation, the necessary step is to refrain from viewing the relationship from the point of view of two parties - the brand and the individual consumer; the strategic change should focus on the relationship of consumer-brand-consumer (Muñiz \& O'Guinn, 2001). Muñiz and O'Guinn argued that brands are social objects that are socially created. Managers should be wary of this point: for all the brand management in the world, the development of a brand lies just as squarely in the hands of the consumer, and their relationships with other users of it. Including the consumer in the creation and development of a brand suggests creating a vested interest in the brand's future welfare. Consumers have the power to make a brand, and they equally have the power potentially to break it.

One possible answer to this is to include the consumer in the brand's development and maintenance. Rather than view the consumer as just a buyer or user of the product or service, importance could be placed on considering the consumer as a member of the community around the brand, or a stake or shareholder in the brand's future. This 
procedure may resemble the move into 'relationship marketing,' however the difference between this and the brand community is that the later values interaction amongst consumers.

Investing in the antecedents that lead to the development of brand community and social identification can assist in the creation of a community centred on the product brand. By providing group experiences, being aware of and including history within branding strategy, initiating meaningful rituals involving the consumption process (Underwood et al., 2001), along with considering the physical facility as a direct link to the brand in service contexts, companies will go a long way toward fostering strong levels of consumer identification with their brand.

\subsection{Implications for Future Research}

This research study has contributed to the extension of two specific disciplines: marketing and sport marketing. This study provides a preliminary extension of the brand community concept into foreign contexts, namely services and professional sports. It has combined the work of Muñiz and O'Guinn (2001) and Underwood et al. (2001) to provide a group of antecedents that contribute to the creation of brand community. It has also presented and ideally initiated future research into how new brands can compete with established competitors. Along with the work of Heere and James (in press), this work acknowledges the similarities of brand communities to those featured in the professional sport environment, and will ideally contribute to the development of literature investigating the brand community nature of professional sport fans.

In relation to future academic attention, brand community research thus far has failed to acknowledge service brands. Concentration on product contexts has ignored strong service areas such as the internet, restaurants, entertainment or lifestyle events, and 
professional sport. Future work should endeavour to investigate the presence of communities devoted to service brands, and discrepancies between service and product brand communities.

In direct association to the work of Underwood et al. (2001), future inquiry into the area of social identification around sports brands is advised to investigate the prominence of the four antecedents within non-successful or less influential sports teams. As Underwood et al. looked at teams that were famous for their strong levels of brand equity to develop their framework, future research may benefit from first investigating the difference between this context and established teams with less significant brand equity. The potential differences or similarities in those antecedents that consumers of these teams regard as important may further validate or contribute to this work and to that of Underwood et al.

Future empirical testing of the propositions made by Muñiz and O'Guinn (2001) and Underwood et al. (2001) is also required to validate the use of these frameworks in future research. Quantitative, large-scale investigations may prove useful in not only testing the correlation of antecedents with brand community and the work of Underwood et al. (2001), but also the potential detection of alternate drivers of both consumer identification and community creation. The above areas of future inquiry will contribute to the potential development of a conceptual framework, including areas featured within the foundation concepts of this research: brand community and social identification. An ideal framework would incorporate potential antecedents toward strengthening identification with the team and developing a community around the team brand derived from established teams; with both high and low brand equity examples; and the incorporation of teams with histories of either typically winning or losing. 


\subsection{Limitations of the Study}

The contributors to the development of brand community and social identification included in this study are based on the previous work of Muñiz and O'Guinn (2001) and Underwood et al. (2001). As suggested above, future work into the contributors to social identification amongst sports brands should extend to established teams of lesser brand equity. The work of Underwood et al. fails to investigate the characteristics that loyal fans of these teams associate with their brands. Perhaps enquiry into this will result in the creation or refinement of these antecedents.

Although the researcher's visits to each organisation's game environment allowed for validation of the interview data gathered and insights into branding or marketing campaigns, future validation could include media and print sources. While the physical facilities overall portrayed a lack of brand-based marketing on the part of the organisations, media and organisation print sources may be a more worthwhile source to validate the consistency of managers' interview data. This is particularly appropriate for analysis of the physical facility's incorporation within brand strategy, as it is predicted that this antecedent will be found in alternate sources from the stadium itself.

Although respondents did outline future branding strategy and the way in which it may incorporate aspects of brand community or foster identification, this study is unable to examine whether managers will act upon these thoughts. To complement and assess these findings, a longitudinal perspective may prove beneficial in examining whether future brand strategies correspond with those respondent comments featured here. 


\subsection{Conclusion}

The above chapter has sought to provide a discussion of the findings of this study, partnered with a commentary on the implementation of brand community, social identification, and antecedents that contribute to their development.

Apart from the poor playing results that have affected the included teams, issues such as previous brand image and awareness, the domination of rugby, lack of support for minor and female sports, and most importantly, a lack of history, have affected the development of the three cases. While the majority of antecedents were deemed important to brand development, organisational objectives and brand strategies did not reflect this. The group experience appeared to be that which was most supported by the teams, while history was largely ignored.

For new sports team brands, managers may be of the opinion that their brand does not radiate a great deal of social identification, nor possess a large community of loyal consumers. However, it is advised that a new team carefully consider the brand community concept, and regard themselves as the centre to a community from the time when the team is created. Heere and James (in press) suggest that regarding fans as members of the organisation and managing fan relationships is imperative in the current, highly competitive sports market. Through a long-term focus on brand equity and consumer identification with the team, the implementation of the antecedents included in this study will provide a path toward cultivating a sports team brand community.

With regard to the development of generic brands, managers are advised to examine those brands included in previous brand community research, such as Harley-Davidson Motorcycles, Apple Computers, or European vehicles, or any other brand(s) that possess a large amount of consumer identification. Examination of marketing strategies and brand 
initiatives from these companies could provide validation and examples for replication and adaptation by other company brands. It is also advised that companies view their brands, where appropriate, as a catalyst for consumer interaction; the relationship now is not just between the brand and the consumer, but consumers interacting amongst themselves through their use of or interest in the host brand.

To conclude, this study reaffirms comments by Algesheimer et al. (2005), who suggest that brand communities offer a fresh, effective, and vital approach to building brands in the present-day unresponsive marketing environment. While the overriding argument of this thesis resides in the importance of brand community and social identification techniques to brand development and management, the creation of brand community has the ability to transcend simple marketing objectives. Realisation and preservation of brand communities within the professional sport environment or consumer products may have the ability to offer social interaction and personal sanctuary, contributing to the never-ending human search for belonging. 


\section{REFERENCES}

Aaker, D. A. (1991). Managing brand equity: Capitalizing on the value of a brand name. New York: The Free Press.

Aaker, D. A. (1996). Building strong brands. London: Simon \& Schuster UK Ltd.

Aaker, D. A., \& Keller, K. L. (1990). Consumer evaluations of brand extensions. Journal of Marketing, 54(1), 27-41.

Algesheimer, R., Dholakia, U. M., \& Herrmann, A. (2005). The social influence of brand community: Evidence from European car clubs. Journal of Marketing, 69(3), 19-34.

Ambler, T. (1992). Need-to-know-marketing. London: Century Business.

Ambler, T., \& Styles, C. (1997). Brand development versus new product development: Towards a process model of extension decisions. Journal of Product \& Brand Management, 6(1), 13-26.

Auerbach, C. F., \& Silverstein, L. B. (2003). Qualitative data: An introduction to coding and analysis. New York: New York University Press.

Bagozzi, R. P., \& Dholakia, U. M. (2006). Antecedents and purchase consequences of customer participation in small group brand communities. International Journal of Research in Marketing, 23(1), 45-61.

Baker, J., Grewal, D., \& Parasuraman, A. (1994). The influence of the store environment on quality inferences and store image. Journal of the Academy of Marketing Science, 22(Fall), 328-339.

Baram, U., \& Rowan, Y. (2004). Archaeology after nationalism: Globalization and the consumption of past. In Y. Rowan \& U. Baram (Eds.), Marketing heritage: Archaeology and the consumption of the past (pp. 3-23). Walnut Creek: Altamira Press.

Berg, B. L. (1998). Qualitative research methods for the social sciences (3 ed.). Needham Heights: Allyn and Bacon.

Bitner, M. J. (1990). Evaluating service encounters: The effects of physical surroundings and employee responses. Journal of Marketing, 54(2), 69-82.

Bitner, M. J. (1992). Servicescapes: The impact of physical surroundings on customers and employees. Journal of Marketing, 56(2), 57-71.

Bonoma, T. V. (1985). Case research in marketing: Opportunities, problems, and a process. Journal of Marketing Research, 22(2), 199-208.

Bristow, D. N., \& Sebastian, R. J. (2001). Holy cow! Wait 'til next year! A closer look at the brand loyalty of Chicago Cubs baseball fans. Journal of Consumer Marketing, $18(3), 256-275$. 
Brown, M. (2006). A-league boss says Knights need another chairman. Retrieved 16 November, 2006, from http://www.nzherald.co.nz/topic/story.cfm?c id=242\&objectid=10409193

Calantone, R., \& Cooper, R. G. (1981). New product scenarios: Prospects for success. Journal of Marketing, 45(2), 48-60.

Canterbury Rugby Football Union. (2006). Crusaders history. Retrieved 14 November, 2006, from http://www.crfu.co.nz/main/index.cfm/1,86,html/Crusaders-History

Chavis, D. M., \& Newbrough, J. R. (1986). The meaning of "community" in community psychology. Journal of Community Psychology, 14(4), 335-340.

Chavis, D. M., \& Wandersman, A. (1990). Sense of community in the urban environment: A catalyst for participation and community development. American Journal of Community Psychology, 18(1), 55-81.

Costa, K. A. (2004). Conflating past and present: Marketing archeaological heritage sites in Ireland. In Y. Rowan \& U. Baram (Eds.), Marketing heritage: Archaeology and the consumption of the past (pp. 69-91). Walnut Creek: Altamira Press.

Cova, B. (1997). Community and consumption: Towards a definition of the "linking value" of product or services. European Journal of Marketing, 31(3/4), 297-316.

Dawar, N. (2004). What are brands good for? MIT Sloan Management Review, 46(1), 31 37.

de Chernatony, L., \& Dall'Olmo Riley, F. (1998). Defining a "brand": Beyond the literature with experts interpretations. Journal of Marketing Management, 14(4/5), 417-443.

Delanty, G. (2003). Community. London: Routledge.

Doyle, P. (1989). Building successful brands: The strategic options. Journal of Marketing Management, 5(1), 77-95.

Eisenhardt, K. M. (1989). Building theories from case study research. Academy of Management Review, 14(4), 532-550.

Farquhar, P. H. (1989). Managing brand equity. Marketing Research, 1(3), 24-33.

Fisher, R. J., \& Wakefield, K. (1998). Factors leading to group identification: A field study of winners and losers. Psychology \& Marketing, 15(1), 23-40.

Flint, D. J., Woodruff, R. B., \& Fisher-Gardial, S. (2002). Exploring the phenomenon of customers' desired value change in a business-to-business context. Journal of Marketing, 66(4), 102-117.

Forbes. (2006). Lists. Retrieved 2 November, 2006, from http://www.forbes.com/lists/ 
Friedman, M. T., \& Silk, M. L. (2005). Expressing Fenway: Managing and marketing heritage within the global sports marketplace. International Journal of Sport Management and Marketing, 1(1/2), 37-55.

Gilhooly, B. M. (1999). A multi-method analysis of the sport brand development process. Unpublished Thesis, University of Otago, Dunedin.

Gillham, B. (2000). Case study research methods. London: Continuum.

Gladden, J. M., \& Funk, D. C. (2001). Understanding brand loyalty in professional sport: Examining the link between brand associations and brand loyalty. International Journal of Sports Marketing \& Sponsorship, 3(1), 67-94.

Glaser, B. G., \& Strauss, A. (1967). The discovery of grounded theory: Strategies for qualitative research. Chicago: Aldine.

Glynn, M. S., \& Brodie, R. J. (1998). The importance of brand-specific associations in brand extension: Further empirical results. Journal of Product \& Brand Management, 7(6), 509-518.

Grace, D., \& O'Cass, A. (2002). Brand associations: Looking through the eye of the beholder. Qualitative Market Research, 5(2), 96-111.

Graham, B. (2002). Heritage as knowledge: Capital or culture? Urban Studies, 39(5/6), 1003-1017.

Gusfield, J. R. (1975). Community: A critical response. New York: Harper Colophon Books.

Haimes, G. (2005). Organizational culture and identity: A case study from the Australian football league. Unpublished Thesis, Victoria University, Perth.

Heere, B., \& James, J. D. (in press). Sports teams and their communities: Examining the role of external and internal group identities. Journal of Sport Management.

Heller, K. (1989). The return to community. American Journal of Community Psychology, 17(1), 1-15.

Hightower Jr, R., Brady, M. K., \& Baker, T. L. (2002). Investigating the role of the physical environment in hedonic service consumption: An exploratory study of sporting events. Journal of Business Research, 55(9), 697-707.

Hindson, A. (1999). The evolution of sport management in New Zealand. In L. Trenberth \& C. Collins (Eds.), Sport business management in New Zealand (pp. 25-38). Palmerston North: Dunmore Press.

Hirschman, E. C. (1986). Humanistic inquiry in marketing research: Philosophy, method, and criteria. Journal of Marketing Research, 23(3), 237-249.

Howard, J. (1997). Frozen in time. Sports Illustrated, 86, 70-80. 
Imber-Black, E., \& Roberts, J. (1992). Rituals for our times: Celebrating, healing, and changing our lives and our relationships: HarperCollins.

James, J. D., Kolbe, R. H., \& Trail, G. T. (2002). Psychological connection to a new sport team: Building or maintaining the consumer base? Sport Marketing Quarterly, 11(4), 215-225.

Jary, M., \& Wileman, A. (1998). Managing retail brands. In S. Hart \& J. Murphy (Eds.), Brands: The new wealth creators (pp. 152-160). New York: Palgrave.

Kelley, S. W., \& Hoffman, K. D. (1999). Franchise relocation and sport introduction: A sports marketing case study of the Carolina Hurricanes' fan adoption plan. Journal of Services Marketing, 13(6), 469-480.

Kelly, J. D., \& Kaplan, M. (1990). History, structure, and ritual. Annual Review of Anthropology, 19, 119-150.

Konig, R. (1968). The community. London: Routledge and Kegan Paul.

Kotler, P. (1972). A generic concept of marketing. Journal of Marketing, 36(2), 46-54.

Kotler, P., \& Levy, S. J. (1969). Broadening the concept of marketing. Journal of Marketing, 33(1), 10-15.

Kotler, P. H. (1991). Marketing management: Analysis, planning and control (8th ed.). Englewood Cliffs, NJ: Prentice-Hall, Inc.

Kozinets, R. V. (2001). Utopian enterprise: Articulating the meanings of Star Trek's culture of consumption. Journal of Consumer Research, 28(1), 67-88.

Kumar, N. (2003). Kill a brand, keep a customer. Harvard Business Review, 81(12), 86-95.

Leuthesser, L., Kohli, C. S., \& Harich, K. R. (1995). Brand equity: The halo effect measure. European Journal of Marketing, 29(4), 57-66.

Levin, A. M., Beasley, F., \& Gamble, T. (2004). Brand loyalty of NASCAR fans towards sponsors: The impact of fan identification. International Journal of Sports Marketing \& Sponsorship, 6(1), 11-21.

Mahony, D. F., \& Howard, D. A. (2001). Sport business in the next decade: A general overview of expected trends. Journal of Sport Management, 15(4), 275.

May, T. (2001). Social research: Issues, methods and process (3 ed.). Buckingham: Open University Press.

McAlexander, J. H., Schouten, J. W., \& Koenig, H. F. (2002). Building brand community. Journal of Marketing, 66(1), 38-54.

McMillan, D. W., \& Chavis, D. M. (1986). Sense of community: A definition and theory. Journal of Community Psychology, 14(1), 6-23. 
Melnick, M. J. (1993). Searching for sociability in the stands: A theory of sports spectating. Journal of Sport Management, 7, 44-60.

Mirams, C. (2001). Beleaguered! The Warriors: From dream to nightmare. Auckland: Hodder Moa Beckett.

Misiura, S. (2006). Heritage marketing. Jordan Hill: Butterworth-Heinemann.

Muñiz, A. M., \& O'Guinn, T. C. (2001). Brand community. Journal of Consumer Research, $27(4), 412-432$.

Muñiz, A. M., \& Schau, H. J. (2005). Religiosity in the abandoned Apple Newton brand community. Journal of Consumer Research, 31(4), 737-747.

Murphy, J. (1998). What is branding? In S. Hart \& J. Murphy (Eds.), Brands: The new wealth creators (pp. 1-12). New York: Palgrave.

National Basketball League. (2006). Ladder. Retrieved 25 May, 2006, from http://www.nbl.com.au/default.aspx?s=ladder\&sid=3

National Rugby League. (2006). Competition history. Retrieved 24 May, 2006, from http://nrl.com/CompetitionHistory/tabid/281/Default.aspx

Netball New Zealand. (2006). The history of netball in New Zealand. Retrieved 28 October, 2006, from http://netballnz.co.nz/index.cfm?layout=game history

New Zealand Warriors. (2006). Club history - 1995-2005. Retrieved 25 May, 2006, from http://warriors.co.nz/page/club_history_1995_2005.html

O'Leary, Z. (2005). Researching real-world problems: A guide to methods of inquiry. London: Sage Publications.

O'Reilly, N. J., \& Nadeau, J. P. (2006). Revenue generation in professional sport: A diagnostic analysis. International Journal of Sport Management and Marketing, 1(4), 311-330.

Passikoff, R. (1997). Pro sports needs to manage fan loyalty. Brandweek, 38(27), 9.

Patton, M. Q. (2002). Qualitative research \& evaluation methods (3 ed.). Thousand Oaks: Sage.

Putnam, R. D. (2000). Bowling alone: The collapse and revival of American community. New York: Simon \& Schuster.

Richardson, B., \& O'Dwyer, E. (2003). Football supporters and football team brands: A study in consumer brand loyalty. Irish Marketing Review, 16(1), 43-53.

Richelieu, A. (2003). A brand new world for sports teams. In B. G. Pitts (Ed.), Sharing best practices in sport marketing: The sport marketing association's inaugural book of papers. Morgantown, WV: Fitness Information Technology. 
Riessman, C. (2002). Narrative analysis. In A. M. Huberman \& M. B. Miles (Eds.), The qualitative researcher's companion (pp. 217-270). Thousand Oaks: Sage Publications.

Robertson, P. (1998). New brand development. In S. Hart \& J. Murphy (Eds.), Brands: The new wealth creators (pp. 24-33). New York: Palgrave.

Rook, D. W. (1985). The ritual dimension of consumer behaviour. Journal of Consumer Research, 12(3), 251-264.

Rossman, G. B., \& Rallis, S. F. (2003). Learning in the field: An introduction to qualitative research (2 ed.). Thousand Oaks: Sage.

Schein, E. H. (1992). Organizational culture and leadership (2 ed.). San Francisco: JosseyBass.

Schouten, J. W., \& McAlexander, J. H. (1995). Subcultures of consumption: An ethnography of the new bikers. Journal of Consumer Research, 22(1), 43-61.

Sekaran, U. (2003). Research methods for business: A skill building approach. New York: John Wiley \& Sons.

Shocker, A. D., Srivastava, R. K., \& Ruekert, R. W. (1994). Challenges and opportunities facing brand management: An introduction to the special issue. Journal of Marketing Research, 31(2), 149-158.

Silverman, D. (2000). Doing qualitative research: A practical handbook. London: Sage.

Statistics New Zealand. (2001). Describing ourselves - the individual and the class. Retrieved 27 October, 2006, from http://www.stats.govt.nz/NR/rdonlyres/CFAEB744-03F6-45F4-B2B562736FBBEC71/0/1Part1.pdf

Strauss, A., \& Corbin, J. (1998). Basics of qualitative research: Techniques and procedures for developing grounded theory (2 ed.). Thousand Oaks: Sage.

Styles, C., \& Ambler, T. (1995). Brand management. In S. Crainer (Ed.), Financial times handbook of management (pp. 581-593). London: Pitman.

Suttles, G. D. (1972). The social construction of community. Chicago: University of Chicago Press.

Tajfel, H. (1978). Differentiation between social groups: Studies in the social psychology of intergroup relations. London: Academic.

Taylor, S. J., \& Bogdan, R. (1998). Introduction to qualitative research methods: A guidebook and resource (3 ed.). Canada: John Wiley \& Sons, Inc. 
Underwood, R., Bond, E., \& Baer, R. (2001). Building service brands via social identity: Lessons from the sports marketplace. Journal of Marketing Theory \& Practice, 9(1), 1-13.

Vincent, L. (2002). Legendary brands: Unleashing the power of storytelling to create a winning marketing strategy. Chicago: Dearborn Trade Publishing.

Waitt, G. (2000). Consuming heritage: Perceived historical authenticity. Annals of Tourism Research, 27(4), 835-862.

Wakefield, K. L., \& Blodgett, J. G. (1994). The importance of servicescapes in leisure service settings. Journal of Services Marketing, 8(3), 66-76.

Wakefield, K. L., \& Blodgett, J. G. (1996). The effect of the servicescape on customers' behavioural intentions in leisure service settings. Journal of Services Marketing, $10(6), 45-61$.

Wallendorf, M., \& Arnould, E. J. (1991). "We gather together": Consumption rituals of thanksgiving day. Journal of Consumer Research, 18(1), 13-31.

Wann, D. L., Melnick, M. J., Russell, G. W., \& Pease, D. G. (2001). Sport fans: The psychology and social impact of spectators. New York: Routledge.

Wellman, B. (2001). Physical place and cyberspace: The rise of personalized networking. International Journal of Urban and Regional Research, 25(2), 227-252.

Wells, P. A. (1994). The marketing of tradition: A new approach. In T. Brewer (Ed.), The marketing of tradition: Perspectives on folklore, tourism and the heritage industry (pp. 53-58). Enfield Lock: Hisarlik Press.

Wells, W. D., \& Lo Sciuto, L. A. (1966). Direct observation of purchasing behaviour. Journal of Marketing Research, 3(3), 227-233.

Westerbeek, H., \& Smith, A. (2003). Sport business in the global marketplace. New York, NY: Palgrave MacMillan.

Williams, R. L., \& Cothrel, J. (2000). Four smart ways to run online communities. Sloan Management Review, 41(4), 81-91.

Yin, R. K. (1994). Case study research: Design and methods (2 ed.). Thousand Oaks: Sage Publications.

Yin, R. K. (2003). Case study research: Design and methods (3 ed.). Thousand Oaks: Sage Publications. 


\section{APPENDICES}

\section{Appendix 1: Respondent Experience and Demographics}

\begin{tabular}{|c|c|c|c|c|}
\hline Personnel & $\begin{array}{c}\text { General } \\
\text { marketing } \\
\text { experience } \\
\text { (years) }\end{array}$ & $\begin{array}{c}\text { Sports } \\
\text { marketing } \\
\text { experience } \\
\text { (years) }\end{array}$ & $\begin{array}{c}\text { Sports industry } \\
\text { experience } \\
\text { (years) }\end{array}$ & Gender \\
\hline \multicolumn{5}{|l|}{ Warriors } \\
\hline Football manager & 8 & 8 & 8 & Male \\
\hline $\begin{array}{l}\text { Sales and marketing } \\
\text { manager }\end{array}$ & $8-9$ & $8-9$ & 9 & Male \\
\hline \multicolumn{5}{|l|}{ Diamonds } \\
\hline General manager & 15 & 15 & 15 & Male \\
\hline Chairman & 16 & 10 & 8 & Male \\
\hline \multicolumn{5}{|l|}{ Breakers } \\
\hline $\begin{array}{l}\text { Marketing services } \\
\text { manager }\end{array}$ & 8 & 4 & 4 & Female \\
\hline General manager & 10 & 10 & 10 & Male \\
\hline
\end{tabular}




\section{Appendix 2: Participant Information Sheet}

\section{Participant Information Sheet

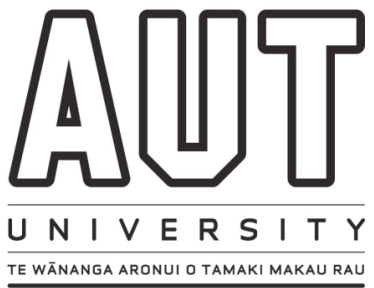

\section{Date Information Sheet Produced:}

20 March 2006

\section{Project Title}

Positioning a new team: Brand development of newly established New Zealand sports teams

\section{Invitation}

Your are invited to participate in a research project seeking to investigate brand development in newly established New Zealand sports teams. Your organisation fits perfectly within the context of this study, and we believe that you will be able to offer an extremely important insight into the New Zealand sports market place and the way new sports team brands are built. This perspective would not be obtainable without your participation.

\section{What is the purpose of this research?}

The purpose of this research is to investigate the development of newly established sport team brands within New Zealand. As well as being a largely undeveloped research area, this field is extremely important to the welfare and survival of new sports teams within the industry. The need exists to build consumer interest and attention to teams based upon qualities other than on-field performance. This is where developing a strong brand is vital.

The research project will result in the publication of findings within an academic journal. This research will also have practical implications for the industry, as it will ideally contribute to the development of successful marketing and branding strategy for sports organisations. The project is also contributing to the researcher's final year of a Master of Business, and the production of a thesis research study.

\section{How are people chosen to be asked to be part of this research?}

You have been chosen as a representative of your organisation due to your involvement in the marketing and development of your organisation's team brand. Due to this involvement, you are a natural fit to our investigation's focus on how an organisation internally utilises different marketing techniques to develop its brand.

\section{What happens in this research?}

Participants will be required to participate in an interview lasting approximately 90 minutes. This interview will seek to investigate the involvement the participant has had or currently has with the brand, and the ways in which they have been and are planning on developing the brand. 


\section{What are the discomforts and risks?}

There will be minimal discomfort or risk to the participant. Interviews will be fairly structured, but will allow for free discussion to take place when relevant and interesting themes are uncovered. Respondents may feel uncomfortable when asked about organisational marketing practices, but participant identities will remain confidential along with the omission of information likely to put the organisation or participant at any risk.

\section{How will these discomforts and risks be alleviated?}

As mentioned above, individual identities of the participants will be protected and remain confidential. Information taken from the interviews will be closely examined for confidentiality conflicts. Is a situation similar to this arises, the comment will be omitted from the remainder of the study. Participants have the right at any time to stop the interview or refrain from answering a specific question.

\section{What are the benefits?}

The benefits of this research project will be to both the academic community and the practicing industry. By participating in this study, your organisation is contributing to the development of a much-need literature regarding branding in sports. These studies are required to produce eventual practical advice and market research for organisations such as yours'.

This field is vital to successful application of marketing strategy to sports, and the subsequent construction of sports as a first choice in the entertainment industry. With the successful development of a strong brand, an organisation can focus on long-term goals and spectator cultivation rather than simply looking to survive from season to season.

\section{How will my privacy be protected?}

As mentioned above, individual identities will remain strictly confidential. Information gathered will be stringently examined for confidential comments and issues that may personally identify the respondent.

\section{What are the costs of participating in this research?}

There are no financial costs of participation. The requirement that is required from a participant is approximately 90 minutes to undertake the required interview. Possible follow up communication to clarify information gathered may require the participant to be in communication with the researcher for periods of up to 15 minutes during a period of several days following the interview.

\section{What opportunity do I have to consider this invitation?}

You have two weeks following your reception of this offer. The researchers will be in communication to ensure that you have received the information and consent to participate form.

\section{How do I agree to participate in this research?}

Agreement to participate in the study will come through the signing of the enclosed participant consent form. This will be required to be sent back to the researcher in the self-addressed envelope provided. 


\section{Will I receive feedback on the results of this research?}

Yes, feedback from the study will be provided in the form of a summary of results from those organisations involved. This will provide the participant with an insight into the current state of branding new sports teams within the New Zealand sports industry. This summary will be provided upon successful completion of the research project, and will be sent through either electronic or mail format depending on the preference of the participant. An approximate date for this summary will be between December 2006 and January 2007.

\section{What do I do if I have concerns about this research?}

Any concerns regarding the nature of this project should be notified in the first instance to the Project Supervisor, Dr Geoff Dickson, geoff.dickson@aut.ac.nz, 9219999 ext 7851, or Dr Mark Glynn, mark.glynn@aut.ac.nz, 9219999 ext 5813.

Concerns regarding the conduct of the research should be notified to the Executive Secretary, AUTEC, Madeline Banda, madeline.banda@aut.ac.nz , 9219999 ext 8044.

Who do I contact for further information about this research?

\section{Researcher Contact Details:}

Nigel Grant

Institute of Sport and Recreation Research New Zealand

Division of Sport and Recreation

Auckland University of Technology

Ph: 9219999 ext 7119

Mob: 0211702741

E: nigel.grant@aut.ac.nz

\section{Project Supervisor Contact Details:}

Dr Geoff Dickson

Research Lecturer

Institute of Sport and Recreation Research New Zealand

Division of Sport and Recreation

Auckland University of Technology

Ph: 9219999 ext 7851

E: geoff.dickson@aut.ac.nz

Dr Mark Glynn

Senior Lecturer - Marketing and Advertising

Faculty of Business

Auckland University of Technology

Ph: 9219999 ext 5813

E: mark.glynn@aut.ac.nz 
Appendix 3: Consent Form

\section{CONSENT TO PARTICIPATION IN}

RESEARCH

Title of Project: Positioning a new team: Brand development of newly established New Zealand sports teams

Project Supervisor: Dr Geoff Dickson

Dr Mark Glynn

Researcher: Nigel Grant

- I have read and understood the information provided about this research project (Information Sheet dated 20 March 2006.)

- I have had an opportunity to ask questions and to have them answered.

- I understand that the interview will be audio-taped and transcribed.

- I understand that I may withdraw myself or any information that I have provided for this project at any time prior to completion of data collection, without being disadvantaged in any way.

- If I withdraw, I understand that all relevant tapes and transcripts, or parts thereof, will be destroyed.

- I agree to take part in this research.

- I wish to receive a copy of the report from the research: tick one: Yes $\mathrm{O}$ No $\mathrm{O}$

Participant signature:

Participant name:

Participant Contact Details (if appropriate):

Date:

Approved by the Auckland University of Technology Ethics Committee on 30 March 2006 AUTEC Reference number 06/50 